\title{
REDUCTION OF NITRIC OXIDE BY CARBON MONOXIDE OVER A SILICA SUPPORTED PLATINUM CATALYST: \\ INFRARED AND KINETIC STUDIES
}

\section{D'Arcy Harold Lorimer \\ (Ph.D thesis)}

JuTy 1978
FE CE
WAWRENCE
GRRKABY LABORATORY

AU6301978

LIBRARY AND OCUMENTS SEETION

Prepared for the U. S. Department of Energy under Contract $W-7405-E N G-48$

\section{TWO-WEEK LOAN COPY}

This is a Library Circulating Copy which may be borrowed for two weeks. For a personal retention copy, call

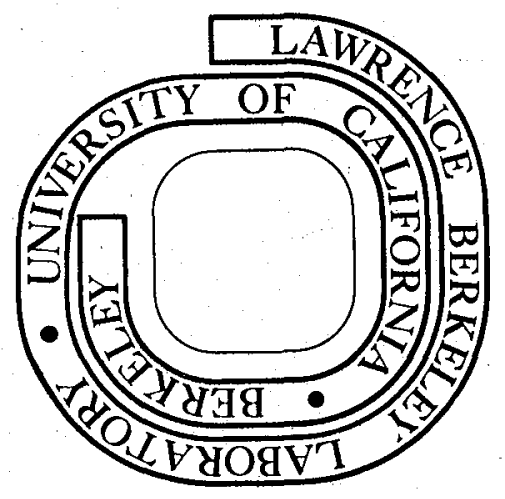
Tech. Info. Dívision, Ext. 6782 


\begin{tabular}{ll}
\hline This ref & as $r$ \\
United & Go \\
men & ly, \\
traci & in: \\
expr & lif \\
the : & $2 c$ \\
ratus & o \\
not & ivi \\
\hline
\end{tabular}

:E •

insored by the or the Departof their coniy warranty, $\begin{array}{ll}y & \text { onsibility for } \\ \text { ny } & \text { ration, appa- }\end{array}$ if ts use would 
LBL-8007

\section{REDUCTION OF NITRIC OXIDE BY CARBON MONOXIDE OVER A SILICA SUPPORTED PLATINUM CATALYST: INFRARED AND KINETIC STUDIES}

by

D'Arcy Harold Lorimer

Lawrence Berkeley Laboratory
University of Cal ifornia
Berkeley, Cal ifornia 94720

Work performed with support by the U. S. Department of Energy. 



\section{Table of Contents}

Abstract. . . . . . . . . . . . . . . . . . . viii

I. Introduction and Literature Review . . . . . . . . 1

A. Introduction .................. 2

B. Literature Review ............... 2

1. Nitric Oxide and Carbon Monoxide

Adsorption Studies............ . 2

2. Rinetic Studies ............. 3

3. Studies Relating to the Formation and

Observation of the Isocyanate Species. . . . . 4

II. Experimental section............... 6

A. Apparatus... . . . . . . . . . . . 6

1. Gas Feed System. ............. 6

2. Reactor and Recycle Loop............ 10

3. Analysis system. . . . . . . . . . . 26

B. Procedures. . . . . . . . . . . . . 33

1. Catalyst Preparation ............ 33

2. Infrared Disk Preparation. . . . . . . . 38

3. Catalyst Characterization. ........... 42

4. Preliminary Experiments .......... 44

5. Blank Reactor Activity ........... 46

III. Results and Discussion .............. . . 54

A. Introduction. ............... 54

B. Kinetic Results . . . . . . . . . . . . 57 
1. Reducing Region ............. 57

2. Oxidizing Region ............. 71

c. Infrared Spectra. . . . . . . . . . . 83

1. Reducing Region. ............ 83

2. Oxidizing Region ............. 96

D. Correlation of Selectivity . . . . . . . . 96

1. Reducing Region. . . . . . . . . . . 102

2. Oxidizing Region ............. 105

E. Investigation of the Deactivation Process . . . . 115

1. Oxygen. ............... 115

2. Carbon. ............... 119

3. Isocyanate Species. . . . . . . . . . 123

IV. Conclusions . . . . . . . . . . . . . 136

Acknowledgements. . . . . . . . . . . . 138

Appendices. . . . . . . . . . . . . . . . . . 139

1. Gas Flow System Calculations. . . . . . . . 139

2. Derivation of $\mathrm{R}_{\mathrm{N}_{2}} / \mathrm{R}_{\mathrm{N}_{2}} \mathrm{O}$ Expressions From Proposed Reaction Mechanism, Reducing Region........ 141

3. Derivation of $\mathrm{R}_{\mathrm{N}_{2}} / \mathrm{R}_{\mathrm{N}_{2}}$ O Expressions From Proposed Reaction Mechanism, Oxidizing Region........ 145

References. ..................... 149 


\section{List of Figures}

Figure 1 Schematic of Gas Feed System. . . . . . . 8

Figure 2 Schematic of Reactor and Recycle Loop . . . . . 12

Figure 3 Schematic of Heating Power Distribution . . . . 15

Figure 4 Schematic of Thermocouple Placement and

Digital Readout............. 17

Figure 5 Schematic of Reactor. ............ 19

Figure $6 \quad$ Schematic of Sealing Flange and Track

Assembly. . . . . . . . . . . . . 22

Figure 7 Schematic of Chromatographic Gas Flow

System. ............... 28

Figure 8 Electrical Signal Processing Schematic

for Gas Chromatographic Analysis System . . . . 32

Figure 9 Catalyst Reduction Apparatus. . . . . . . . 37

Figure 10 Infrared Disk Pressing Die. . . . . . . . . 41

Figure 11 Blank Conversion as a Function of Time

During Preliminary Experimentation. . . . . 49

Figure 12 Range of Background Activity for Reported

Kinetic Data............. 53

Figure 13 Range of Feed Concentrations. . . . . . . . 56 ,

Figure 14 Nitric Oxide Conversion as a Function of

Time, Reducing Region ........... 59

Figure 15 Nitric Oxide Reaction Rate as a Function of

$\mathrm{P}_{\mathrm{NO}} / \mathrm{P}_{\mathrm{CO}}{ }^{2}$, Reducing Region.......... 64

Figure 16 Stoichiometric Ratio as a Function of Time,

Reducing Region ............. 67 
Figure 17 Excess Carbon Dioxide as a Function of Time,

Reducing Region............ 69

Figure 18 Nitrous Oxide Selectivity as a Function of

Time, Reducing Region ........... 73

Figure 19 Carbon Monoxide Conversion as a Function of

Time, Oxidizing Region. . . . . . . . 75

Figure 20 Stoichiometric Ratio as a Function of Time,

Oxidizing Region. . . . . . . . . 77

Figure 21 Nitrous Oxide Selectivity as a Function of

Time, Oxidizing Region. . . . . . . . 80

Figure 22 Nitrous Oxide Selectivity as a Function of

Nitric Oxide Concentration, Oxiding Region. . . 82

Figure 23 Typical Infrared Spectra. . . . . . . . 85

Figure 24 Carbon Monoxide Infrared Band Absorbance as

a Function of Carbon Monoxide Concentration,

Reducing Region ........... 87

Figure 25 Infrared Spectra for Run KOR-22 . . . . . . . 9 90

Figure 26 Infrared Spectra for Run KOR-32 . . . . . . . 92

Figure 27 Removal of the Isocyanate Infrared Band with

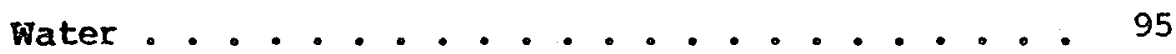

Figure 28 Reaction Mechanism for Nitrous Oxide Selectivity

$$
\text { Analysis. . . . . . . . . . . . . }
$$

Figure 29 Test of Selectivity Data; Langmuir-Hinshelwood

Mechanism, Reducing Region. .......... 106

Figure 30 Test of Selectivity Data; Langmuir-Hinshelwood

Mechanism, Oxidizing Region .......... 111 
Figure 31 Test of Selectivity Data; Eley-Rideal Mechanism,

Oxidizing Region ............... 113

Figure 32 Effect of Nitric Oxide Pretreatment on

Catalyst Deactivation. . . . . . ... . 117

Figure 33 Effect of Carbon Monoxide Pretreatment on

Catalyst Deactivation. . . . . . . . . 120

Figure 34 Nitric Oxide Conversion as a Function of Time

for Runs KOR-38A and KOR-38B . . . . . . . 124

\section{List of Tables}

Table 1 Gas Chromatograph Operating Conditions . . . . . . 29

Table 2 Catalyst properties. ............ 43

Table $3 \quad$ Sumary of Experimental Conditions and

Procedures ............... 47

Table 4 Reactor Outlet Concentrations, Reducing

Region ..................... 60

Table 5 Excess Carbon Dioxide Production . . . . . . . 70

Table 6. Expressions of $\mathrm{R}_{\mathrm{N}_{2}} / \mathrm{R}_{\mathrm{N}_{2} \mathrm{O}}$ for Eley-Rideal and

Langmuir-Hinshelwood Nitrous Oxide Production,

Reducing Region............... 103

Table 7 Expressions of $\mathrm{R}_{\mathrm{N}_{2}} / \mathrm{R}_{\mathrm{N}_{2} \mathrm{O}}$ for Eley-Rideal and

Langmuir-Hinshelwood Nitrous Oxide Production,

Oxidizing Region .............. 107 
-viii-

\author{
REDUCTION OF NITRIC OXIDE BY CARBON MONOXIDE OVER A SLICA \\ SUPPORTED PLATINUM CATALYST: INFRARED AND KINETIC STUDIES \\ D'Arcy H. Lor imer
}

\begin{abstract}
Materials and Molecular Research Division
Lawrence Berkeley Laboratory and Department of Chemistry University of California

Berkeley, California 94720
\end{abstract}

\begin{abstract}
$\underline{\text { ABSTRACT }}$
The reduction of nitric oxide by carbon monoxide over a 4.5 weight precent platinum catalyst supported on silica was studied at $300^{\circ} \mathrm{C}$. Reaction rate data was obtained together with in situ infrared spectra of species on the catalyst surface. The kinetics of the system were found to exhibit two distinct trends, depending on the molar ratio of $\mathrm{CO} / \mathrm{NO}$ in the reactor. For net reducing conditions ( $\mathrm{CO} / \mathrm{NO}>\mathrm{I}$ ) the catalyst underwent a transient deactivation, the extent of which was dependent on the specific CO/NO ratio during reaction. Reactivation of the catalyst was obtained with both oxidizing and reducing pretreatments. For molar feed ratios of CO/NO less than one, carbon monoxide conversion was typically 95 to 1008 , resulting in strongly oxidizing conditions over the catalyst. Under these conditions no deactivation was apparent. Infrared spectra recorded under reaction conditions revealed intense " bands at 2075 and $2300 \mathrm{~cm}^{-1}$, which were identified as carbon monoxide adsorbed on Pt and Si-NCO, respectively. Isocyanate bands formed under reducing conditions were more intense and exhibited greater stability than those formed under oxidizing conditions.

A reaction mechanism based on the dissociation of nitric oxide as the rate-limiting step was used to correlate nitric oxide reaction
\end{abstract}




$$
-i x-
$$

rates and nitrous oxide selectivities observed under reducing conditions. As part of this mechanism it is assumed that nitrous oxide is formed via a Langmuir-Hinshelwood process in which an adsorbed nitrogen atom reacts with an adsorbed nitric oxide molecule. The nitric oxide reaction rate was found to be first order in nitric oxide partial pressure, and inverse second order in carbon monoxide partial pressure. A mechanism is proposed to qualitatively explain the deactivation process observed under reducing conditions. The essential part of this mechanism is the formation of an isocyanate species on the Pt crystallites of the catalyst and the subsequent transient diffusion of these species to the silica support. The deactivation is believed to result from the build-up of $\mathrm{NCO}$ on vacant sites necessary for the dissociation of nitric oxide. 


\section{INTRODUCTION AND LITERATURE REVIEW}

The importance of automative emissions control in recent years has focused much attention on the catalytic reduction of nitric oxide. Since 1975; most automobile manufacturexs have used catalytic oxidation to reduce $\mathrm{CO}$ and hydrocarbon emissions, and have relied on engine modifications for the reduction of $\mathrm{NO}_{\mathbf{x}}$ emissions. However, such modifications are inadequate to comply with future ${ }^{N O}{ }_{x}$ emission requirements. As a result, the catalytic approach is being consiodered for the control of all three major pollutants; $\mathrm{NO}_{\mathrm{x}}, \mathrm{CO}$, and hydrocarbons. This means that the catalyst must be capable of utilizing the reducing agents present in the exhaust stream for nitric oxide reduction. Previous investigations have revealed that $\mathrm{CO}$ and $\mathrm{H}_{2}$ are the major reducing agents involved in No reduction and that the major nitrogen containing reaction products are $\mathrm{N}_{2}, \mathrm{~N}_{2} \mathrm{O}$, and $\mathrm{NH}_{3}$. This work has also demonstrated that at least eight reactions pertaining to No reduction take place simultaneously in a catalytic converter. Obviously, with such complexity it is not possible to obtain information regaxding the surface mechanisms through which the reduction of. No occurs. Since the gathering of basic mechanistic information is of central importance in this study, simplification of the reaction system to two reactants was necessary to accomplish this goal. 


\section{A. Introduction}

The purpose of this investigation was to study the mechanisms by which NO and CO interact over a platinum catalyst. As yet these mechanisms have not been firmly established, since very little work has been reported containing quantitative rate expressions. Platinum was chosen as the catalyst due to its potential widespread use as the main constituent in the proposed three way automotive catalytic converters. In addition, a significant amount of adsorption and infrared data is available in the literature for various gases on platinum. The experimental approach involved the recording of infrared spectra of species adsorbed on the catalyst under reaction conditions and the simultaneous collection of kinetic data.

\section{B. Literature Review}

1. Nitric Oxide and Carbon Monoxide Adsorption Studies

Recent work gives detailed information on the absorption of carbon monoxide on platinum. Winterbottom (2) found two distinct surface states for carbon monoxide on polycrystalline platium in thermal desorption studies. In thermal desorption work on the 110 surface of platinum, Lambert and Comrie (3) also found two carbon monoxide adsorption sites with heats of adsorption of 25 and $31 \mathrm{kcal} / \mathrm{mole}$. Somorjai et al (4) has reported the dissociative adsorption of carbon monoxide at the steps and kinks of a platinum vicinal surface, the adsorption being associative at the terrace sites. Finally, infrared spectra of carbon monoxide adsorbed on platinum exhibit a strong band at $2075 \mathrm{~cm}^{-1}$ (5). A significant amount of work on the adsorption of nitric oxide on platinum has also been reported. The work of Lambert and Comrie (3) 
indicates that two surface sites for the molecular adsortion of ntric oxide, having heats of adsorption of 23 and $28 \mathrm{kcal} / \mathrm{mole}$, exist on the 110 surface of platinum. The nitric oxide on one of these sites dissociates readily into adsorbed nitrogen and oxygen atoms at temper.atures greater than $200^{\circ} \mathrm{C}$. These results are in good agreement with those of Pirug and Bonzel $(6,7)$ who found significant nitric oxide dissociation in the temperature range of 180 to $220^{\circ} \mathrm{C}$ on the 100 surface of platinum. These authors $(6,7)$ found only molecular nitric oxide adsorbed at temperatures lower than $100^{\circ} \mathrm{C}$. The adsorption and desorption of nitric oxide on a $58 \mathrm{Pt} / \mathrm{Al}_{2} \mathrm{O}_{3}$ catalyst has been reported by solywosi et al (8). At adsorption temperatures greater than $100^{\circ} \mathrm{C}$, nitrous oxide was detected in the gas phase during nitric oxide adsorpidos? and at $400^{\circ} \mathrm{C}$, significant amounts of nitrous oxide, oxygen and nitrogen were detected. The characteristics of the thermal desorption of $\mathrm{ritric}$ oxide were complex and highly dependent on the temperature of adsorption. Broad infrared bands, in the region of 1760 to $1785 \mathrm{~cm}^{-1}$, arising from adsorbed nitric oxide (at low temperature) on platinum have been report by Ludvik (9), Duken and Hobert (10), and Brown and Gonzalez (1I).

\section{Kinetic Studies}

Experimental investigations of nitric oxide reduction by carbon monoxide have been reported by a number of researchers. Some of these studies (12-15) have been aimed at comparing the relative activity of various noble metal and transition metal oxide catalysts, and have not been directed toward establishing rate expressions and mechanisms for the kinetics. Lambert and Comrie (3) have studied the LangmuirHinshelwood reaction between co-adsorbed nitric oxide and carbon monoxide 
at low pressure on the 111 and 110 platinum surfaces. A reaction mechanism was proposed which accounts for the relative amounts of the individual products, and involves the dissociation of adsorbed NO prior to the formation of any products. Cant et al (1) have studied the reduction of nitric oxide by carbon monoxide over five silica supported noble metal catalysts, including platinum. The nitric oxide reaction rate over the platinum catalyst was determined to be approximately first order in nitric oxide partial pressure, and approached inverse order in carbon monoxide. A mechanism involving nitric oxide dissociation as the rate limiting step was proposed to explain the observed kinetics. Nitrous oxide formation was assumed to occur via a Langmuir-Hinshelwood process involving nitrogen atoms and adsorbed nitric oxide molecules, and molecular nitrogen was assumed to form via the recombination of two absorbed nitrogen atoms. Finally, Nilyama et al (16) have also studied the reduction of NO by $C O$ and reported the decline in activity of a $\mathrm{Pt} / \mathrm{Al}_{2} \mathrm{O}_{3}$ catalyst under reaction conditions, which was attributed to the formation of a platinum isocyanate species.

3. Studies Relating to the Formation and Observation of Isocyanate Species Infrared studies of the interaction of NO and $\mathrm{CO}$ on noble metal catalysts have revealed the formation of an isocyanate species and a number of authors have speculated about its role in the reduction mechanism. Unland (17-19) has observed intense infrared bands at $2270 \mathrm{~cm}^{-1}$ in studies involving the high temperature dosing of an alumina supported platinum catalyst with mixtures of nitric oxide and carbon monoxide. These results are consistent with those reported by Solymosi et al (8) and Nilyama (16) for alumina supported platinum catalysts. 
Ludvik (9) has identified an infrared band at $2300 \mathrm{~cm}^{-1}$ as belonging to an isocyanate. species formed during the reaction of nitric oxide and carbon monoxide over a platinum catalyst supported on silica.

Recently it has been proposed that the isocyanate species observed by infrared absorption is bonded to the catalyst support rather than to the metal. Dalla Betta and Shelef (20) have studied isocyanate formation over silica and alumina supported platinum catalysts, and have observed intense infrared bands at $2260 \mathrm{~cm}^{-1}$ for alumina supported platinum and $2304 \mathrm{~cm}^{-1}$ for silica supported platinum. Due to the large intensity of the infrared bands and the significant $44 \mathrm{~cm}^{-1}$ frequency shift between bands on different supports, these authors have identified the infrared bands as belonging, to isocyanate species bonded to the alumina and silica supports. These results are in good agreement with studies reported by Eley et al (21) and Guillet et al (22), in which the dissociative adsorption of ethyl isocyanate on silica, and n-butyl isocyanate on alumina and silica, were investigated. Intense infrared bands at $2300 \mathrm{~cm}^{-1}$ on silica $(21,22)$ and $2270 \mathrm{~cm}^{-1}$ on alumina (22) were identified as belonging to the isocyanate species. 


\section{EXPERIMENTAL SECTION}

\section{A. Apparatus}

The apparatus used for this study consisted of a gas feed system for mixing and controlling reactant flows, a backmix reactor, and an analysis system consisting of two gas chromatographs in series coupled to an automated digital data acquisition system. A more detailed description of this equipment is presented below.

\section{Gas Feed System}

A schematic of the gas feed system is shown in Figure 1. Feed to the reactor originated from one of two main subsystems, designated as system $A$ and system B. A gas stream from each could be fed independently to the reactor or vented, without disturbing the other's status. System A was used primarily for the blending of feed mixtures, while System B was used for purge and and in situ catalyst pretreatment. This arrangement was especially useful in that the reactor could be purged without disturbing the steady state status of system A.

Feed system $A$ is made up of four independent sections which can be used to make mixtures of up to four components. Only three of the sections were used in this study. The gas in each section is passed through a glass capillary tube and the pressure drop across the tube measured by a manometer filled with silicon diffusion pump oil. The pressure in each section was held above atmospheric (nominally 15 to $30 \mathrm{psig)}$ to prevent leaks into the system. The pressure and flow rate were controlled by metering needle valves before and after each capillary. A shut-off valve was connected in parallel with each 
$-7-$

Figure 1. Schematic of gas feed system 


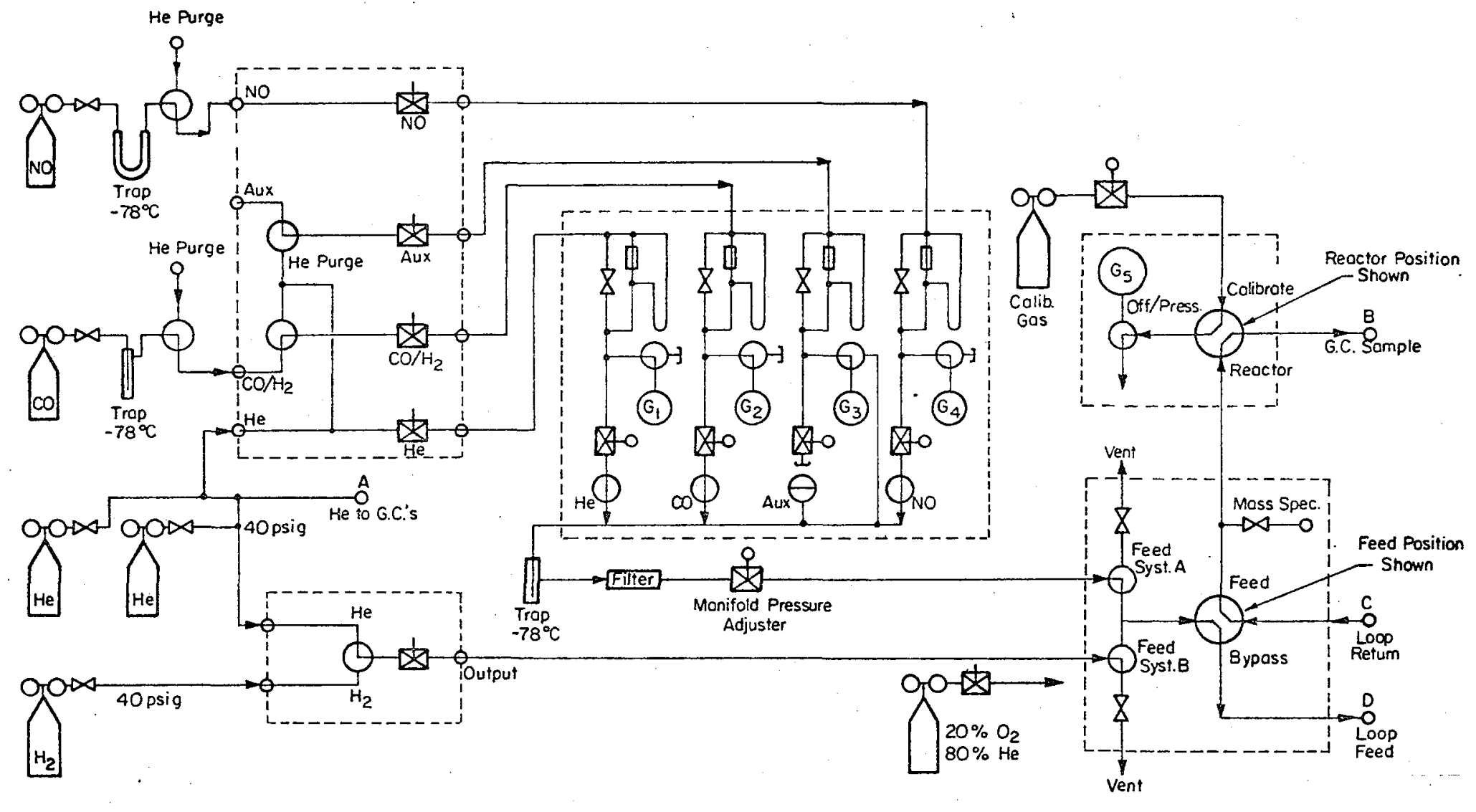

FLOW CONTROL AND FEEO SYSTEM

Fig. 1 
capillary as a bypass to prevent surges from overloading the manometers during start up and shut down.

Under operating conditions, the gas flow in the capillary tubes is laminar and the pressure drop is proportional to the volumetric flow rate. Each component section was calibrated by measuring the volumetric flow rate and pressure drop though each capillary using He. Correction for the individual components was made using gas viscosity data, based on the Hagen-Poiseuille law. The error associated with the flow measurement of each component was approximately 28 , and was due mainly to the error of the pressure gauges used to measure the total pressure in each capillary. Details relating to the calculation of flow rates can be found in Appendix 1.

The component streams were mixed in a manifold and the total stream was passed through a metering needle valve. This valve was used to keep the manifold pressure at 7 to $8 \mathrm{psig}$ in order to minimize leaks and isolate the capillary flow systems from downstream pressure fluctuations. Prior to this valve, the gas mixture was passed through a dry ice/trichloroethylene trap and a sintered stainless steel 15 micron filter. This was done to insure that oil vapor (from the capillary manometer tubes) would not to be fed to the reactor.

A four way ball valve was used to control the feeding or bypassing of the reactor. In the FEED position this valve routes the selected feed system (A or B) to the input of the recycle loop, and the exit stream from the loop is routed to the chromatographic analysis train. The BYPASS position of this valve shorts the loop input and exit streams, while routing the feed stream directly to the analysis train. 


\section{Reactor and Recycle Loop}

The reactor was connected to a gas recycle loop (Figure 2) containing two preheaters located upstream of the reactor and a forced air cooled tubing coil immediately downstream of the reactor. Gas flow in the loop was provided by a stainless steel bellows pump with a nominal volumetric flow rate of 40 liters/min. Total volumetric feed rates to the recycle loop were nominally $200 \mathrm{~cm}^{3} / \mathrm{min}$, which results in a recycle ratio of approximately $200: 1$. Under these conditions the reactor/recycle loop behavior closely approximates that of a constant flow stirred tank reactor (CFSTR).

The preheaters were made of $1 / 4^{n}$ o.d. aluminum tubing (alloy T6061), 30" long, wound axialy in a helical groove cut in the surface of a solid copper cylinder. The $1 / 4$ " width groove was round bottomed (1/8" radius) for good surface contact with the tubing. Heating was provided by a cylindrical cartridge heater inserted in the center of the block. The preheaters were designed to heat the entire recycle stream per pass, to avoid operation of the bellows pump at the elevated reaction temperatures.

Tubing in all hot sections of the recycle loop was made of T6061 aluminum in order to minimize blank activity problems encountered with stainless steel tubing. Connections between aluminum preheater sections were welded, however a problem was encountered in mating the aluminum tubing to the stainless steel fittings on the reactor. A special fitting had to be developed for this purpose, since no commercially available fitting tested would remain sealed under temperature cycling. 
$-11-$

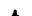

Figure 2. Schematic of the reactor recycle loop 


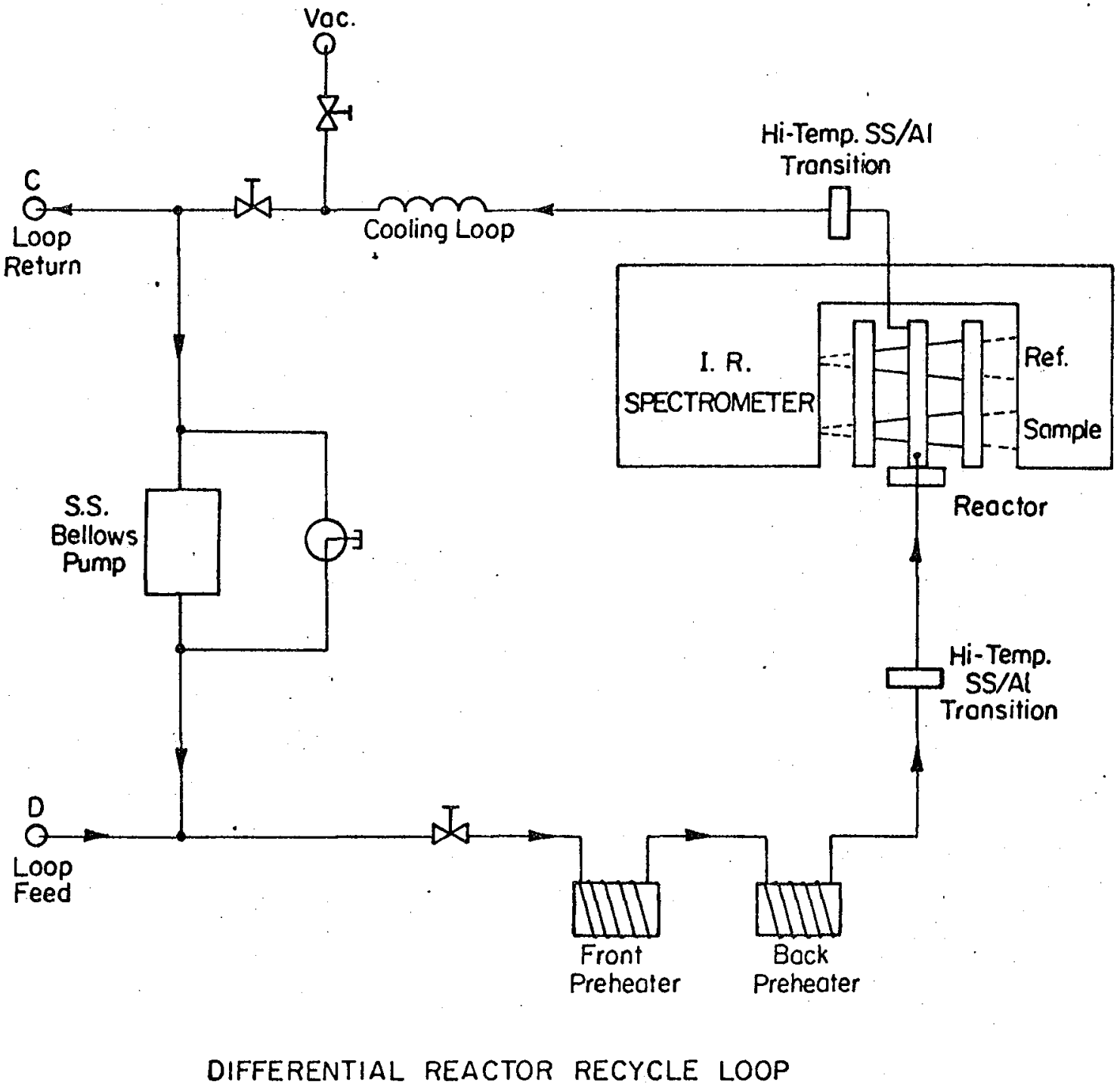

XBL 784- 4814

Fig. 2 
With 250 watt cartridge heaters installed in the preheaters, temperatures in excess of $400^{\circ} \mathrm{C}$ could easily be reached. This was the maximum practical limit, since the annealing point of the aluminum tubing is about $400^{\circ} \mathrm{C}$, and significant softening becomes a problem at higher temperatures. Operation of only one preheater was sufficient to preheat the gas to a $3000 \mathrm{C}$ reaction temperature. The feed line between the preheaters and the reactor input was traced with a heating tape to minimize heat losses and provide a means for fine adjustment of the inlet gas temperature. Power for the heaters was provided by manually controlled variacs. A schematic of the power distribution system is shown in Figure 3.

Temperature measurement was made using chromel-constantan thermocouples distributed throughout the system. The output voltage of the thermocouples was fed to a digital panel meter which was capable of displaying either voltage (in mv) or temperature (in ${ }^{\circ} \mathrm{C}$ ). Thermocouple location and switching circuitry, including the digital panel meter, are shown in Figure 4.

The reactor used for these studies was designed to allow infrared spectra of the catalyst to be taken under reaction conditions. This reactor was situated in the sample cavity of a Perkin-Elmer 457 infrared spectrometer and is shown schematically in Figure 5. The reactor was aligned so that converging sample and reference beams pass through the conical channels of the reactor, perpendicular to the catalyst and reference infrared disks and gas flow channel. Each of the beam channels was sealed via IR transparent windows and viton $0-r$ ings. The windows and $0-r i n g$ seals were maintained near room temperature 
$-14-$

Figure 3. Schematic of heating power distribution system 


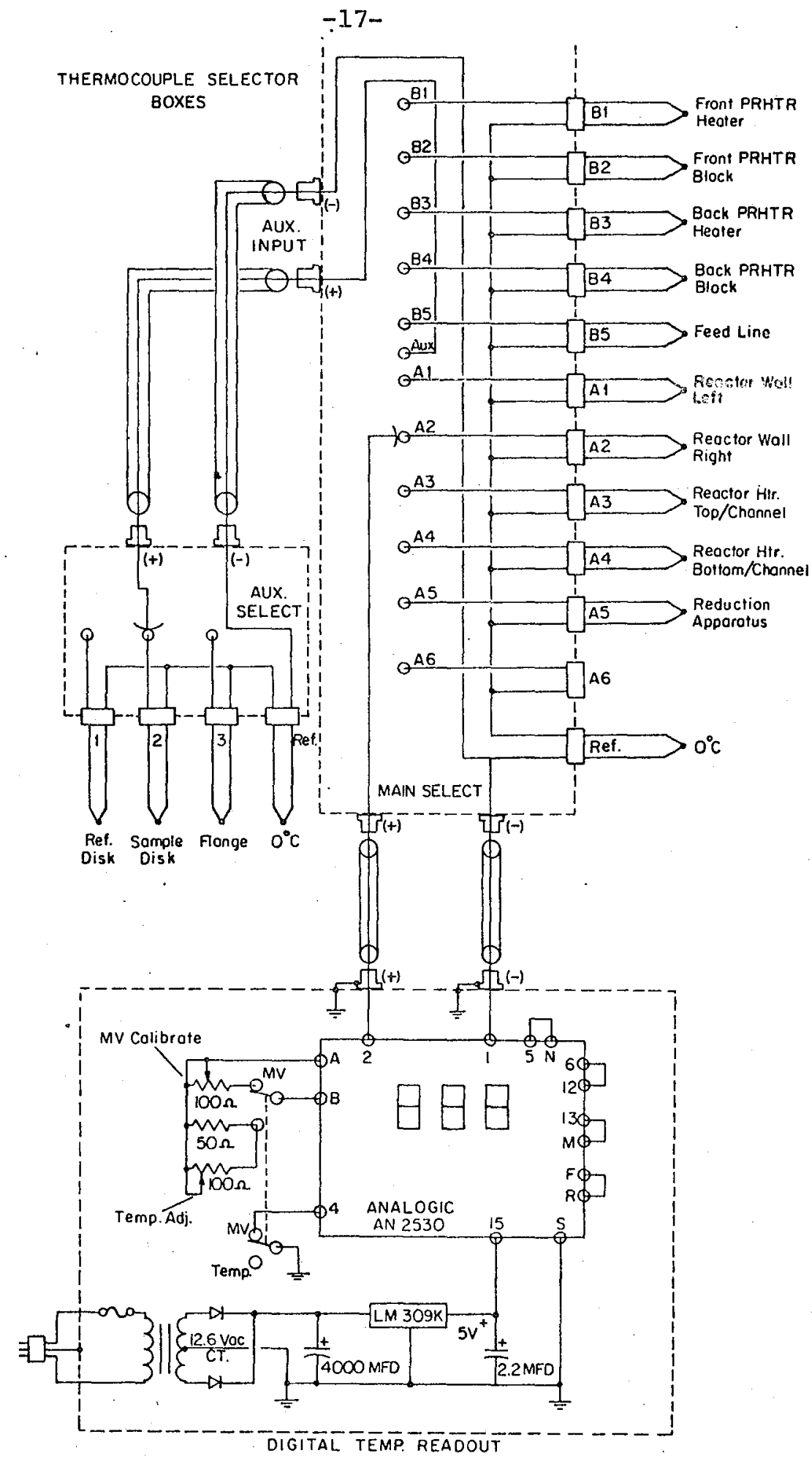

XBL 784-4818

Fig. 4 
Figure 5. Schematic of reactor 

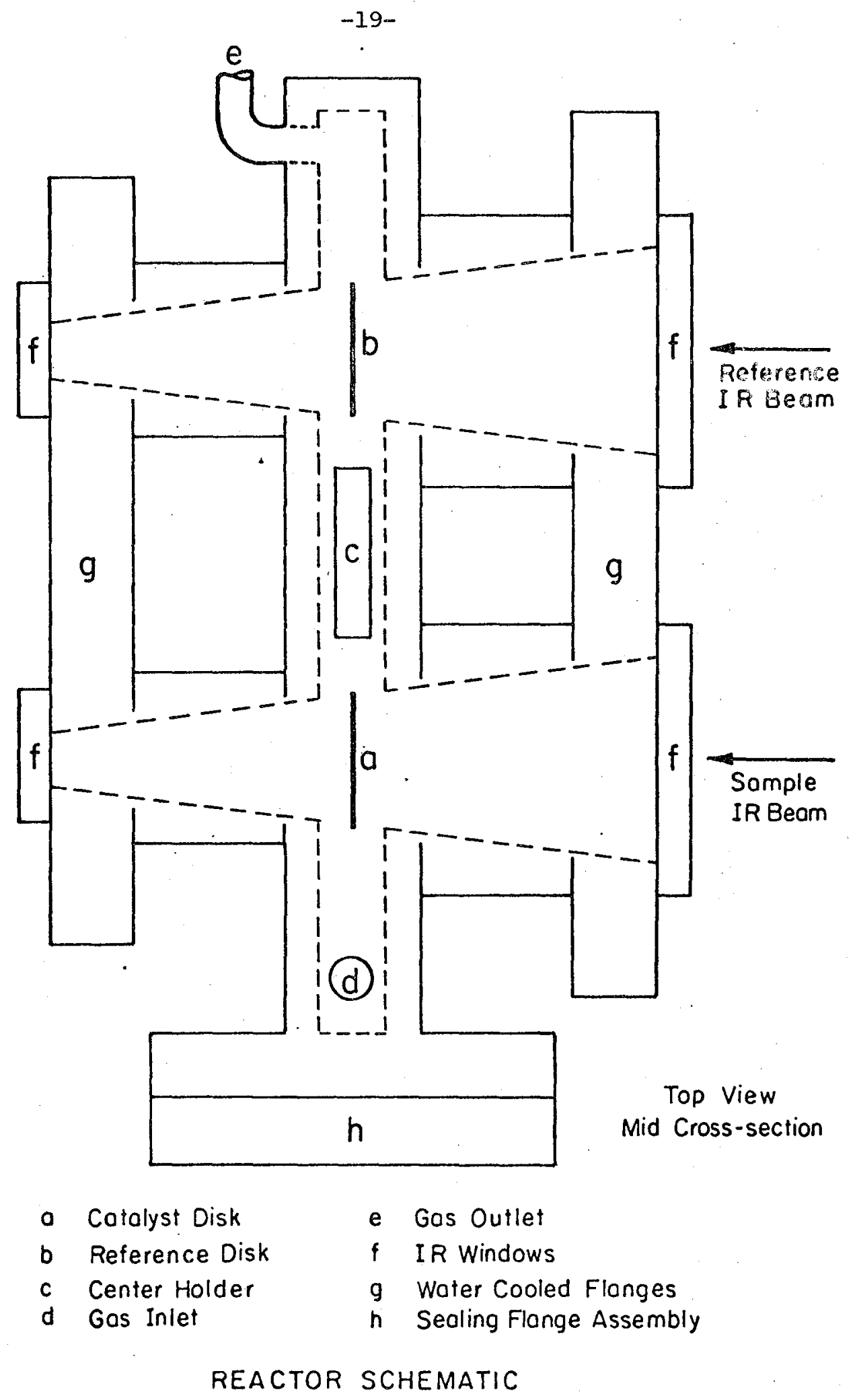

XBL 784-4815

Fig. 5 
by cooling water circulated through the slabs to which the windows were attached. The windows used in initial experiments were crystalline $\mathrm{KBr}$, however these proved to be impractical due to frequent breakage. Both $\mathrm{CaF}_{2}$ and polycrystalline $\mathrm{NaCl}$ were used for subsequent experiments. A rectangular channel $\left(1 / 2^{n} \times 1-1 / 2^{n} \times 7^{n}\right)$ milled in the central section of the reactor served as the primary reaction chamber containing the catalyst. Passage of gas through the reactor was facilitated by ports at both extremes of the channel. Sealing of the channel was accomplished by a weld seal at one end and a removable flange system at the other.

Heating of the channel was accomplished by cartridge heaters inserted in the top and bottom channel walls. Thermocouples were mounted outside the reactor on the channel walls to monitor wall temperatures. The sealing flange system was heated (to balance cemperature gradients) by a fiberglass insulated heating tape wound around the flange circumference. Gas phase temperatures in the channel were limited to a maximum of $320^{\circ} \mathrm{C}$ due to thermal gradients and heat loss to the water cooled window mounting flanges.

Catalyst insertion, removal and alignment in the infrared beams was provided by mounting the catalyst to an assembly rigidly fixed to the removable sealing flange. This track assembly was inserted in the reactor channel during operation and is shown in Figure 6 . The 1" diameter infrared catalyst and reference disks were mounted on this assembly via disk holders attached with small screws.

Between the disk holders an additional catalyst holder was placed, with an approximate capacity of 1 gram of catalyst. This holdex 
$-21-$

Figure 6. Schematic of flange, track assembly, and center catalyst holder 


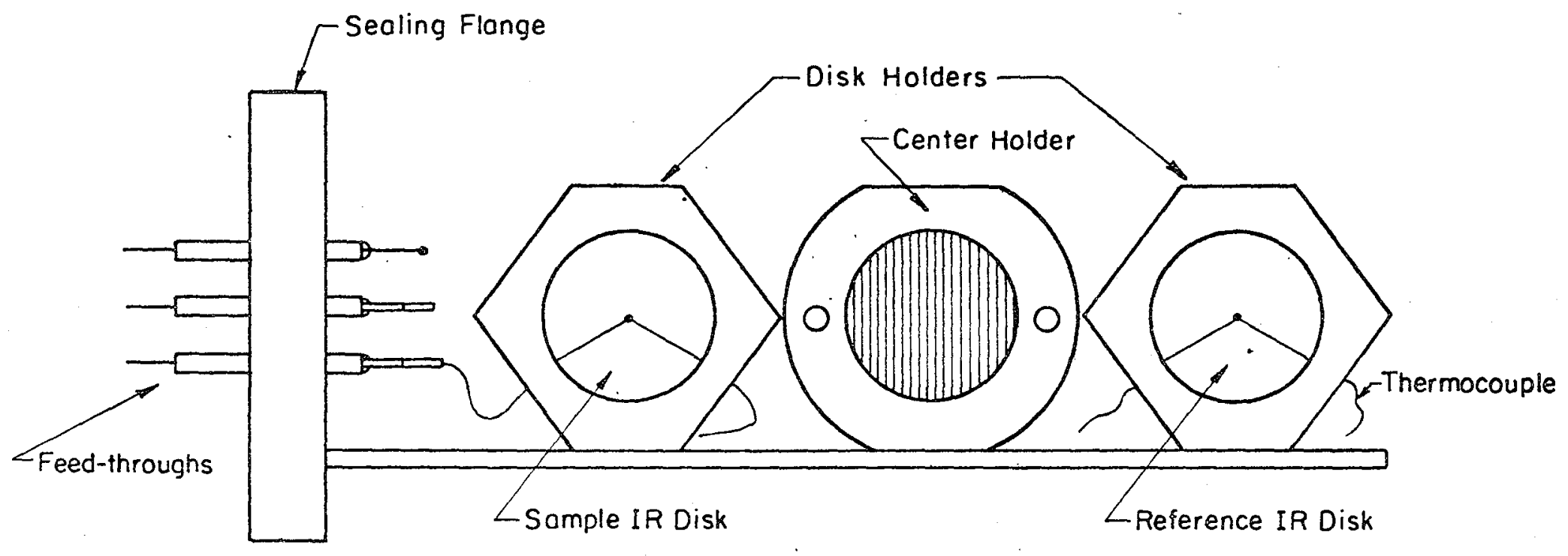

FLANGE AND TRACK ASSEMBLY

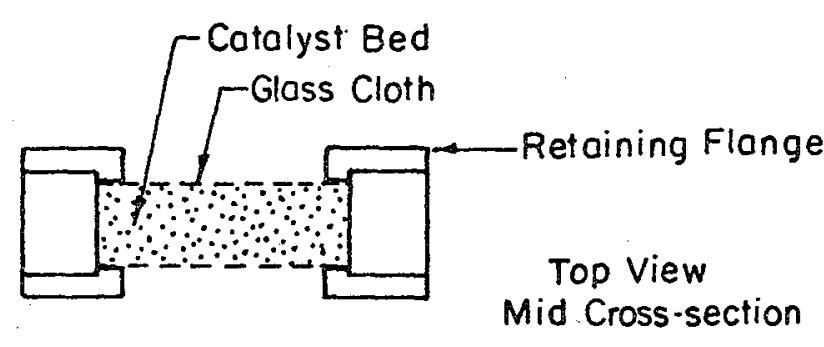

CENTER HOLDER

Fig. 6 
provided a cylindrical bed $1 "$ in diameter and $1 / 4 "$ deep. Containment of the catalyst was provided by fiberglass cloth stretched across both circular faces of the bed. When installed in the reactor channel, gas flow is parallel to the circular faces of the bed. Calculations indicated that bed diffusion would not be a problem for the feed rates studied. Bed permeability was aided by the significant channel blockage caused by the center holder, causing high gas velocities and turbulence at the bed faces. The pulsatile nature of the flow resulted in additional pressure fluctuations and turbulence.

The track assembly was attached to a sealing flange containing electrically isolated, gas tight feedthroughs. These provided electrical access to the thermocouples mounted on the infrared disk holders, in close proximity to the disks. A third thermocouple was placed at the gas flow entrance to the reactor. The electrical feedthroughs were constructed by brazing a ceramic disk to $1 / 8$ " Kovar tubes placed through holes drilled in the disk, then brazing the disk to the stainless steel sealing flange. Pin connectors and thermocouple wires silver soldered to the Kovar tubes completed the seal.

All parts of the track assembly (omitting feedthroughs and thermocouples), sealing flange, and reactor cell were machined from 304 or 316 type stainless steels. These parts were electroless nickel plated to remove surface roughness prior to the application of a special ion plated aluminum coating, described below. 


\section{Aluminum Coating}

Because stainless steel is known to be active for the catalytic reduction of No by $\mathrm{CO}$, the acquisition of rate data in a steel reactor may be complicated by high background activity. This activity makes it difficult to study the NO-CO system in apparatus constructed of stainless steel. Peterson and coworkers (23) have shown that continual cyclic oxidation and reduction of the stainless steel surface promotes surface cracking and spalling. This cracking and spalling contributes to a significant increase in the surface area of the steel. Initial experiments performed with the reactor described here showed that the blank activity could be quite significant and result in as much as 408 No conversion.

In the light of these problems, a considerable amount of effort was expended to reduce the blank activity of the apparatus. Due to the highly specialized construction of the reactor, it was considered impractical to build a duplicate unit from another material. There are very few materials that have the desired corrosion resistance, machinability, weldability, mechanical sțrength, and are non-catalytic as well. It was decided, therefore, that the most practical approach would be to find a catalyticly inactive coating for the internal surfaces of the reactor. An ideal coating should be: (1) noncatalytic, (2) stable at temperatures up to $450^{\circ} \mathrm{C}$ in both oxidizing and reducing atmospheres, (3) have low $\mathrm{Cr}, \mathrm{Ni}$, and Fe solubility to inhibit diffusion of these metals to the surface, (4) be nonporous to prevent significant gas diffusion to the underlying steel, (5) have low solubility in stainless 
steel to prevent eventual loss of the film, (6) be physically durable and (7) easy to apply.

Gold plating was considered due to the inert nature of gold, however test strips of gold plated stainless steel showed very poor high temperature stability. This can be explained by noting that in order to electroplate gold on stainless steel, the steel must first be plated with nickel and then copper, since the gold will not adhere to the steel surface directly. As the temperature of the $\mathrm{Au} / \mathrm{Cu} / \mathrm{Ni}$ plate is raised, the metals interdiffuse and a surface of copper oxide is formed. The rate of diffusion is extremely slow at room temperature, but increases rapidly at higher temperatures as a result of the exponential dependence of the diffusion rates on absolute temperature. Calculations indicated a diffusion time constant of approximately $1 \mathrm{hr}$ for a $1 \mathrm{mil}(0.001 \mathrm{in.)}$ thick $\mathrm{Au} / \mathrm{Cu}$ plate at a temperature of $300^{\circ} \mathrm{C}$. This time constant was confirmed by experiment. One material which meets the ideal coating criteria quite well is aluminum. Aluminum films form dense $\mathrm{Al}_{2} \mathrm{O}_{3}$ surfaces (24) that exhibit low catalytic activity, excellent resistance to oxidizing and reducing atmospheres at high temperatures, and good adhesion to stainless steel. Aluminum has a low solubility in stainless steel, and $\mathrm{Fe}, \mathrm{Cr}$, and Ni all have very low solubilities in aluminum. In addition, aluminum is an easy material to apply by either vapor deposition or ion plating. Since ion plating is capable of covering intricate shapes, this method was selected.

The stainless steel parts to be coated were cleaned and electroless nickel plated to help smooth any surface roughness. Two $2000 \AA$ ion 
plated aluminum coatings were applied, with an oxidation step following the first coating and preceding the second. The purpose of the oxidation was to provide a diffusion barrier of $\mathrm{Al}_{2} \mathrm{O}_{3}$ to prevent diffusion of the top protective coating into the steel bulk. This barrier also prevents diffusion of any $\mathrm{Fe}, \mathrm{Ni}$, or $\mathrm{Cr}$ to the surface. It is beyond the scope of this work to give a detailed description of the ion plating process itself. However, a brief description is in order. The parts to be plated are placed in a vacuum chamber and charged to -1000 volts in the vicinity of a hot aluminum filament at ground potential. Aluminum ions leaving the filament are accelerated into the steel surface, resulting in good adhesion and dense coverage. After the application of the second coating, the coated steel parts were placed in an air oven at $400^{\circ} \mathrm{C}$ for $200 \mathrm{hr}$ to grow a dense $\gamma-\mathrm{Al}_{2} \mathrm{O}_{3}$ crystalline film (2A).

\section{Analysis System}

Analysis of the gas phase compositions was accomplished using two gas chromatographs connected in series. This approach made it possible to obtain a clean separation between $\mathrm{NO}, \mathrm{CO}, \mathrm{N}_{2}, \mathrm{~N}_{2} \mathrm{O}$, and $\mathrm{CO}_{2}$ without the use of cryogenic temperatures or temperature programming. A schematic of this system is shown in Figure 7.

The first chromatograph (GC1) contained a Poropak R column to separate $\mathrm{N}_{2} \mathrm{O}$ and $\mathrm{CO}_{2}$. The components $\mathrm{NO}, \mathrm{CO}, \mathrm{N}_{2}$ were eluted from the Poropak $R$ column as a single unresolved peak prior to $\mathrm{N}_{2} \mathrm{O}$ and $\mathrm{CO}_{2}$. The combination peak was resolved in the second chromatograph (GC2) which contained a $5 \AA$ molecular sieve column. Column operating conditions are given in Table 1. Column temperatures were adjusted to prevent overlapping of $\mathrm{N}_{2}$ (first peak from GCl) with $\mathrm{N}_{2} \mathrm{O}$ (last 
Figure 7. Gas flow schematic for the chromatographic analysis system 


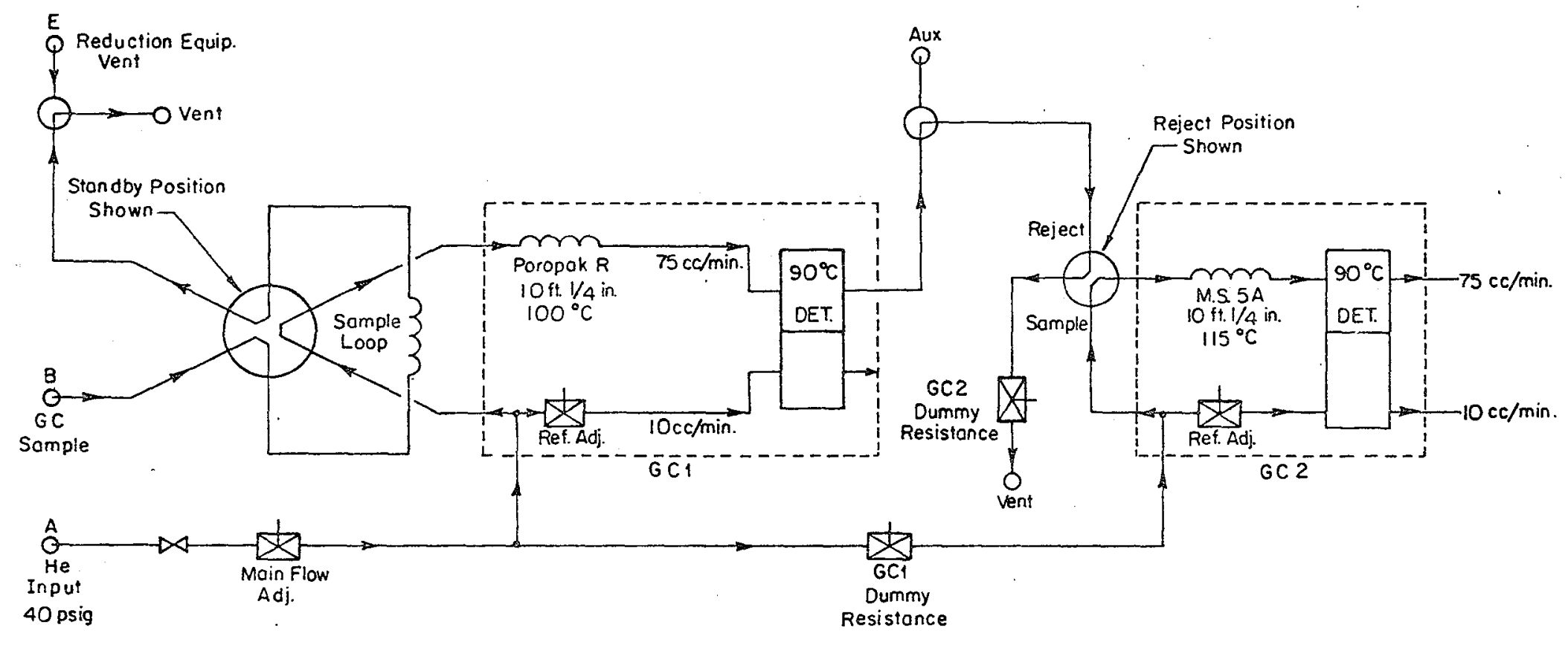

GC ANALYSIS TRAIN

Fig. 7 
Table 1. GC Column Operating Conditions

\begin{tabular}{lll}
\hline & \multicolumn{1}{c}{ GCl } & \multicolumn{1}{c}{ GC2 } \\
\hline Packing material & Porapak R & Mole sieve 5A \\
Column dimensions & $\begin{array}{l}10 \mathrm{ft} \times 1 / 4 " \text { od } \\
\text { stainless tubing }\end{array}$ & $\begin{array}{l}10 \mathrm{ft} \times 1 / 4 " \text { od } \\
\text { stainless tubing }\end{array}$ \\
Column temperature & $100^{\circ} \mathrm{C}$ & $900^{\circ}$ \\
He carrier flow rate & $75 \mathrm{cc} / \mathrm{min}$ & $75 \mathrm{cc} / \mathrm{min}$ \\
Filament current & $250 \mathrm{~mA}$ & $250 \mathrm{~mA}$ \\
Detector temperature & $900^{\circ} \mathrm{C}$ & $900^{\circ}$ \\
\hline
\end{tabular}


peak from GC2), since only the one detector output could be observed at a time. Valving between the chromatographs was necessary to prevent the components $\mathrm{CO}_{2}$ and $\mathrm{N}_{2} \mathrm{O}$ from entering the mole sieve column and irreversibly adsorbing. This function was performed by a two position four-port ball valve. In the SAMPLE position the effluent from the Poropak column is introduced directly into the mole sieve column. After the passage of the combination ( $\left.\mathrm{CO}, \mathrm{NO}, \mathrm{N}_{2}\right)$ peak through $\mathrm{GCl}$, the ball valve is manually switched to the REJECT position which vents succeeding components from GCl while simultaneously providing He carrier flow for the column in GC2. Since thermal conductivity detectors are sensitive to carrier flow rate, needle valves were used to provide identical (within 18) carrier flow rates for each column in both valve positions. A two position six-port sampling valve was used to fill and inject the contents of the sampling loop. In the STANDBY position, the sample stream is directed through the sample loop and then vented, while He carrier gas is routed directly to the column. In the SAMPLE position, the carrier stream purges the contents of the sample loop into the column, and the sample stream is vented.

The output of the chromatograph detectors (0 to $1 \mathrm{mV})$ was amplified (to 0 to $10 \mathrm{~V}$ ) and then fed to a chart recorder and a data acquisition system (Figure 8). The data acquisition system has been described elsewhere (25) and shall not be discussed.

Initial calibration of the chromotagraphs was performed using Primary Standard Certified gas mixtures obtained from Matheson. Three separate mixtures of $\mathrm{N}_{2} \mathrm{O}, \mathrm{CO}_{2}$, and $\mathrm{N}_{2}$ in He ranging in concentration from 0.5 molez to 5.0 mole 8 per component were used $\left(0.5\right.$ each $\mathrm{CO}_{2}$ ' 
Figure 8. Electrical signal processing schematic for the chromatographic analysis system 


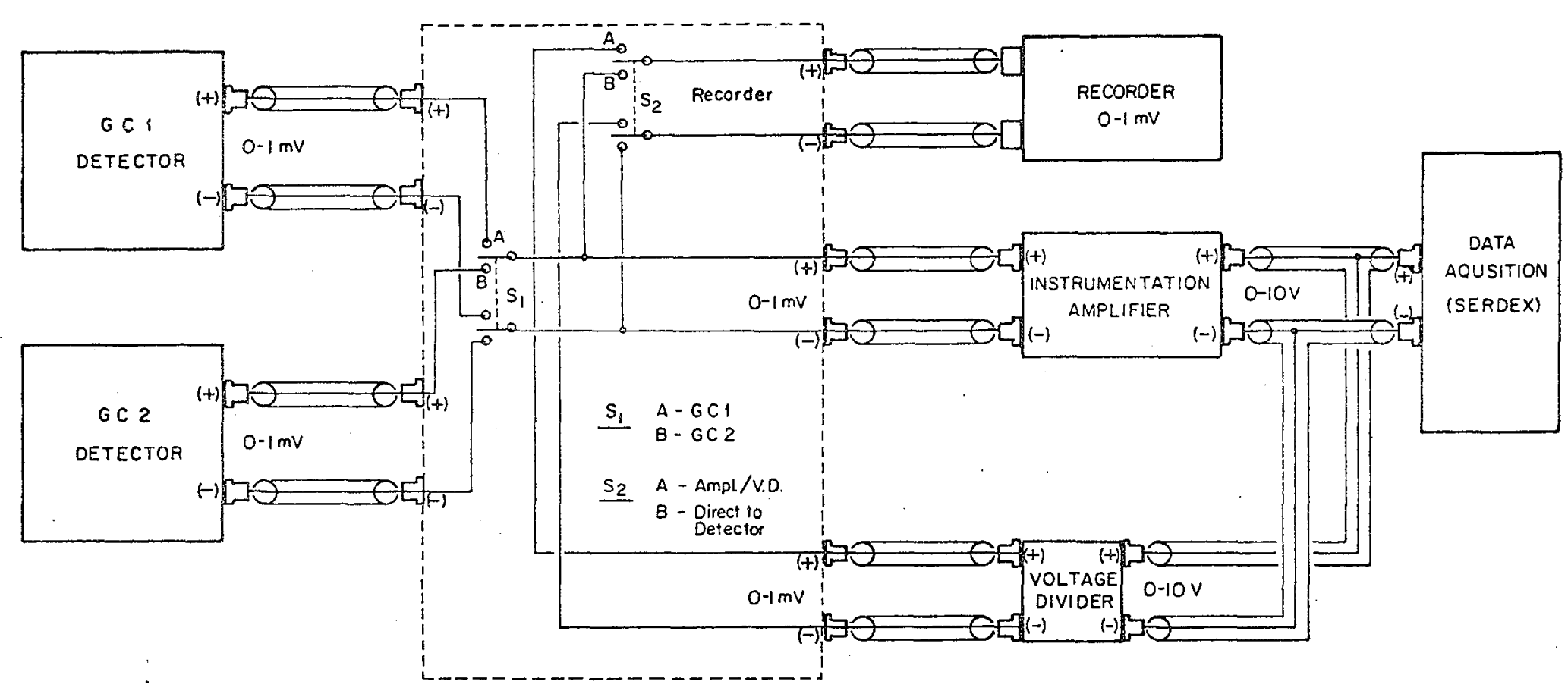


$\mathrm{N}_{2} \mathrm{O}, \mathrm{N}_{2}$ in $\left.\mathrm{He}\right)$. Calculation of the sample component concentrations was made by computing peak amplitudes from the digital printout and ratioing these to peak amplitudes obtained during calibration.

Reproducability using the peak height method was within 18. Quantitative analysis was not attempted for NO and $C O$ due to difficulties in obtaining a reproducable separation in the mole sieve column. Calibration could be performed with reasonable reproducability for either No or CO separately, but the response for No-CO mixtures was often erratic. No and $\mathrm{CO}$ compositions in the reactor product stream were determined by mass balance after analysis for $\mathrm{N}_{2} \mathrm{O}, \mathrm{CO}_{2}, \mathrm{~N}_{2}$.

\section{B. Procedures}

\section{Catalyst Preparation}

The catalyst used in this study was a high dispersion platinum catalyst supported on silica. Two types of silica were used to support the Pt, corresponding to the different requirements of the two catalyst positions in the reactor. Catalyst in the center holder was supported on silica gel (Davidson type $70,-80+150$ mesh), while catalyst making up the IR disk was supported on fumed silica (Cabot type HS-5 Cabosil). The preparation procedure was essentially the same for both types of silica support, and was based on the platinum ammine ion exchange , technique described by Boronin et al (27) and Benesi et al (26) . The heart of this process involves contacting the silica support with a platinum ammine solution at high $\mathrm{pH}(\geqslant 9)$.

To obtain the desired Pt catalyst loading of approximately 4 wt. 8 , $110 \mathrm{ml}$ of a previously prepared chloroplatinic acid solution $(4.988 \mathrm{gm}$ $\mathrm{H}_{2} \mathrm{PtCl}_{6} \cdot 6 \mathrm{H}_{2} \mathrm{O}$ in $500 \mathrm{ml}$ distilled $\mathrm{H}_{2} \mathrm{O}$ ) was added to $265 \mathrm{ml}$ distilled. 
$-36-$

Figure 9. Catalyst reduction apparatus 


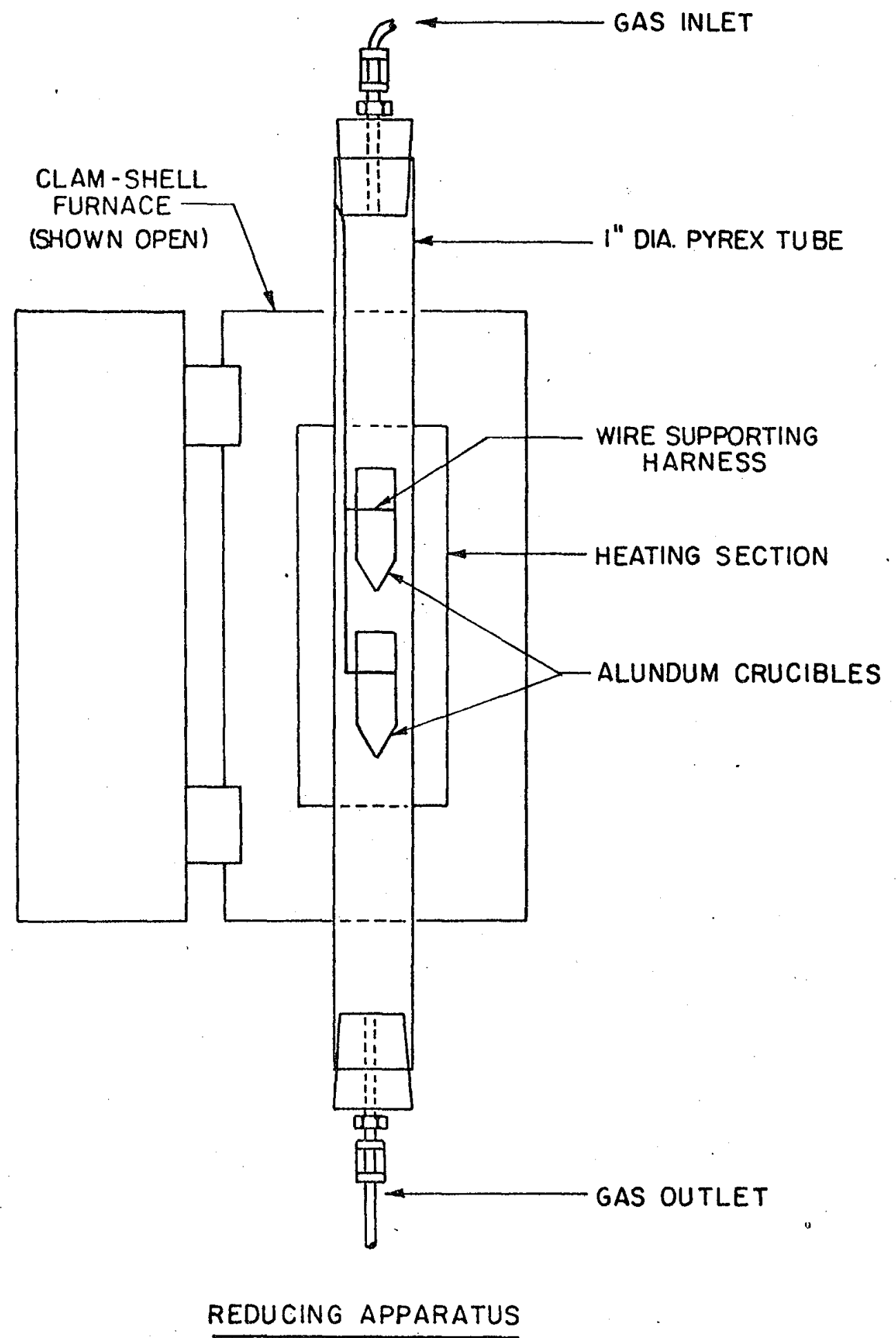

XBL 785-5070

Fig. 9 
The reduction procedure was also carried out with the Cabosil IR reference disk material, in order to remove any chlorine remaining after manufacture.

The reduced catalyst was sieved in stainless steel screens by mechanical vibration. The Cabosil supported catalyst and reference material was sized to -325 mesh, and the silica gel supported catalyst was sized to $-80+150$ mesh.

\section{IR Disk Preparation}

The catalyst was pressed into thin disks or wafers in order to perform transmission infrared spectroscopy. This was accomplished by compressing the finely powdered; supported catalyst in a steel die at high pressure.

Many variables were optimized in this process in order to yield disks of good infrared transparency and durability. The type of silica support, mass of the disk, pressing procedure and pressure, and die material and construction, all had an effect on the resulting IR disks.

Concerning the type of support, it was found that Cabosil disks had better IR transparency than silica gel ( -325 mesh) disks when pressed under the samè conditions.

The mass of the disk was optimized with respect to two competing effects. Heavy disks contain more catalyst, and are desirable since observed IR bands are more intense, and smaller amounts of an adsorbed species are detectable. However, higher mass disks have poorer transparency since they are thicker, and this is not desirable since spectrometer response is sluggish leading to a corresponding loss in resolution. If the disks are too light, they will break or 
crack easily and are difficult to handle. The optimum mass was determined to be in the range of 160 to $200 \mathrm{mg}$.

The die used in this study was similar in design to that used by Ludvik (9), and was constructed of case hardened tool steel. The die faces were surface ground flat and parallel. Experimentally it was found that the tool steel die would produce durable, transparent IR disks at much lower pressures than the stainless steel die used by Ludvik. The die is shown schematically in Figure 10.

The disks were pressed at the lowest pressure consistent with acceptable IR transparency and good physical durability. High pressures yield disks of good IR transparency and physical durability, but there is a possibility that these disks may have poor mass transfer characteristics due to a "skin" produced at high compression. After loading approximately $200 \mathrm{mg}$ in the die assembly, the pressure was raised to a maximum of 7700 psi (on disk) over a period of 3-4 minutes. This pressure was held for 6 to 7 minutes and then released gradually over a period of 8 to 10 minutes. Releasing the presence at a faster rate resulted in puckered and cracked disks.

Three catalyst disks and three reference disks were made and used in this study. The catalyst disks (designated $\mathrm{Cl}, \mathrm{C} 2$, and $\mathrm{C} 3$ ) weighed $168 \mathrm{mg}, 157 \mathrm{mg}$, and $160 \mathrm{mg}$, respectively. The reference disks (designated R1, R2, and R3) weighed $203 \mathrm{mg}, 171 \mathrm{mg}$, and $166 \mathrm{mg}$, respectively. Each of the three catalyst disks (as well as each of the three reference disks) were used interchangeably in later experiments. 
$-40-$

Figure 10. Die for pressing catalyst disks 

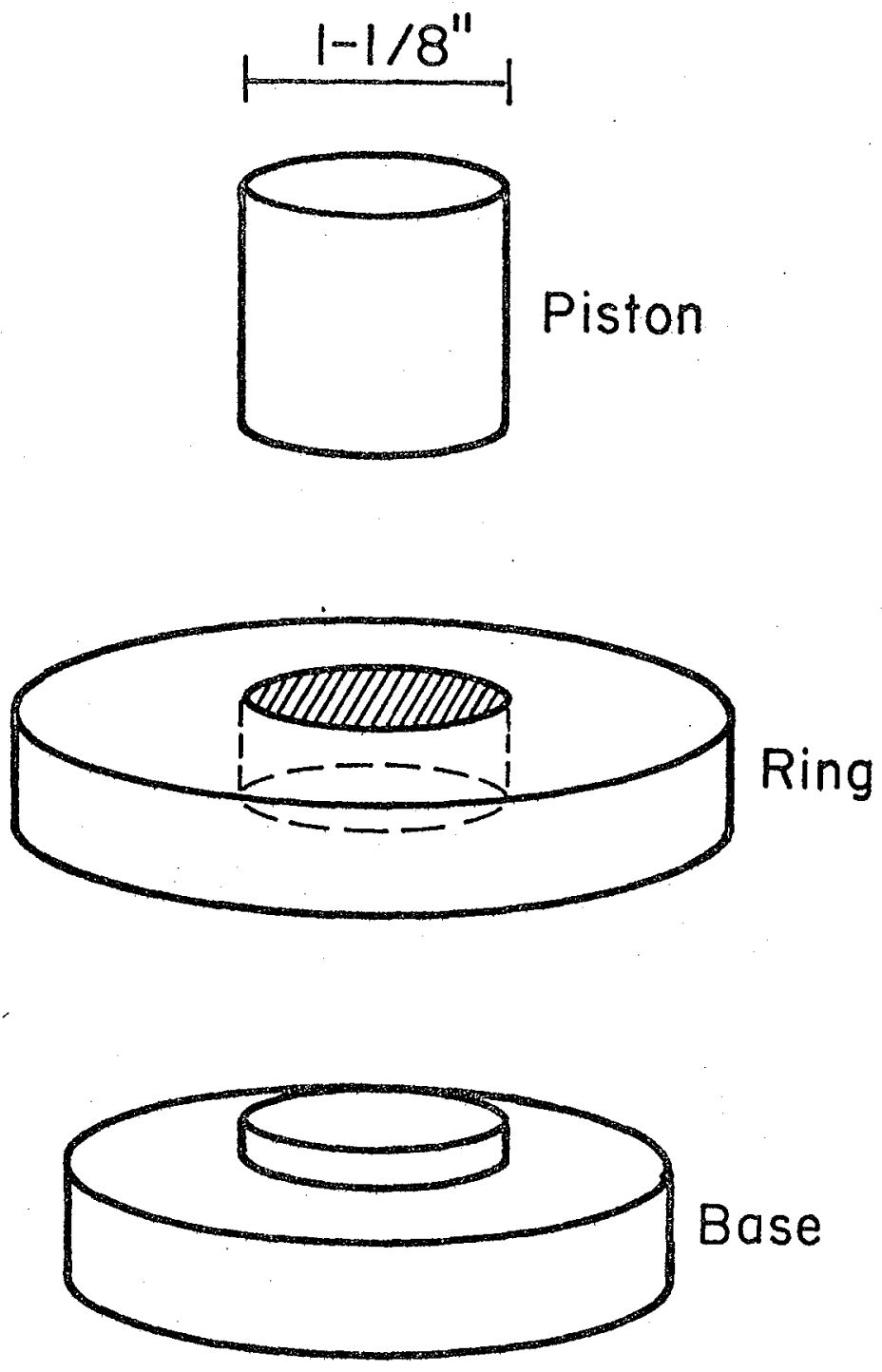

XBL 786-9314

Fig. 10 


\section{Catalyst Characterization}

Properties of the silica supported platinum catalyst used in this study are shown in Table 2. Also shown are the properties of the catalyst used by Ludvik (9) for comparison. Several analyses were performed in order to characterize the catalyst, including $\mathrm{x}$ ray fluorescence, hydrogen chemisorption, and a semi-qualitative spectrographic analysis for trace metals.

Platinum weight loadings were determined by $\mathrm{x}$-ray fluorescence and are accurate to $\pm 5 \%$. This analysis was performed by Mr. Bob Giaque at the Lawrence Berkeley Laboratory.

Metal surface area was determined by hydrogen chemisorption, performed by Pacific Sorption Service. Dispersion was calculated by multiplying the hydrogen chemisorbed (micro-moles/gm catalyst) by 2 and dividing by the total platinum present (micro-moles/gm catalyst). As can be seen in Table 2, dispersions are very high and in good agreement with the dispersion reported by Ludvik.

The average crystallite size was estimated from:

$$
D=\frac{2 n^{2}+(n-2)(3 n-2)}{n^{3}}
$$

where: $\quad D=$ dispersion

$$
\mathrm{n}=\text { of Pt atoms per side of crysallite }
$$

In deriving this equation, a simple cubic lattice was assumed, and the crystal was assumed cubic as well. Corner atoms were counted only once in accounting for surface area, and it was assumed that the crystal is resting on a planar surface with five sides exposed to the gas phase. The equation predicts, for a catalyst of 908 dispersion, 
Table 2. Catalyst Properties

\begin{tabular}{|c|c|c|c|c|}
\hline & Batch \#1 & Batch 2 & Batch \#6 & Ludvik \\
\hline $\begin{array}{l}\text { weight } \\
\text { loading, } 8\end{array}$ & $4.57 \pm 0.23$ & $4.25 \pm 0.21$ & $4.68 \pm 0.23$ & 3.00 \\
\hline support & HS-5 Cabosil & $\begin{array}{l}\text { Davidson } 70 \\
\text { silica gel }\end{array}$ & $\begin{array}{l}\text { Davidson } 70 \\
\text { silica ge } 1\end{array}$ & M-5 Cabosil \\
\hline $\begin{array}{l}\text { hydrogen } \\
\text { chemis. } \\
\text { umoles/g }\end{array}$ & 106 & 100 & 101 & 69 \\
\hline dispersion & 908 & $91 ㅇ ㅛ ㅇ$ & 848 & 908 \\
\hline $\begin{array}{l}\text { avg. crys. } \\
\text { size, } \AA\end{array}$ & 14 & 14 & 15 & 17 \\
\hline
\end{tabular}


that an average crystallite will contain between 3 and 4 Pt atoms per side. Assuming a diameter of approximately $4 \AA$ per Pt atom, the average crystallite size would be between 12 and $16 \AA$. These estimates were not verified by direct measurement, however the estimates are in good agreement with the average crystallite size determined by electron microscopy in Ludvik's study.

4. Preliminary Experiments

Initial experiments were performed to determine the range of conditions which would yield accurate and reproducible kinetic information.' These experiments were primarily concentrated in two problem areas: 1) minimizing the effect of reactor background activity and 2) obtaining consistent and reproducible catalyst activity from run to run. It should be noted, in the light of future discussion (see Results section), that initial experimentation was carried out under highly reducing $\left(\mathrm{P}_{\mathrm{CO}}>\mathrm{P}_{\mathrm{NO}}\right)$ conditions. As a result, operating parameters were chosen with respect to the lowest catalytic activity and "worst case" conditions. In order to minimize background activity, experimental results indicated that it was desirable to place as much catalyst in the reactor as possible, and operate at the maximum allowable reaction temperature. High reaction temperatures preferentially increased the activity of the platinum catalyst, with respect to that of the reactor walls, due to the higher activation energy associated with the platinum catalyzed reactions. The maximum allowable reaction temperature was limited to $300^{\circ} \mathrm{C}$, and all kinetic data reported in this study were taken at this temperature. Operation at temperatures below $3000^{\circ} \mathrm{C}$ did not yield data of acceptable accuracy due to low kinetic activity. 
The maximum amount of catalyst which could be placed in the reactor was limited to approximately $1.2 \mathrm{gm}$, including the infrared catalyst disk and the catalyst in the center holder. Experiments were performed using both the Cabosil and the silica gel supported catalysts in the center holder. No difference in activity was detected between catalysts on the two types of support. In addition, since the Cabosil supported catalyst was in the form of broken IR disks $(\sim 1 / 4$ " diameter), these experiments indicated that the IR disks were free of mass transfer limitations. The silica gel supported catalyst was used in the center holder because the broken IR disks were prone to dusting. The silica gel did not exhibit this problem and was easier to retain.

After the operating conditions had been established, the problem of reproducibility was addressed. Initial results revealed that, for feed ratios of $\mathrm{CO} / \mathrm{NO}>1$, the catalyst exhibited a time dependent deactivation (see the Results section for a more complete discussion on this point). This indicated that the catalyst was undergoing some type of poisoning, and a pretreatment procedure was developed to restore catalyst activity between runs. A pretreatment of a 2 hr oxidation (in $20 \mathrm{O}_{2}$ in $\mathrm{He}$ ) followed by a $5 \mathrm{hr}$ reduction (in $\mathrm{H}_{2}$ ) at $3000 \mathrm{C}$ was found to restore the initial activity reproducibility. This pretreatment preceded every kinetic run unless otherwise noted.

The rather lengthy pretreatment procedure appeared to have no effect on the dispersion of the catalyst. This was determined by observation of the CO IR band. Under high CO partial pressures, a large percentage of the platinum surface will be covered with adsorbed Co. Since many of the experiments were run under high $c 0$ partial 
pressures ( 5 to 70 torr), one would expect to see a change in the $C O$ infrared absorbance over a series of runs if the catalyst surface area was changing significantly. Only small changes were noted, none of which were permanent or irreversible.

A summary of experimental conditions and procedures is given in Table 3.

\section{Blank Activity}

Despite all the effort expended in coating the reactor, background activity was still found to be significant and could not be ignored when analyzing the kinetic data. The blank activity was found to be transient in nature, and exhibited a time dependent decay over the time period of a run $(3 \mathrm{hr})$. In addition, operation of the reactor over a long time span with many pretreatment and run cycles resulted in a gradual increase in activity. This activity could he reduced by recoating the internal surfaces of the reactor.

Experiments were performed in an attemyt to isolate the cause of the reactor activity. During the preliminary experimentation period, the blank activity had risen to very high conversions, as can be seen in Figure 11, curve a. Removal of the track assembly reduced the activity significantly (curve b) and recoating the walls and track assembly with Vacseal (Space Environmental Labs) reduced the activity still further (curve c). From these results it is clear that the largest contribution to the background activity was due to the track assembly.

The cause of the high track activity is not understood. Flexing of the track during handling and temperature cycling resulted in some 
Table 3. Summary of Procedures and Conditions

Experimental Conditions

Reaction temperature: $300^{\circ} \mathrm{C}$

Total feed rate: $200 \mathrm{cc} / \mathrm{min}\left(25^{\circ} \mathrm{C}, 1 \mathrm{~atm}\right)$

Range of feed concentrations: 1.0 to 10.0 mole 8 , NO and/or $\mathrm{CO}$ in $\mathrm{He}$

Catalyst: $4.5 \mathrm{wtz} \mathrm{Pt} / \mathrm{silica}, 1.2$ to $1.3 \mathrm{gm}$

Mode: Recycle reactor, recycle ratio $=200: 1$, nominal volume of $300 \mathrm{cc}$

Procedures

Standard Pretreatment

1) Reactor preheated to $300^{\circ} \mathrm{C}$ in $\mathrm{He}$

2) Feed $20 \mathrm{~g}_{2}$ in He for $2 \mathrm{hrs}$

3) Purge with He for $30 \mathrm{~min}$

4) Feed $\mathrm{H}_{2}$ for $5 \mathrm{hrs}$

5) Purge with He for $1 \mathrm{hr}$

Rinetic Run

1) At $t=0$, feed reactants mixture; $\mathrm{NO}$ and $\mathrm{CO}$ in He

2) Sample outlet concentrations at $t=5,15,30,60$, and $180 \mathrm{~min}$

3) Record IR spectra at $t=30,90$, and $150 \mathrm{~min}$

4) At $t=180 \mathrm{~min}$, disconnect feed, purge with He 
Figure 11. Blank conversion as a function of time during preliminary experimentation. Curve a: activity of track assembly and reactor walls prior to recoating, curve b: activity of reactor walls after track removal, curve c: activity of track assembly and reactor walls after recoating with Vacseal. Feed composition for all cases was $810 \mathrm{Co}$, 58 No in He. Temp. $=300 \circ \mathrm{C}$. 


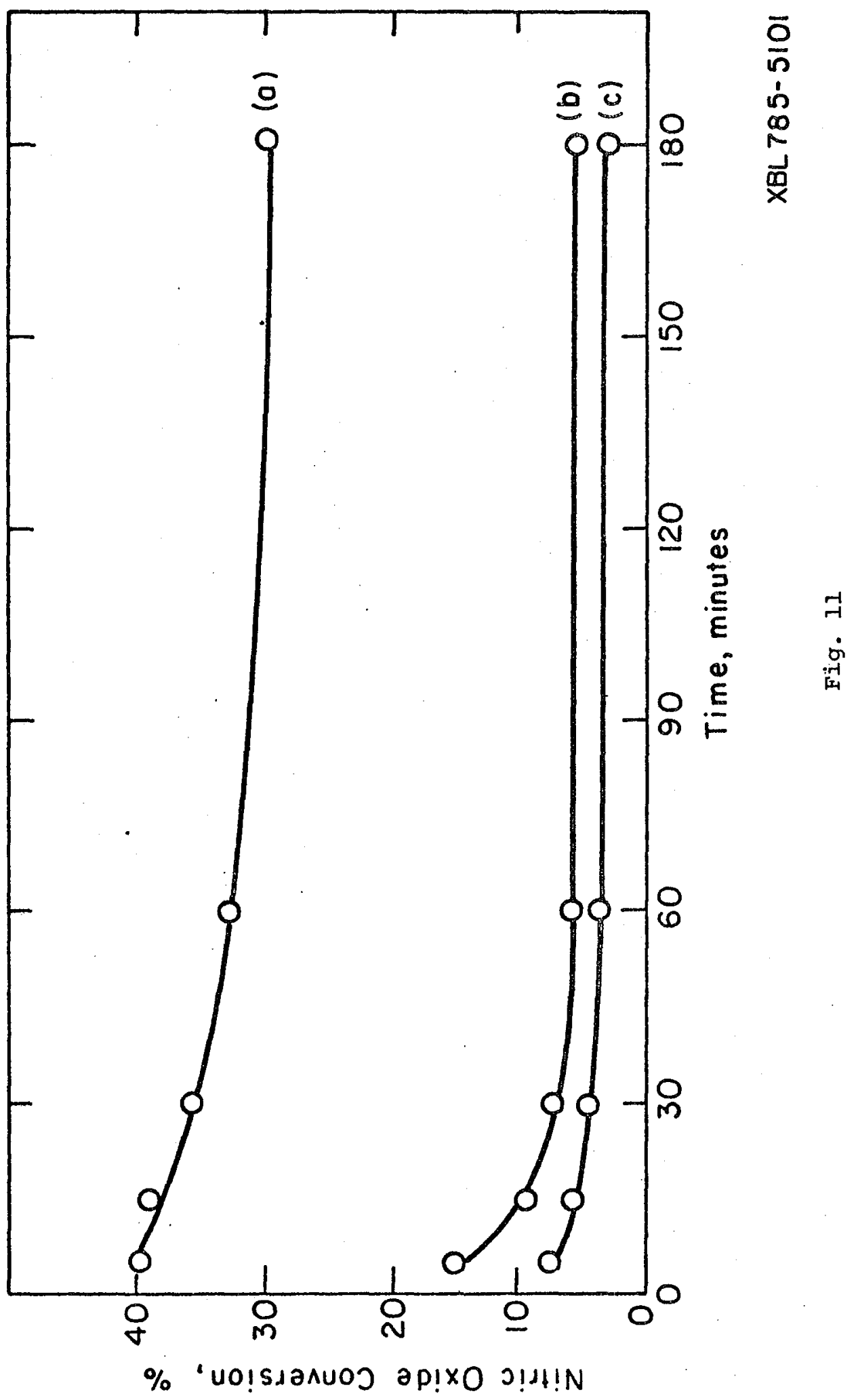


cracking and spalling of the aluminum coating. It is possible that the loss of integrity of the coating is responsible for the increase in activity, however the cracking did not appear to be severe, and it would be difficult to explain such a high degree of activity in terms of the small area of exposed steel. Impurities being fed to the reactor (such as metal carbonyls) were ruled out since they would probably decompose in the first hot section of the recycle loop they enter. This would cause a rise in activity of the preheaters, which was not observed. There is also no reason for a gas phase impurity to selectively decompose on or contaminate the track, unless perhaps it were being formed by the catalyst. There is, however, no evidence for the existence of such a species.

The transient nature of the blank activity required that the blank data be taken as close to the kinetic data as possible, and at the same concentrations, temperature, and pretreatment conditions. This was necessary in order to subtract the reaction rate contribution of the background, and obtain the true catalyst kinetic behavior. Kinetic data was taken in a sequence of three or four runs before the corresponding blank data. Good reproducibility was obtained as long as the blank run sequence immediately followed the kinetic run sequence. This was done for convenience, since the reactor and recycle loop had to be cooled before catalyst removal, and reheated afterward. The lengthy heating and cooling period prohibited taking background data immediately after kinetic data for any given set of conditions in a single run. 
It was not possible to duplicate kinetic run gas phase concentrations during the corresponding blank run, since this would involve a time consuming trial and error procedure due to the backmix nature of the recycle reactor. Instead, the blank data was corrected for the concentration differences by assuming a first order dependence of the reaction rate on No concentration. This assumption was verified experimentally by comparing reaction rates for blank data at different concentrations. The background activity exhibited only a small dependence on $\mathrm{CO}$ concentration, and therefore no $\mathrm{CO}$ dependence was included in the corrections.

The behavior of the background activity over the course of kinetic runs reported in this study is summarized in Figure 12. This figure shows the corrected activity level for the background corresponding to the first and last experiments in the complete sequence of reported data (Runs KOR-20 to KOR-38). 
Figure 12. Range of background activity for kinetic data reported 


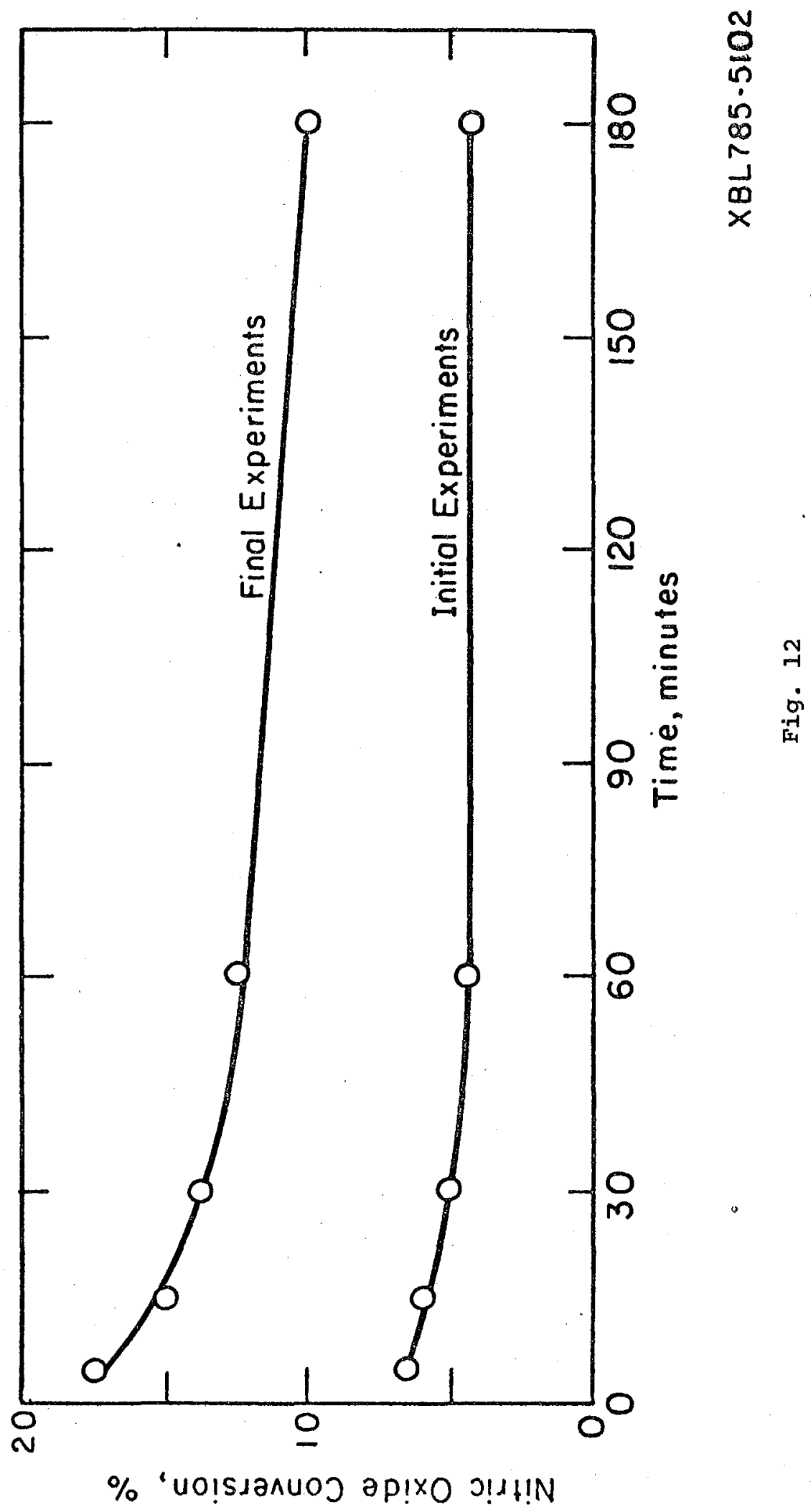




\section{RESULTS AND DISCUSSION}

\section{A. Introduction}

The range of feed concentrations investigated in this study is shown in Figure 13. The kinetic behavior of the system was found to exhibit two distinct trends, depending on the ratio of the molar feed concentrations of $\mathrm{NO}$ and $\mathrm{CO}$. Molar feed ratios of CO/NO greater than one shall be refexed to as the reducing region (the region above the 1:1 line in Figure 13), and molar feed ratios of CO/NO less than one shall be refered to as the oxidizing region. Future discussion of results shall be organized with respect to these two regions.

The variables of interest in this study were reactant conversion, product selectivity and distribution, and the infrared spectra of the catalyst during reaction. Product selectivity and distribution were characterized by two parameters; nitrous oxide selectivity, $\mathrm{S}_{\mathrm{N}_{2}} \mathrm{O}^{\prime}$ and the stoichiometric ratio, $\mathrm{R}_{\mathrm{S}}$, defined below:

$$
\begin{aligned}
\mathrm{S}_{2} \mathrm{O} & =\left(\mathrm{R}_{\mathrm{N}_{2} \mathrm{O}}\right) /\left(\mathrm{R}_{\mathrm{N}_{2} \mathrm{O}}+\mathrm{R}_{\mathrm{N}_{2}}\right) \\
\mathrm{R}_{\mathrm{S}} & =\left(\mathrm{R}_{2} \mathrm{O}+2 \mathrm{R}_{2}\right) / \mathrm{R}_{\mathrm{CO}_{2}}
\end{aligned}
$$

In the above equations, $\mathrm{R}_{\mathrm{N}_{2}} \mathrm{O}^{\prime} \mathrm{R}_{\mathrm{N}_{2}}$, and $\mathrm{R}_{\mathrm{CO}_{2}}$ are the reaction rates of formation of the products $\mathrm{N}_{2} \mathrm{O}, \mathrm{N}_{2}$, and $\mathrm{CO}_{2}$, respectively.

$R_{S}$ is derived from the stoichiometric relationships of the reaction products: 
$-55-$

Figure 13. Range of feed concentrations 
$-56-$

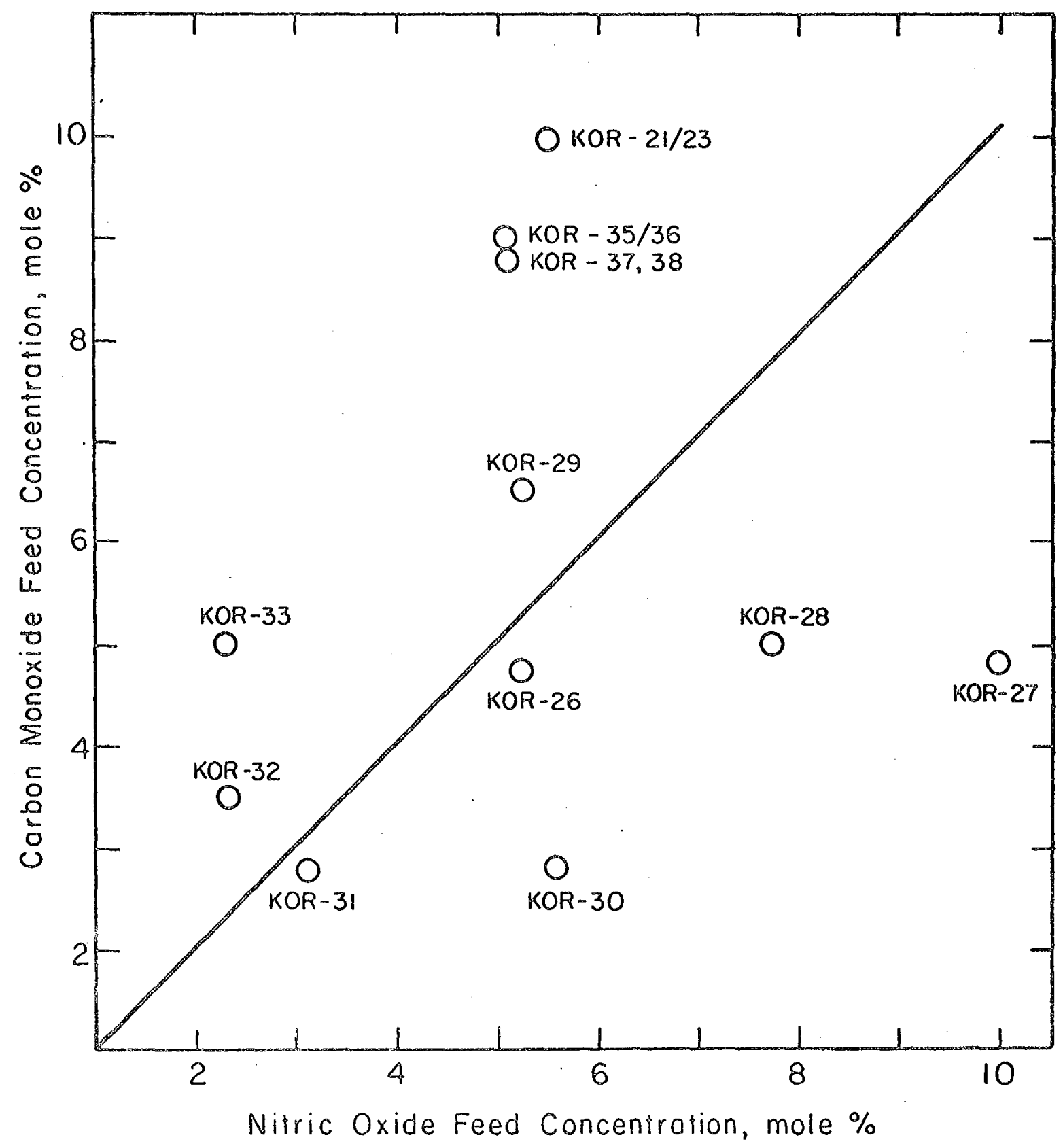

XBL $785-5072$

Fig. 13 


$$
\begin{aligned}
& \mathrm{CO}+\mathrm{NO} \rightarrow \mathrm{CO}_{2}+1 / 2 \mathrm{~N}_{2} \\
& \mathrm{CO}+2 \mathrm{NO} \rightarrow \mathrm{CO}_{2}+\mathrm{N}_{2} \mathrm{O}
\end{aligned}
$$

A value of $R_{S}$ other than unity indicates the existence of a side reaction producing $\mathrm{CO}_{2}, \mathrm{~N}_{2}$, or $\mathrm{N}_{2} \mathrm{O}$. Producton of excess nitrogen products results in a value of $R_{S}$ greater than one. An example of such a side reaction would be the oxidation:

$$
\text { NO }+M \rightarrow M-O+1 / 2 N_{2}
$$

Production of excess $\mathrm{CO}_{2}$ would result in $\mathrm{R}_{\mathrm{S}}$ values less than one, and an example of a side reaction producing $\mathrm{CO}_{2}$ would be:

$$
2 \mathrm{CO} \rightarrow \mathrm{C}_{(\mathrm{s})}+\mathrm{CO}_{2}
$$

For values of $R_{s}$ less than one, the excess $\mathrm{CO}_{2}$ production rate can be determined from the definition of $R_{S}$ :

$$
\mathrm{R}_{\mathrm{CO}} \text {, excess }=\mathrm{R}_{\mathrm{CO}_{2}}\left(1-\mathrm{R}_{\mathrm{s}}\right) \quad \mathrm{R}_{\mathrm{S}}<1
$$

where $\mathrm{R}_{\mathrm{CO}_{2}}$ is the experimentally measured total rate of $\mathrm{CO}_{2}$ production.

\section{B. Kinetic Results}

\section{Reducing Region}

Conversion as a function of time is shown in Figure 14 for runs made under reducing conditions. The accompanying reactor concentrations are given in Table 4. As can be seen in Figure 14, the catalyst exhibited a time dependent loss of activity, manifestd by a transient drop in conversion. The initial conversion level and the rate of decay of activity were functions of the NO and $\mathrm{CO}$ concentrations in the reactor. Run KOR-32 (refer to Figures 13 and 14) had the highest conversion 
Figure 14. Nitric oxide conversion as a function of time for runs in the reducing region. Temperature $=300^{\circ} \mathrm{C}$. 


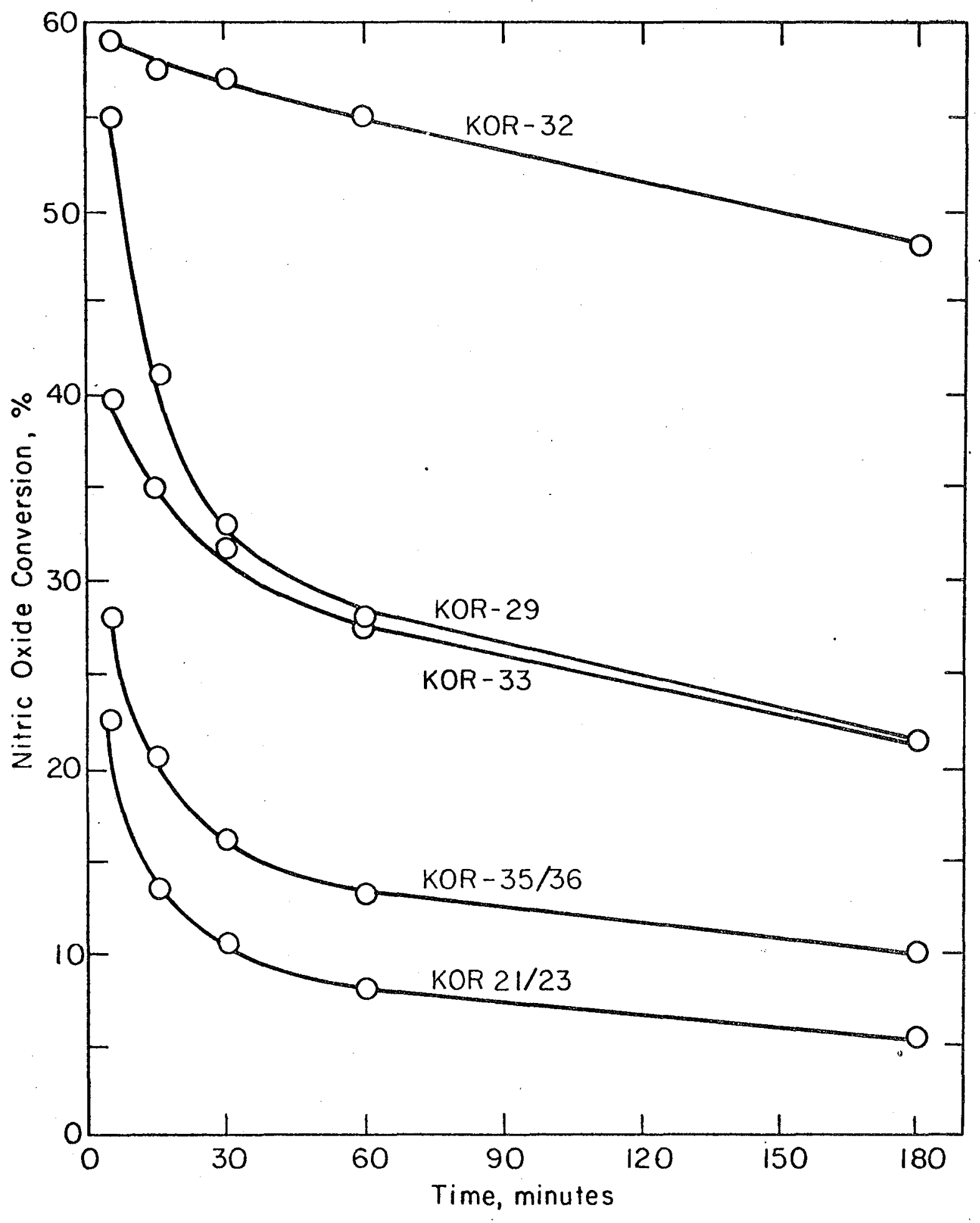

XBL 785-5074

Fig. 14 
Table 4. Reactor Outlet Concertrations, Reducing Region

\begin{tabular}{|c|c|c|c|c|c|c|c|c|c|}
\hline \multirow[t]{2}{*}{ Run } & \multicolumn{4}{|c|}{$\mathrm{C}_{\mathrm{NO}}$ ? } & \multicolumn{2}{|c|}{$\mathrm{C}_{\mathrm{CO}^{\circ}}$} & & & \\
\hline & $t=5$ & $t=85$ & $i=30$ & $t=60$ & $t=5$ & $t=15$ & $t=30$ & $t=60$ & \\
\hline$K O R-21 / 23$ & 3.88 & 4.40 & 4.63 & 4.81 & 8.69 & $9.16^{\circ}$ & $9 \cdot 34$ & 9.49 & \\
\hline KOR -29 & 2.00 & 2.69 & 3.06 & 3.52 & 4.26 & 4.87 & 5014 & 5.44 & $\cdot$ \\
\hline KOR -32 & 0.73 & 0.78 & 0.82 & 0.89 & 2.18 & 2.40 & 2.406 & 2.54 & \\
\hline $\mathrm{KOR}-33$ & 8.06 & 1.98 & $1.2 \%$ & 1.40 & 4.00 & 4.19 & 4.29 & 4.40 & \\
\hline $\operatorname{KOR}-35 / \dot{3} 6$ & 2.82 & $3 \cdot 30$ & 3.53 & 3.75 & 7.28 & 7.67 & 7.86 & 8.00 & \\
\hline
\end{tabular}


level and the smallest percentage loss of activity. This run was made with the lowest concentrations of NO and $\mathrm{CO}$, and a feed molar ratio of co/No close to $1: 1$. Holding the No concentration approximately constant (at the level of KOR-32) and raising the $\mathrm{CO}$ concentration (KOR-33) resulted in a drop in initial activity and a faster rate of decay (compared to KOR-32). Increasing both NO and CO concentrations while keeping the feed stoichiometry close to $1: 1$ (KOR-29) resulted in high initial conversion, with an accompanying greater decay in activity (compared to KOR-33). Keeping the No concentration at the level of KOR-29 and increasing the $\mathrm{CO}$ concentration (KOR-21/23, KOR-35/36) resulted in lower initial activity, with approximately the same percentage loss in activity (at 180 minutes).

From this limited data, two rough generalizations can be pointed out concerning the activity levels and the rate of deactivation. Runs made with the CO/NO ratio closest to $1: 1$ gave the highest initial conversion (KOR-29, KOR-32), while runs furthest from $1: 1$ having high Co concentrations exhibited the lowest initial activity (KOR-21/23). These trends indicate that the activity level exhibits an inverse dependence on the CO/NO ratio. Examination of the functional dependence of the reaction rate on NO and $\mathrm{CO}$ partial pressures (discussed in more detail below) confirms this observation. In addition, it appears that the rate of deactivation is soley linked to No concentration. The run made at the lowest No concentration (KOR-32) showed the smallest percentage loss in activity (or largest time constant), while the higher NO concentration runs (KOR-29, KOR-35/36, KOR-21/23) displayed the more rapid loss in activity (or smallest time constant). It is 
interesting to note that runs $\mathrm{KOR}-29$ and $\mathrm{KOR}-35 / 36$, while having approximately the same deactivation rate, had significantly different Co partial pressures. This observation tends to confirm the lack of dependence of the deactvation rate on $\mathrm{CO}$ concentration. In comparing runs KOR-32 and KOR-33, one also notes that the made with the higher NO concentration (KOR-33) has the higher deactivation rate. The overall rate of reaction of nitric oxide (for times greater than 60 minutes) was reasonably correlated with the simple rate exression:

$$
\mathrm{R}_{\mathrm{NO}}=k \mathrm{P}_{\mathrm{NO}} / \mathrm{P}_{\mathrm{CO}}^{2}
$$

A plot of $\mathrm{R}_{\mathrm{NO}}$ as a function of $\mathrm{p}_{\mathrm{NO}} / \mathrm{P}_{\mathrm{CO}}{ }^{2}$ for $\mathrm{t}=60$ minutes is shown in Figure 15. The slope of the best fitting straight line through the origin, obtained by (least squares) linear regression, yielded a value of $k=1.22 \times 10^{3}$ micromoles-atm/sec/gm catalyst (or 5.63 molecules-atm/surface $\mathrm{Pt} / \mathrm{sec}$ ). The average deviation from the predicted lice was 17\%. A similar analysis for $t=180 \mathrm{~min}$ gave a value of $k 768$ of the value obtained at $t=60 \mathrm{~min}$, with an average deviation of 158. The significant scatter of the data in Figure 15 most 1ikely reflects the influence of the deactivation process on the rate of reaction, which of course is not accounted for in the simple rate expression.

The NO and CO dependence in the rate expression above (Eq. 8) can be derived by assuming that the rate of No consumption is primarily dependent on a rate limiting No dissociation step. Such a process is favored by calculations performed by Weinberg and Merrill (28) 
Figure 15. Nitric oxide reaction rate as a function of $\mathrm{P}_{\mathrm{NO}} / \mathrm{P}_{\mathrm{CO}}{ }^{2}$ for runs made under reducing conditions. 
$-64-$

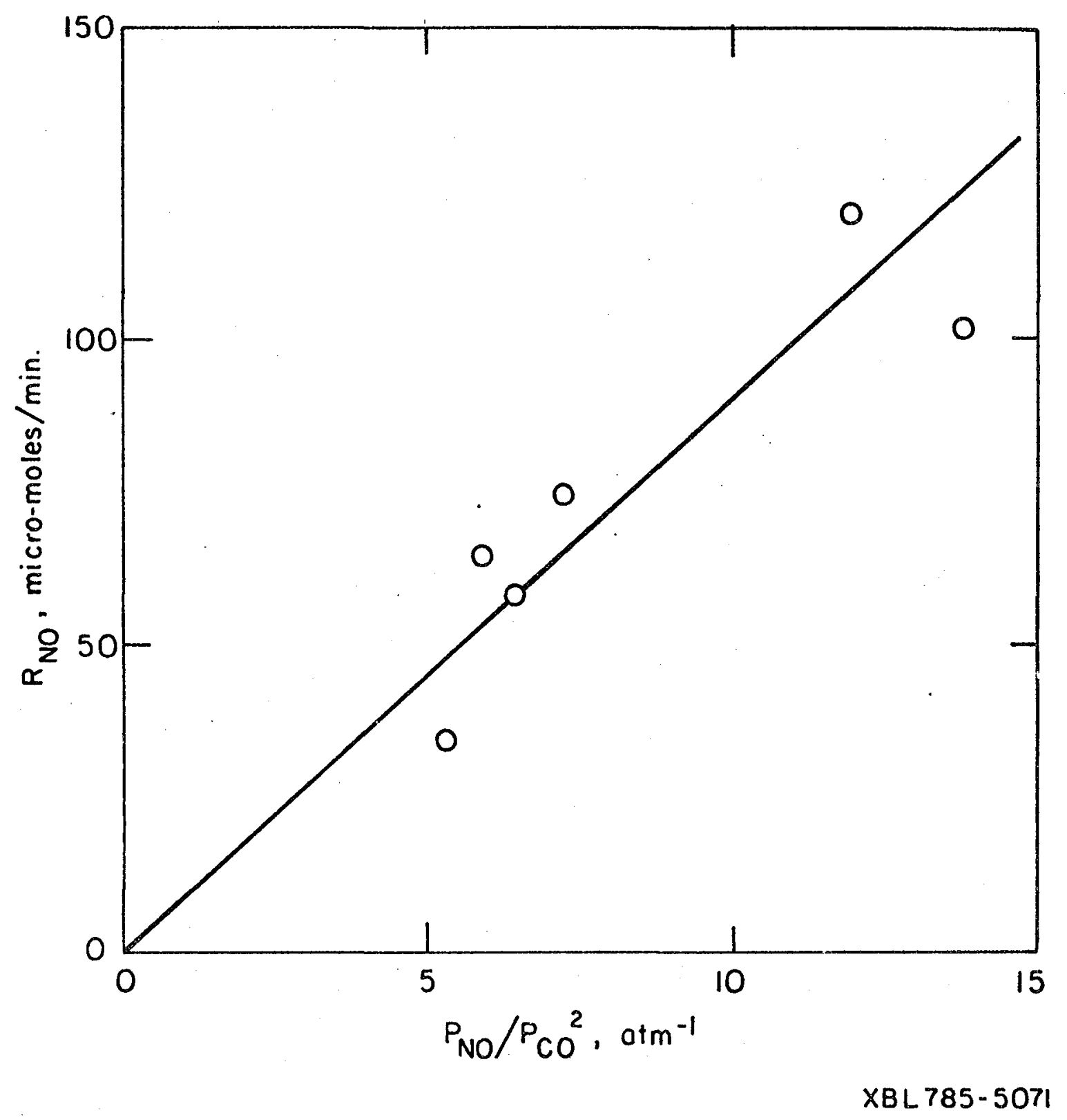

Fig. 15 
and studies done by Lambert and Comrie (3) and Cant et al (1). Rate limiting No dissociation leads to a rate expression of the form:

$$
R_{\text {NO }}=\frac{k^{\prime} P_{\text {NO }}}{\left(1+k_{1} P_{N O}+k_{2} P_{C O}\right)^{2}}
$$

For the reducing conditions being considered, $\mathrm{k}_{2} \mathrm{P}_{\mathrm{CO}} \gg \mathrm{K}_{1} \mathrm{P}_{\mathrm{NO}}$ and $\mathrm{K}_{2} \mathrm{P}_{\mathrm{CO}}>1$, since CO adsorbs more strongly than NO, and will cover a large percentage of the surface. This leads to:

$$
\mathrm{R}_{\mathrm{NO}}=\mathrm{k}^{\prime} \mathrm{P}_{\mathrm{NO}} /\left(\mathrm{K}_{2} \mathrm{P}_{\mathrm{CO}}\right)^{2}
$$

which is indentical to Eq. 8 for $k=k^{1} / k_{2}{ }^{2}$. A more complete discussion of the molecular mechanism is presented in a later section dealing with selectivity.

The behavior of the stoichiometric ratio $\left(R_{S}\right)$ in the reducing region is shown in Figure 16 for the runs KOR-21/23 and KOR-32. The data shown define the range of observed $R_{S}$ values, with all other runs having values falling in the region between the two curves. $R_{S}$ was found to be less than one in all cases, the lowest values corresponding to highly reducing conditions and low activity. Conditions leading to the highest conversion and smallest loss in activity (KOR32) exhibited $R_{S}$ values closest to one.

Excess carbon dioxide production is shown in Figure 17 for runs KOR-21/23, KOR-33, and KOR-32. Similar behavior was observed for the other runs as well. The rate of excess $\mathrm{CO}_{2}$ production decreased rapidly from its initial value over the first 15 to 30 minutes, declining more slowly as time progressed. In some cases, the rate was observed to rise slighly between 50 to 180 minutes. The highest rates of excess 


$$
-66-
$$

Figure 16. Stoichiometric ratio as a function of time for two runs made under reducing conditions. Curve A: run KOR-32. Curve B: run KOR-21/23. 


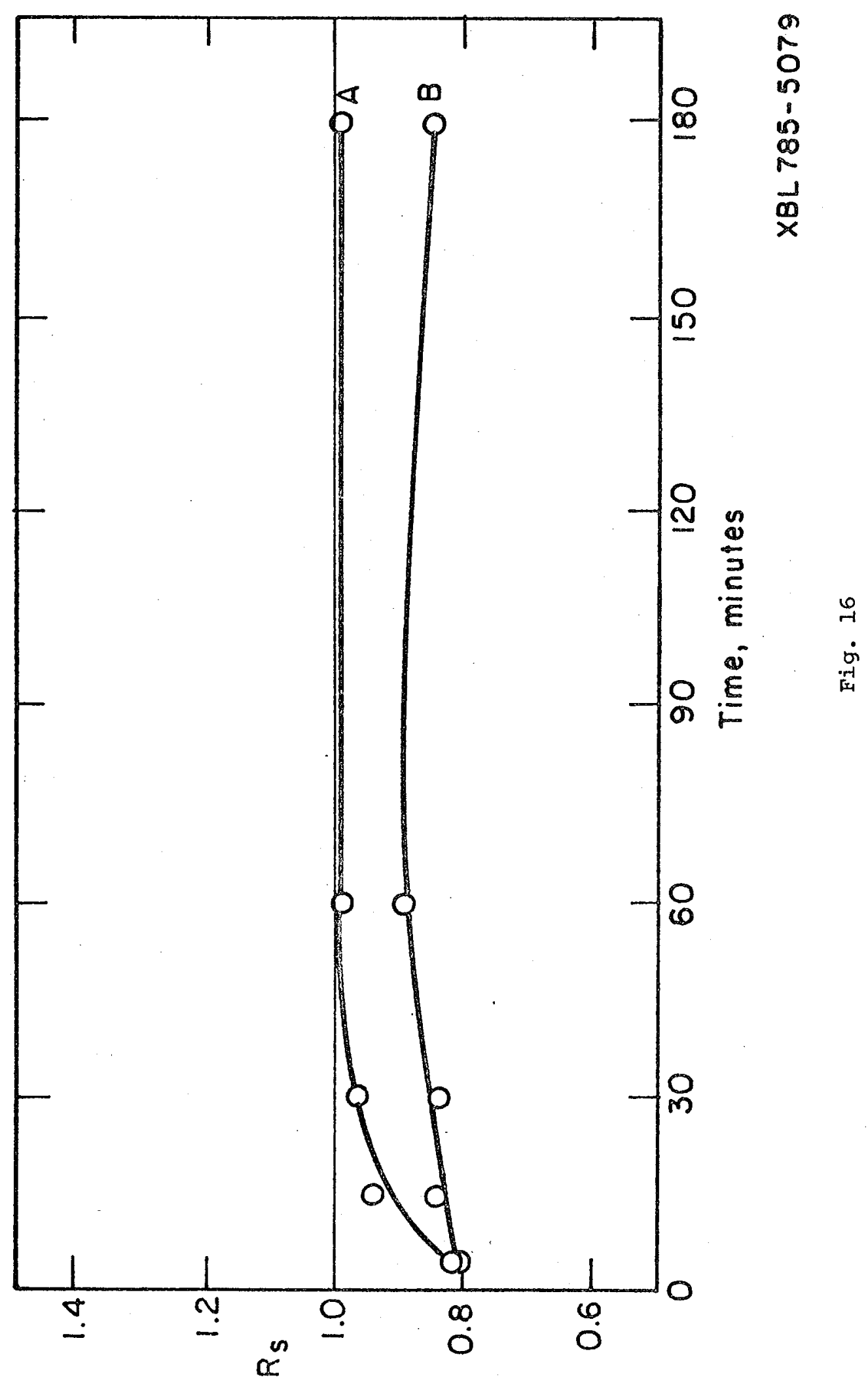


$-68-$

Figure 17. Excess carbon dioxide production as a function of time for three runs in the reducing region. Curve A: run KOR-32. Curve B: run KOR-33. Curve C: run KOR-21/23. 


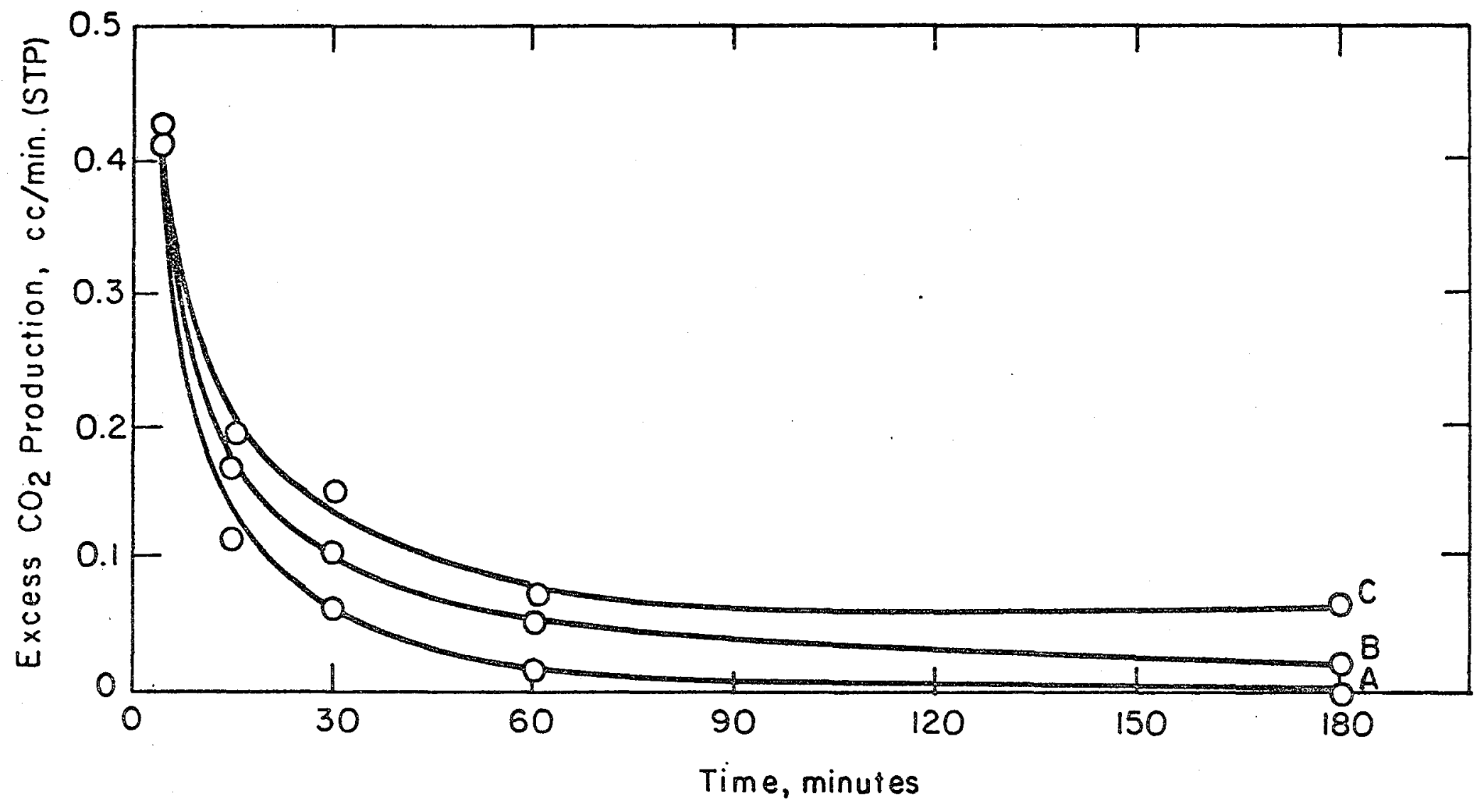


Table 5. Excess $\mathrm{CO}_{2}$ Production

\begin{tabular}{|c|c|c|}
\hline Run & $\mid \begin{array}{l}\text { Total excess } \mathrm{CO}_{2} \\
t=5 \text { to } 180 \mathrm{~min}\end{array}$ & $\begin{array}{l}\text { Equivalent monolayers } \\
\text { or surface pt }\end{array}$ \\
\hline$K O R-21 / 23$ & 707 micromoles & 2.7 \\
\hline KOR -29 & 248 micromolos & 0.95 \\
\hline$K O R-32$ & 264 micromoles & 1.0 \\
\hline$K O R=33$ & 497 micromoles & 8.9 \\
\hline KOR $-35 / 36$ & $1280 \mathrm{micromoles}$ & 4.9 \\
\hline
\end{tabular}

Calculations based on 260 micromolos total Bugsaco Pt 
$\mathrm{CO}_{2}$ production were found for runs made under highly reducing conditions. The lowest rates were observed for low concentration runs close to 1:1 stoichiometry, exhibiting high activity and the smallest rate of deactivation. These trends are also reflected in the total integrated excess $\mathrm{CO}_{2}$ production figures given in Table 5. In all cases, the accumulated excess $\mathrm{CO}_{2}$ was greater than or approximately equal to monolayer coverage.

Nitrous oxide selectivity as a function of time is shown in Figure 18 for three typical runs. The selectivity was found to be in the range of about 0.6 to 0.95 , and was approximately constant during any single run, final values (at $t=180 \mathrm{~min}$ ) being roughly 208 greater than initial values (at $t=0 \mathrm{~min}$ ). A more complete discussion concerning trends and mechanism is presented below in section $\mathrm{C}$.

\section{Oxidizing Region}

The kinetic behavior of the system for feed ratios of co/No less than one was distinctly different from that observed for reducing conditions. The conversion levels (based on $\mathrm{CO}$ ) of all runs were very high, ranging from 95 to 1008. Since the gas feed system was operating near maximum capacity, conversion levels could not be reduced by increasing the feed rate of the reactants or the He diluent. The temperature was held at $300^{\circ} \mathrm{C}$ in order to make comparisons between data taken in the oxidizing and reducing regions more valid.

$R_{s}$ values were found to be slightly greater than one, and therefore no excess $\mathrm{CO}_{2}$ was produced. Typical conversion and $\mathrm{R}_{\mathrm{S}}$ data can be seen in Figures 19 and 20 . 
Figure 18. Nitrous oxide selectivity as a function of time for three runs made under reducing conditions.

Curve A: run KOR-35/36. Curve B: run KOR-33. Curve C: run KOR-32. 


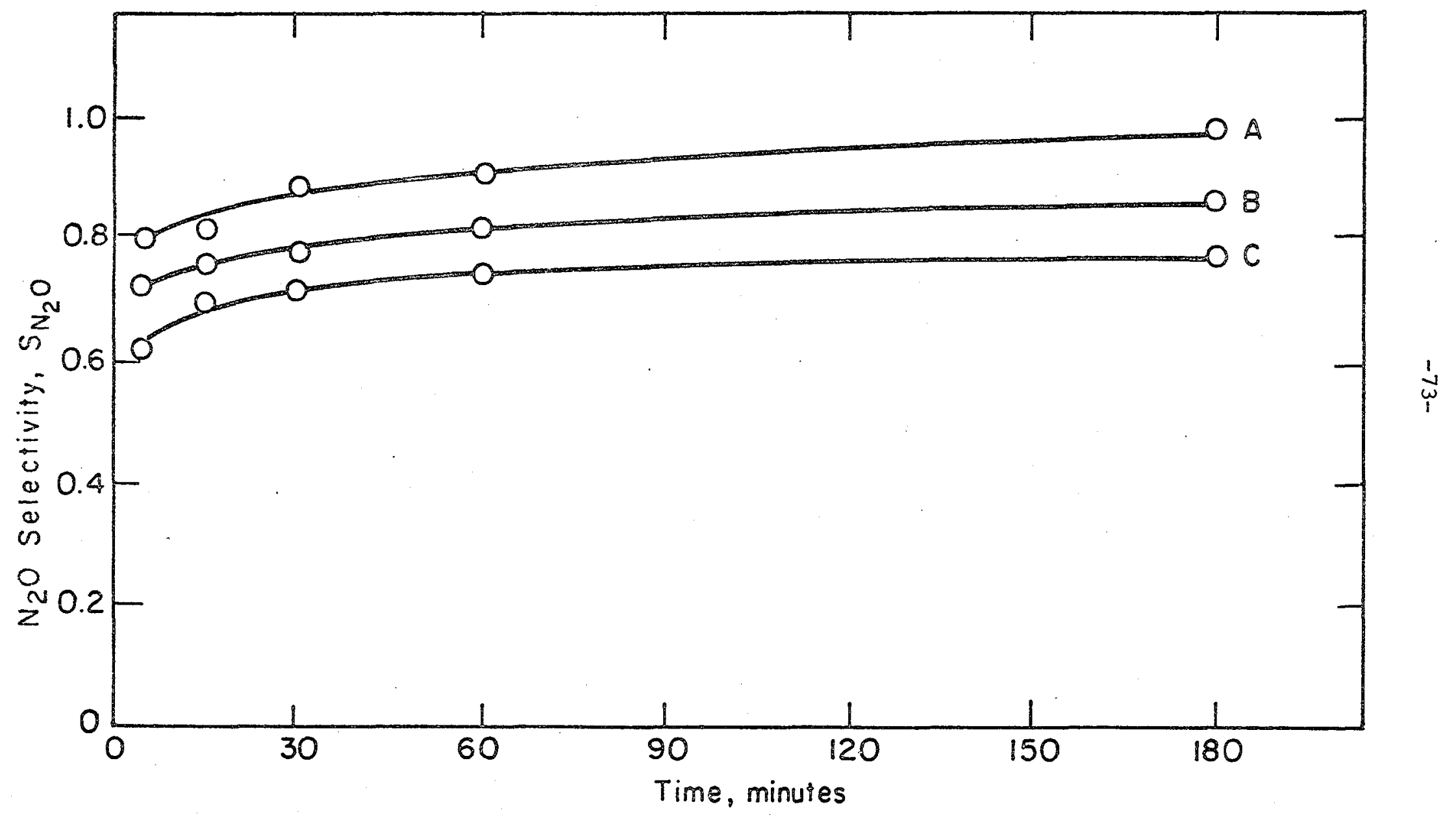

XBL 785-5078

Fig. 18 
Figure 19. Typical carbon monoxide conversion data as a function of time for $r$ uns made in the oxidizing region. Data from run KOR-28. 


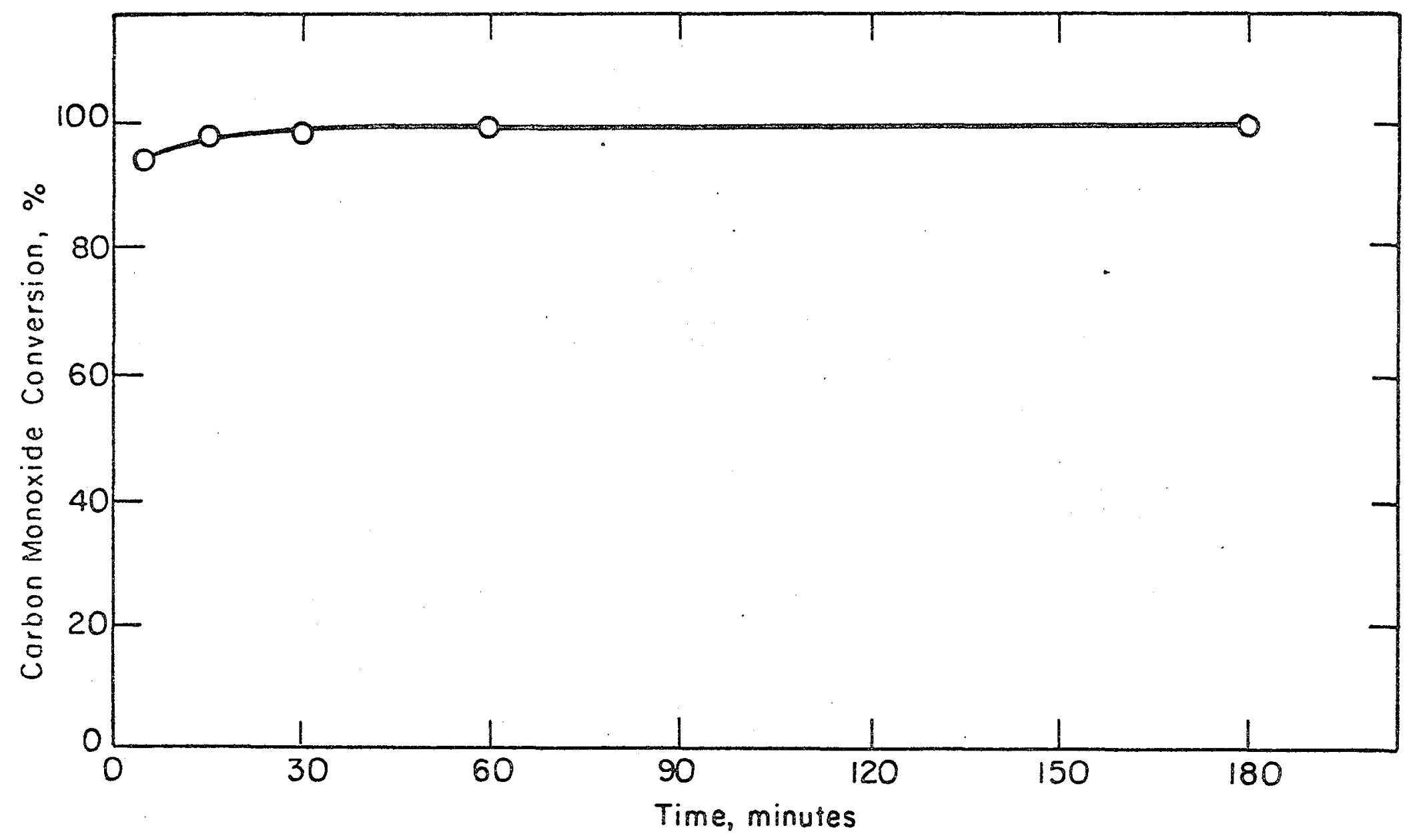

$X 8 L 785-5077$

Fig. 19 
$-76-$

Figure 20. Typical stoichiometric ratio data as a function of time for runs made in the oxidizing region. Data from run KOR-28. 


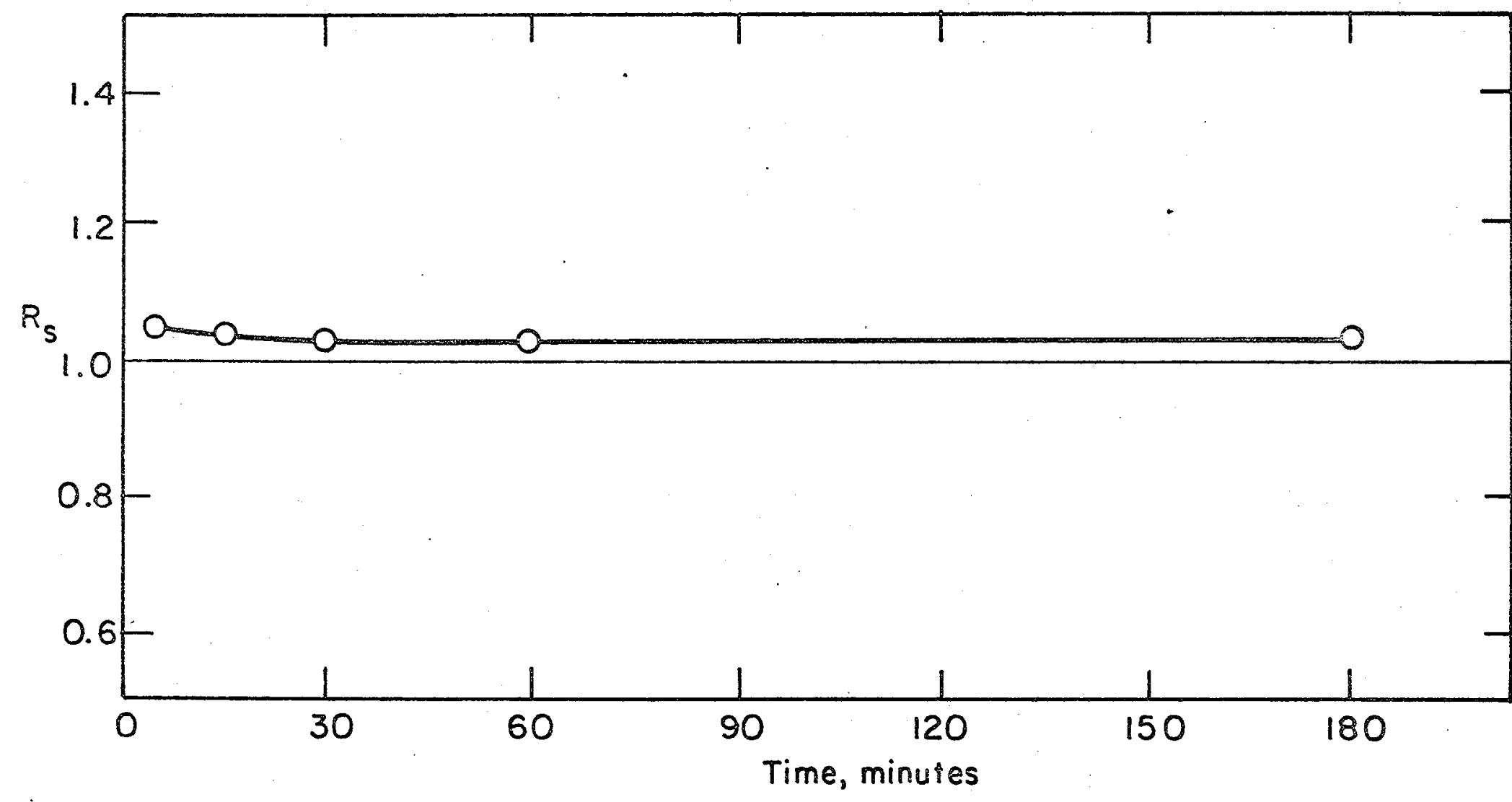

Fig. 20 
Due to the high conversion levels, the very low co concentrations in the reactor could not be accurately determined. Mass transfer limitations may not be negligable under these conditions, however claculations made using the criterion presented by Weisz and Prater (29), indicated that conversion levels greater than $95 \%$ could be attained without diffusional limitation. Thus, in order to detect the importance of mass transfer effects, a precision of at least 18 (or better) would' be needed in measuring $\mathrm{CO}$ conversions. Experimental error associated with Co conversion measurements in this study limited precision to about 5\%. As a result, the importance of mass transfer effects could not be determined within the limits of experimental error. No attempt was made to fit the data to an overall rate expression. Nitrous oxide selectivity for four typical runs is shown in Figure 21. The range of values varied from approximately 0.0 to 0.5 . The lowest $\mathrm{N}_{2} \mathrm{O}$ selectivities were found for runs with molar feed ratios (CO/NO) close to $1: 1(\mathrm{KOR}-31, \mathrm{KOR}-26)$. It is worth moting, that for complete co conversion at unity molar feed ratios, nitrogen is the only allowed product. This is a result of the stoichiometric relationships (Eq. 3 and 4) of NO and $\mathrm{CO}$. Increasing the nitric oxide content of the feed (lowering the CO/NO ratio) resulted in an increase in $\mathrm{N}_{2} \mathrm{O}$ formation, with the largest $\mathrm{N}_{2} \mathrm{O}$ selectivity observed in run KOR-27. Due to the high CO conversions, increasing the NO/CO feed ratio resulted in a direct increase in the No partial pressure in the reactor. The selectivity data is replotted in Figure 22 as a function of No partial pressure in the reactor for the condition of very low accompanying 
Figure 21. Nitrous oxide selectivity as a function of time for runs made under oxidizing conditions. Curve A: run KOR-27. Curve B: run KOR-28. Curve C: run KOR-26. Curve'D: run KOR-31. 


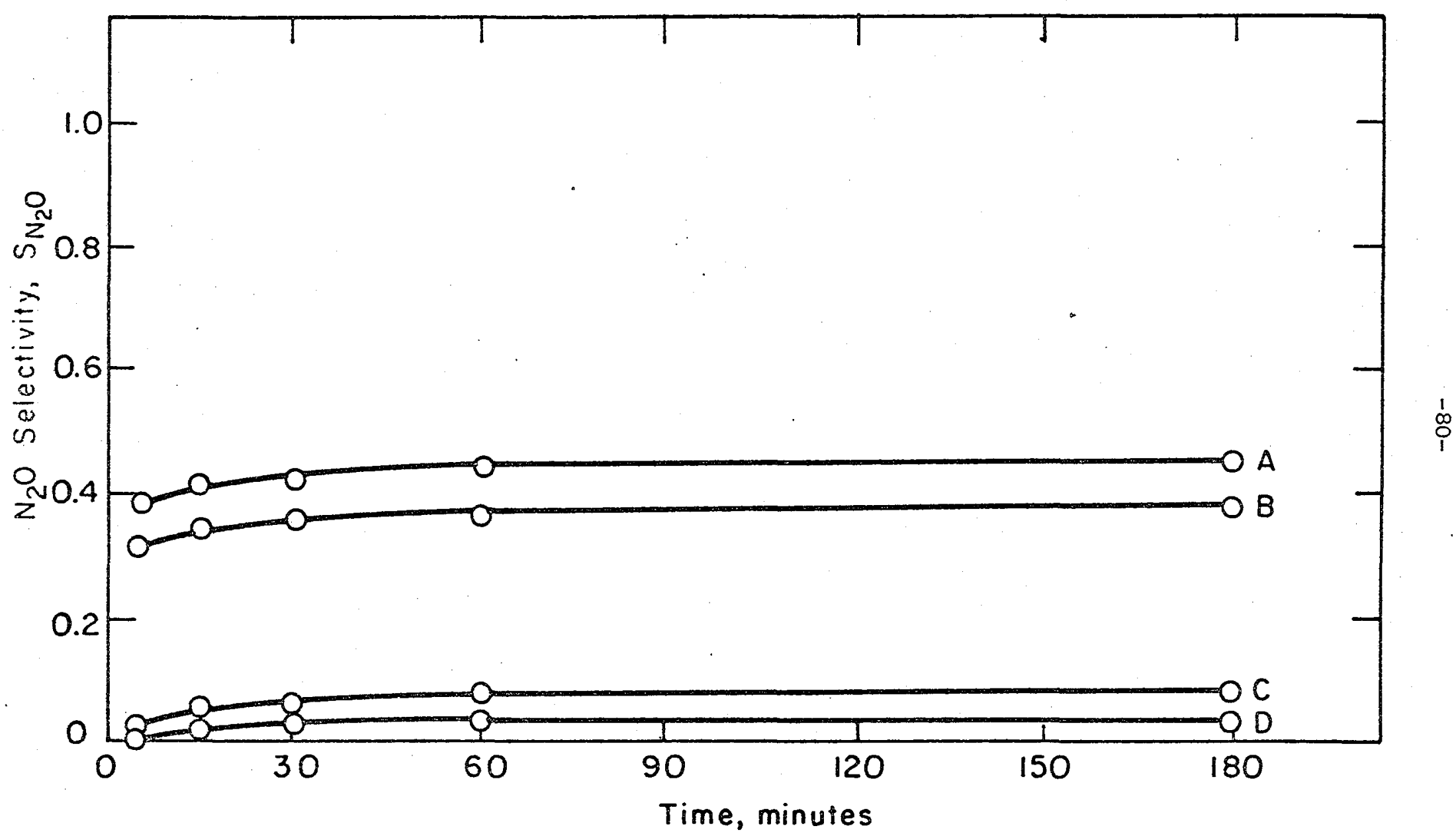

XBL 785-5075

Fig. 21 
$-81-$

Figure 22. Nitrous oxide selectivity as a function of nitric oxide concentration for runs in the oxidizing region. 


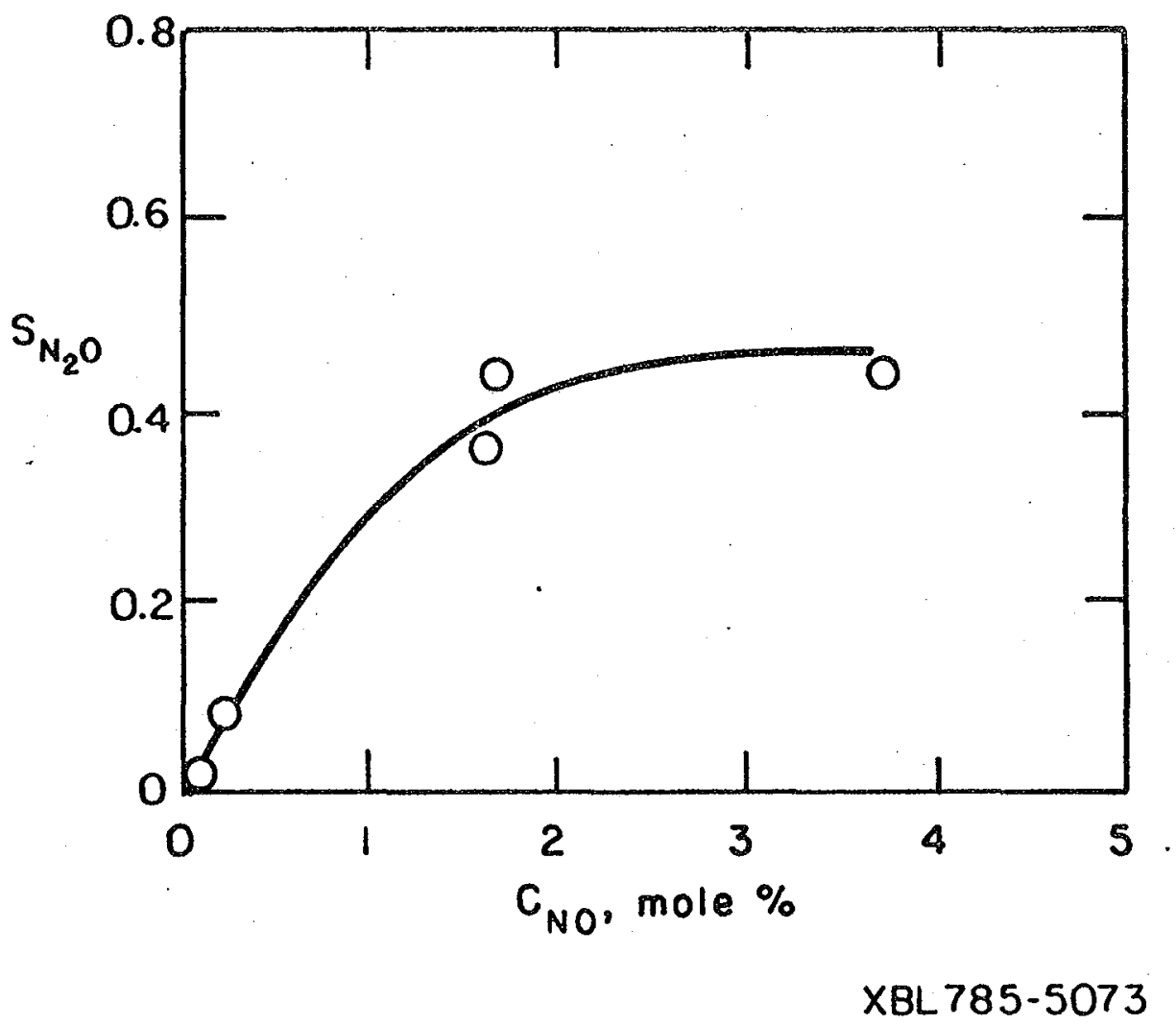

Fig. 22 
Co partial pressures. Each point in this figure represents data from a single run.

\section{Infrared Spectra}

Typical infrared spectra taken under both oxidizing and reducing conditions are shown in Figure 23. The only observable peaks appeared in the region between 2500 and $2000 \mathrm{~cm}^{-1}$. In most of the spectra, two major bands were observed; one at $2070 \mathrm{~cm}^{-1}$ and one at $2300 \mathrm{~cm}^{-1}$. In addition, another band usually much smaller in magnitude, was observed at $2200 \mathrm{~cm}^{-1}$. For the sake of the following discussion, the 2300 and $2200 \mathrm{~cm}^{-1}$ bands shall be assigned to an isocyanate and a cyanide species, respectively. Further discussion concerning the specific assignments of the 2300 and $2200 \mathrm{~cm}^{-1}$ bands is treated in section E. The band at $2070 \mathrm{~cm}^{-1}$ was identified as CO adsorbed on Pt (5). The important features of the experimentally observed infrared spectra are summarized in the following discussion.

\section{Reducing Region}

Under reducing conditions the $C O$ band $\left(2070 \mathrm{~cm}^{-1}\right)$ absorbance varied within a range of about 0.3 to 0.4 . A value of 0.4 represents saturation coverage of $\mathrm{CO}$ at $300^{\circ} \mathrm{C}$, and is the value obtained by exposing the catalyst to a mixture of $108 \mathrm{CO}$ in He. The lowest value (0.3) was reported for KOR-32. The absorbance trends can be clearly seen in Figure 24 where Co absorbance is plotted as a function of the Co concentration in the reactor. During any single run, the co band intensity was not a function of time, and achieved its steady value immediately upon introduction of the reactants. In addition, no frequency shifts were observed for this band under any conditions. 
Figure 23. Typical infrared spectra. Curve a: He at $300^{\circ} \mathrm{C}$. Curve b: run made under oxidizing conditions (from KOR-27). Curve c: run made under reducing conditions (from KOR-21). Spectra represented by curves b and $\mathrm{c}$ taken approximately $30 \mathrm{~min}$ after start of feed to reactor. 


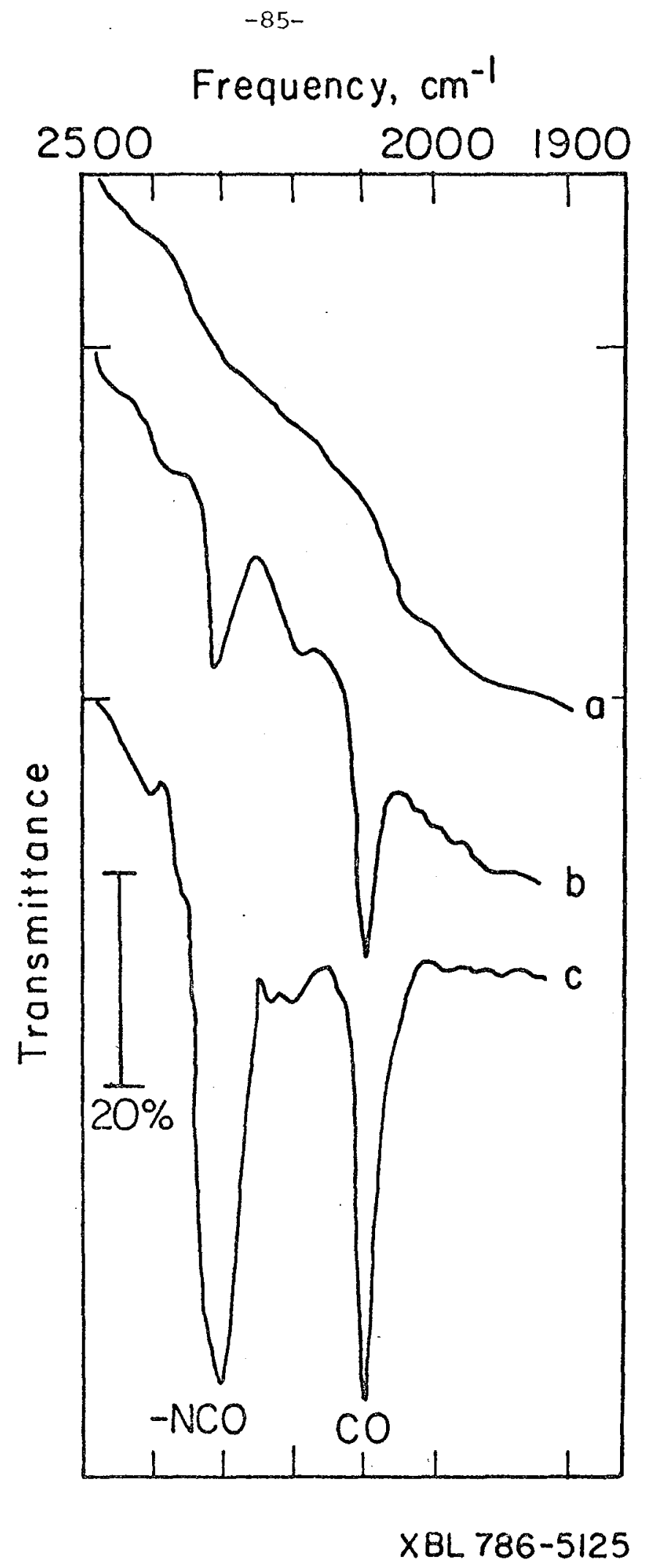

Fig. 23 
Figure 24. Carbon monoxide $\left(2070 \mathrm{~cm}^{-1}\right)$ infraxed band absorbance as a function of carbon monoxide concentration in the reactor for runs made in the reducing region. IR absorbance was calculated from absorbance $=\log \frac{\text { baseline transmittance, } 8}{\text { peak transmittance, } 8}$ 


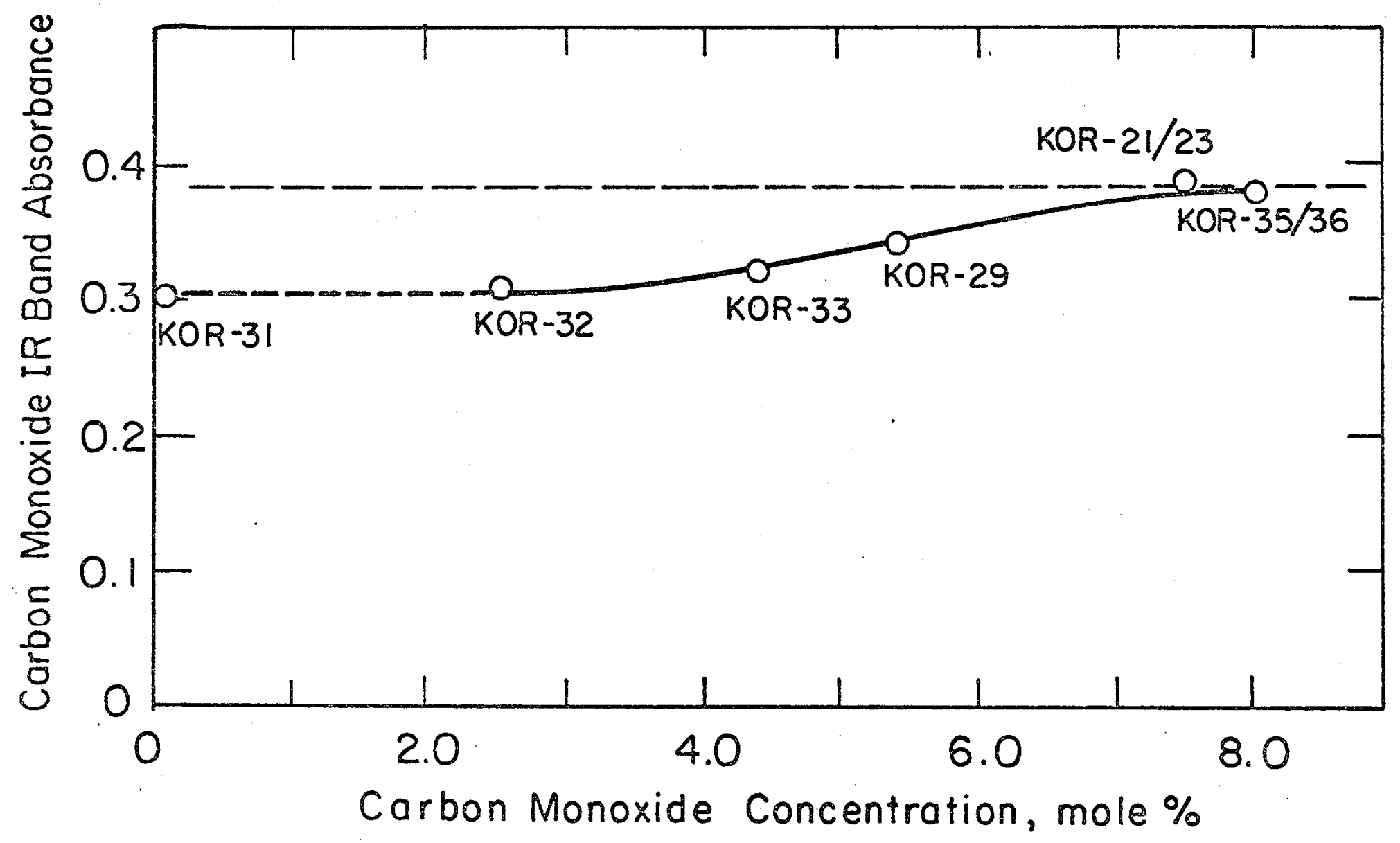


The formation and growth of the isocyanate $\left(2300 \mathrm{~cm}^{-1}\right)$ and cyanide $\left(2200 \mathrm{~cm}^{-1}\right)$ bands were time dependent and very complex. On a fresh catalyst disk, most of the isocyanate band growth took place during the 30 to 60 minutes of exposure to the reactants, in a manner similar to tht observed by Niiyama et al (16). Once formed, the isocyanate band was very stable and could not be removed by prolonged periods of heating in He at $300^{\circ} \mathrm{C}$ or by the standard pretreatment process. Because of this stability, repeated runs made under reducing conditions induced additional band growth during each run, resulting in very large accumulated bands (Figure 25). The growth of these very large isocyanate bands did not affect the intensity of the co band.

The isocyanate band exhibited some rather puzzling growth trends, which were observed for most of the runs made in reducing atmospheres. One of these trends was the growth of isocyanate band between successive runs. This growth often amounted to a significant increase in band size, and took place (very slowly) during the 8 to $10 \mathrm{hr}$ He purge at $300^{\circ} \mathrm{C}$ after the reactants were shut off, prior to the pretreatment of the next run. Another puzzling but consistent trend was the apparent temporary decrease in the isocyanate band intensity upon introduction of the reactants. In one case (KOR-32, Figure 26) negative bands were observed. Treatment of a large (absorbance=0.41) isocyanate band (previously in the at $300^{\circ} \mathrm{C}$ for $8 \mathrm{hrs}$ ) with a mixture of $10 \% \mathrm{CO}$ in He resulted in a 38 absorbance reduction after 15 minutes and an 88 reduction after 30 minutes. These changes were similar in magnitude to isocyanate absorbance changes seen under reaction conditions. 
$-89-$

Figure 25. Infrared spectra for run KOR-22. Curve a: He purge following last step $\left(\mathrm{H}_{2}\right.$ reduction) of standard pretreatment. Band at $2300 \mathrm{~cm}^{-1}$ results from accumulation of previous runs (KOR-20, 21). Curve b: 2 hrs after feed introduction, KOR-22. 


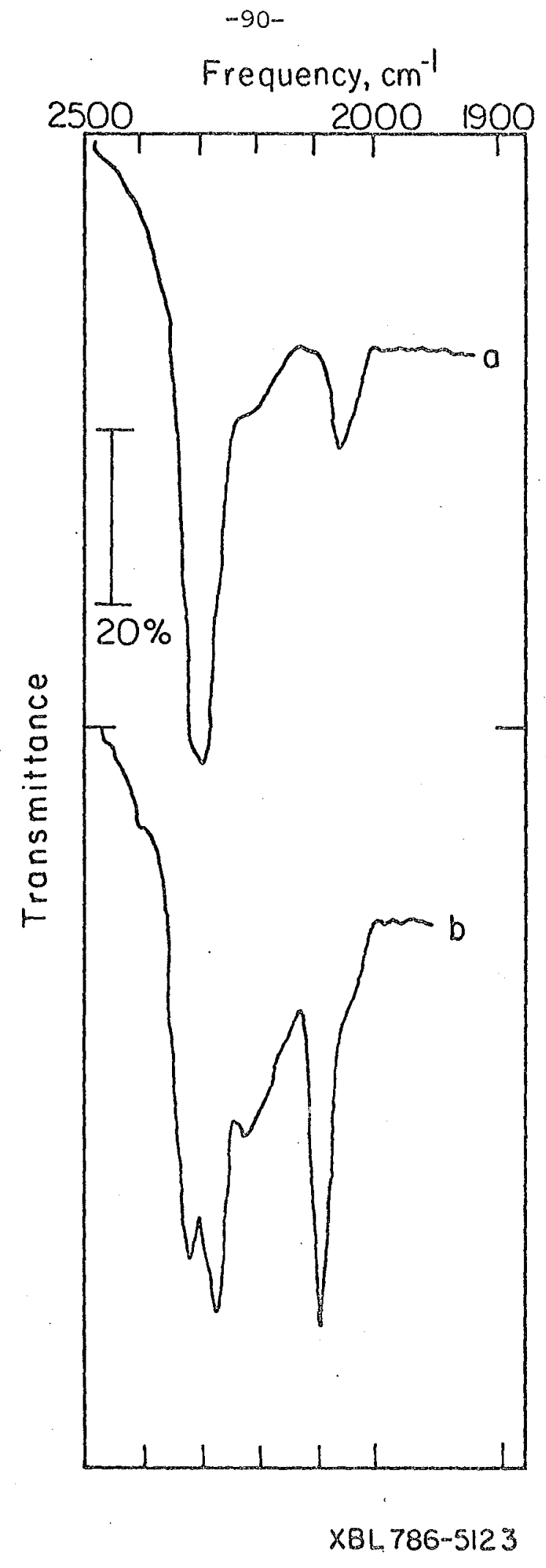

Fig. 25 
Figure 26. Infrared spectra recorded during run KOR-32. Curve a: He purge prior to feed. Curve b: 30 min after introduction of feed. Curve $b^{\prime}: 45 \mathrm{~min}$ after introduction of feed. Curve c: 150 min after introduction of feed. 


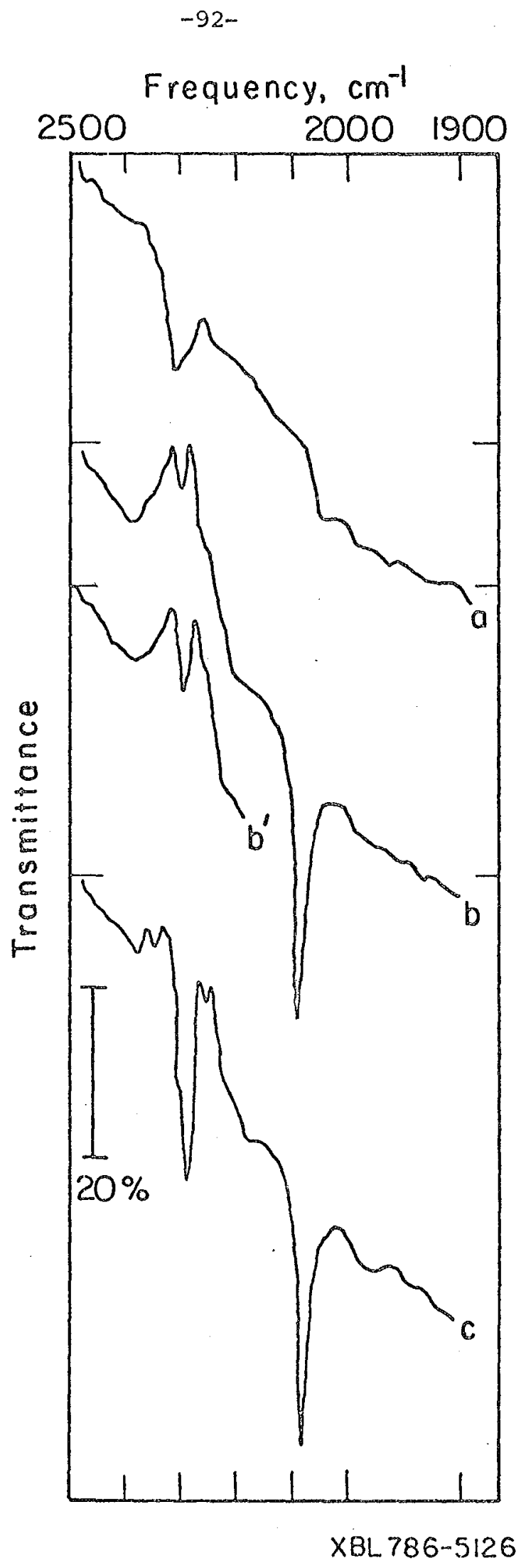

Fig. 26 
Treatment of the isocyanate band with No mixtures resulted in no observable changes.

Interpretation of the isocyanate absorbance changes was complicated by the discovery that this species could be transferred to the reference IR disk. Evidence for this is clearly indicated in the form of negative bands near $2300 \mathrm{~cm}^{-1}$ (Figure 26). Solid confirmation for the presence of the isocyanate species on the reference disk was obtained by direct observation, by placing a reference disk (previously exposed to reactants under reducing conditions) in the sample IR beam, with an unused reference disk in the reference beam. This observation is important because it indicates that the isocyanate species is not only capable of bonding to the silica support, but it is also capable of transferring itself through the gas phase to the reference disk and perhaps the reactor walls. As a result, caution must be exercised in interpreting isocyanate band absorbance changes, since the recorded spectra is indicative only of the difference in the amount of this species between the two disks.

The isocyanate band was easily removed by exposure to water vapor ( 208 relative humidity) at $25^{\circ} \mathrm{C}$. This process is illustrated in Figure 27. It is interesting to note that some cyanide $\left(2200 \mathrm{~cm}^{-1}\right)$ band growth accompanies the removal of the isocyanate band. This indicates that the cyanide species may be a by-product of the isocyanate hydrolysis. In addition, the isocyanate species on the reference disk appears to be more resistant to removal by water at room temperature than the isocyanate species on the catalyst disk. This is evident by the negative band at $2300 \mathrm{~cm}^{-1}$ in curve d, Figure 27 . Complete 
Figure 27. Removal of the isocyanate $\left(2300 \mathrm{~cm}^{-1}\right)$ band with $\mathrm{H}_{2} \mathrm{O}$. Curve a: band prior to treatment. Curve b: 30 min after introduction of approximately 5 torr $\mathrm{H}_{2} \mathrm{O}$ in $\mathrm{He}$ ( 1 atm total pressure, $25^{\circ} \mathrm{C}$ ). Curve c: $1 \mathrm{hr}$ after introduction of $\mathrm{H}_{2} \mathrm{O} / \mathrm{He}$ mixture. Curve d: 4 hrs after incroduction of $\mathrm{H}_{2} \mathrm{O} /$ He mixture. Curve e: after heating in He at $300^{\circ} \mathrm{C}$ for $2 \mathrm{hrs}$. 
that this approach would lead to a more complete understanding of the system behavior than regression to a power law type expression. The mechanism utilized in the selectivity analysis is illustrated in Figure 28. These reactions were chosen as those "most likely to proceed", and were based on results published in recent literature and experimental trends observed in this study. Many of the arguments supporting the mechanism have been presented by Ludvik (9) and shall not be discussed in detail here.

For simplicity, the deactivation process was not considered in the selectivity analysis, and therefore is not included in the mechanism. Since the selectivity does not change to a large extent during deactivation (see Figure 18), the omission of the deactivation mechanism is justified, considering the scope of the selectivity analysis.

Step (1) in Figure 28 describes the strong molecular chemisorption of carbon monoxide. This process is well known and direct evidence is reported in this study in the form of an intense infrared band at $2070 \mathrm{~cm}^{-1}$. 
$-98-$

Figure 28. Reaction mechanism used in the analysis of nitrous oxide selectivity data. 


\section{Reaction Mechanism:}

(1)

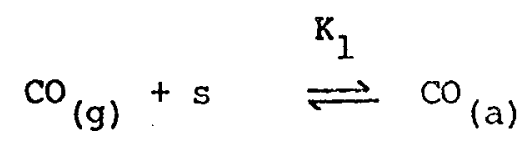

(2)

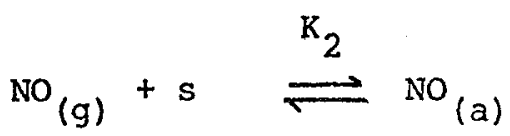

(3)

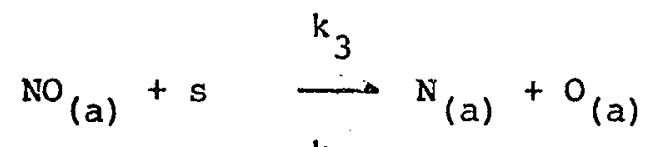

(4)

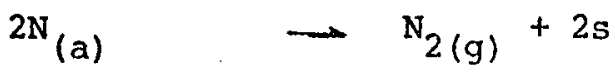

(5a)

(5b)

(6)
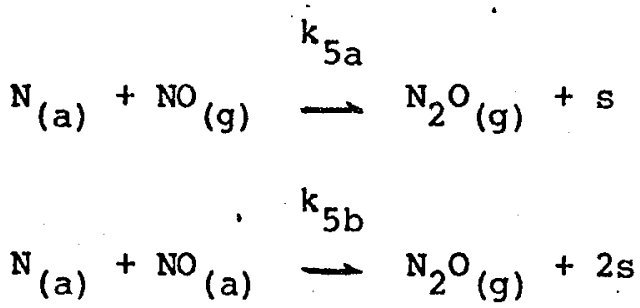

$$
\mathrm{CO}(g)+\mathrm{O}_{(a)} \stackrel{\mathrm{k}_{6}}{\longrightarrow} \mathrm{Co}_{2(g)}+\mathrm{s}
$$


Step (2) represents the molecular chemisorption of nitric oxide. Evidence in support of adsorbed NO molecules on Pt has been reported in thermal desorption studies performed by Lambert and Comrie (3) and others $(6,7,8)$.

The dissociation of adsorbed No molecules into adsorbed nitrogen and oxygen atoms is represented in step (3). Experimental evidence for this process has been reported in work done by Lambert and Comrie (3), Pirug and Bonzel $(6,7)$, and Solymosi et al (8). The dissociation of adsorbed No has also been suggested in a kinetic analysis reported by Cant et al (1). Calculations performed by weinberg and Merrill (28) indicate that this process has an estimated activation energy between zero and $11.3 \mathrm{kcal} / \mathrm{mole}$, however this is somewhat lower than the experimentally measured value of $28 \mathrm{kcal} / \mathrm{mole}$ reported by Pirug and Bonzel ( 8 ) .

The route to $\mathrm{N}_{2}$ production is accounted for by step (4), which represents the recombination of adsorbed nitrogen atoms. Experimental evidence for this reaction process has been presented in studies done by wilf and Dawson (30) and Schawaha and Bechtold (31), as well as the previously mentioned studies $(6,7,3)$. The production of $\mathrm{N}_{2}$ via gas phase $\mathrm{N}_{2} \mathrm{O}$ :

$$
s+\mathrm{N}_{2} \mathrm{O}(\mathrm{g}) \rightarrow \mathrm{O}_{(a)}+\mathrm{N}_{2}(\mathrm{~g})
$$

was not included in this mechanism since it is not considered the primary route to nitrogen. This reaction path does not permit $\mathrm{S}_{\mathrm{H}_{2} \mathrm{O}}$ values close to zero (or very low $\mathrm{P}_{\mathrm{N}_{2} \mathrm{O}}$ ) since the rate of $\mathrm{N}_{2}$ production must 
be proportional to $\mathrm{P}_{\mathrm{N}_{2} \mathrm{O}^{\prime}}$ and therefore is not in agreement with experimental results obtained in this study $\left(\mathrm{S}_{\mathrm{N}_{2} \mathrm{O}} \sim \mathrm{O}\right.$ for $\left.\mathrm{P}_{\mathrm{NO}}>\mathrm{P}_{\mathrm{CO}}, \mathrm{P}_{\mathrm{NO}} / \mathrm{P}_{\mathrm{CO}} \geq 1\right)$. Steps (5a) and (5b) represent two possible paths to nitrous oxide production. Step (5) is the Eley-Rideal process in which an adsorbed nitrogen atom reacts with a gas phase No molecule. This reaction path is favored by BEBO calculations performed by Weinberg and Merrill (28), and is estimated to have an activation energy of approximately $20 \mathrm{kcal} / \mathrm{mole}$. Step (5b) represents the Langmuir-Hinshelwood process in which adsorbed No reacts with adsorbed nitrogen atoms to produce $\mathrm{N}_{2} \mathrm{O}$. This process is favored by Cant et al (1). Both steps (5a) and (5b) were considered in the selectivity analysis presented below. The final step (6) represents the process by which adsorbed oxygen is removed from the surface. This process is estimated to have an activation energy very close to zero (32). The reaction:

$$
\mathrm{O}_{(\mathrm{a})}+\mathrm{CO}(\mathrm{a})-\mathrm{CO}_{2(\mathrm{~g})}+2 \mathrm{~s}
$$

was not considered due to its high activation energy of $27 \mathrm{kcal} / \mathrm{mole}$ (32). Preferential reduction via an Eley-Rideal process is also consistent with experimental results reported by Bonzel and $\mathrm{Ku}$ (33).

1. Reducing Region

Utilizing the proposed reaction mechanism along with some simplifying assumptions, expressions for $\mathrm{R}_{\mathrm{N}_{2}} / \mathrm{R}_{\mathrm{N}_{2} \mathrm{O}}$ were obtained for both the Eley-Rideal and Iangmuir-Hinshelwood $\mathrm{N}_{2} \mathrm{O}$ production steps. These are shown in final form in Table 6 . The primary assumption made in deriving the expressions was that nitric oxide dissociation was rate limiting. Experimental support for this assumption has been presented 
previously (section $\mathrm{B}-1$ ), where the overall rate was correlated assuming No dissociation. Reactions (4), (5), and (6) in Figure 28 were assumed irreversible and fast compared to reaction (3). Reactions (1) and (2) were assumed to be at equilibrium; i.e., the surface concentracions $($ No and $\mathrm{CO}$ ) were set equal to the product of $v$ times the gas phase partial pressure multiplied by an equilibrium constant. In addition, it was assumed that under reducing conditions, co surface coverage will be larger than any other species, reducing the site balance to:

$$
1 \simeq \theta_{v}+\theta_{C O}
$$

where $\theta_{v}$ and $\theta_{C O}$ are fractional coverages of vacant sites and co covered sites, respectively. The complete derivation of the expressions for $R_{N_{2}} / R_{N_{2}} \mathrm{O}$ is given in Appendix 2 .

Using equation (1), the ratio $R_{N_{2}} / R_{N_{2}} \mathrm{O}$ can be related to $\mathrm{S}_{\mathrm{N}_{2}} \mathrm{O}^{\circ}$ Algebraic rearrangement yields the expressions (presented in Table 6) which can be plotted to test the fit of the data to each particular mechanism. For the Eley-Rideal nitrous oxide production step, a plot of

$$
\left\{\mathrm{P}_{\mathrm{NO}}\left[\left(2 / \mathrm{S}_{\mathrm{N}_{2} \mathrm{O}}-1\right)^{2}-1\right]\right\}^{-1 / 2}
$$

versus $\mathrm{P}_{\mathrm{CO}}$ should yield a straight line. For the Langmuir-Hinshelwood mechanism, a plot of $\left(2 / \mathrm{S}_{\mathrm{N}_{2} \mathrm{O}}-1\right)^{2}$ versus $1 / \mathrm{P}_{\mathrm{NO}}$ shoula result in a straight line which passes through the origin. 
TABLE 6

Reducing Region, ${ }^{P_{C O}} P_{\text {NO }}$

Assumed (3) No dissociation rate limiting

Eley-Rideal $\mathrm{N}_{2}$ O production step:

$$
\begin{aligned}
& R_{N_{2}} / R_{N_{2} O}=\frac{1}{2}\left[\left(1+\frac{4 k_{4} k_{3} K_{2}}{k_{5}^{2} \cdot\left(1+k_{1}{ }^{P}{ }_{C O}\right)^{2} P_{N O}}\right)^{\frac{1}{2}}-1\right] \\
& \left(\frac{1}{P_{\text {NO }}\left[\left(2 / s_{N_{2} O}-1\right)^{2}-1\right]}\right)^{\frac{1}{2}} \cdot \frac{k_{5}}{4 k_{4} k_{3} k_{2}}\left(1+x_{1} p_{C O}\right)
\end{aligned}
$$

Lanemuir-llinshelwood $\mathrm{N}_{2}$ o production stop

$$
\begin{aligned}
& R_{N_{2}} / R_{N_{2} O}=\frac{1}{2}\left[\left(1+\frac{4 k_{4} k_{3}}{k_{5}^{2} k_{2} P_{N O}}\right)^{\frac{1}{2}}-1\right] \\
& \left(2 / s_{N_{2} O}-1\right)^{2}-1=\frac{4 k_{l} k_{3}}{k_{5}^{2} k_{2}}\left(1 / P_{N_{O}}\right)
\end{aligned}
$$


In Figure 29 the data is plotted utilizing the expression obtained for the Langmuir-Hinshelwood mechanism. An attempt to plot the data in accordance with the Eley-Riceal mechanism resulted in an excessive amount of scatter and no apparent correlation.

As can be seen in Figure 29, the data fit is reasonably good (except for a single point) over the range of values studied. These results tend to confirm the dominance of the Langmuir-Hinshelwood mechanism'for nitrous oxide production and are in agreement with those of Cant et al (I). It is worth noting, however, that BEBO estimations of activation energies (28) combined with absolute rate theory would have favored an Eley-Rideal process for $\mathrm{N}_{2} \mathrm{O}$ formation.

The scatter introduced by the one point (KOR-29) illustrates the difficulty in obtaining reproducible results for runs made (under reducing conditions) at different times with different pre-run histories. The data closest to the line in Figure 29 were taken from runs kOR32 to KOR-38, all of which were made in a continuous sequence (without an intervening oxidation $r u n)$. Run KOR-29 was preceded by three runs made under oxidizing conditions. In addition, the value of $\mathrm{S}_{\mathrm{N}_{2} \mathrm{O}}$ was Found to be significantly lower for a fresh catalyst, compared to that for an aged catalyst tested under the same conditions. The causes of these effects are not known, and consequently caution must be exercised in interpreting the results presented.

\section{Oxidizing Region}

In the oxidizing region, the rate limiting step was assumed to be (5) in Figure 28 , due to the high conversions and very low co partial pressures. The infrared $\mathrm{CO}$ bands indicated that, even under highly 
$-105-$

Figure 29. Test of selectivity data for runs made under reducing conditions. Langmuir-Hinshelwood mechanism. 


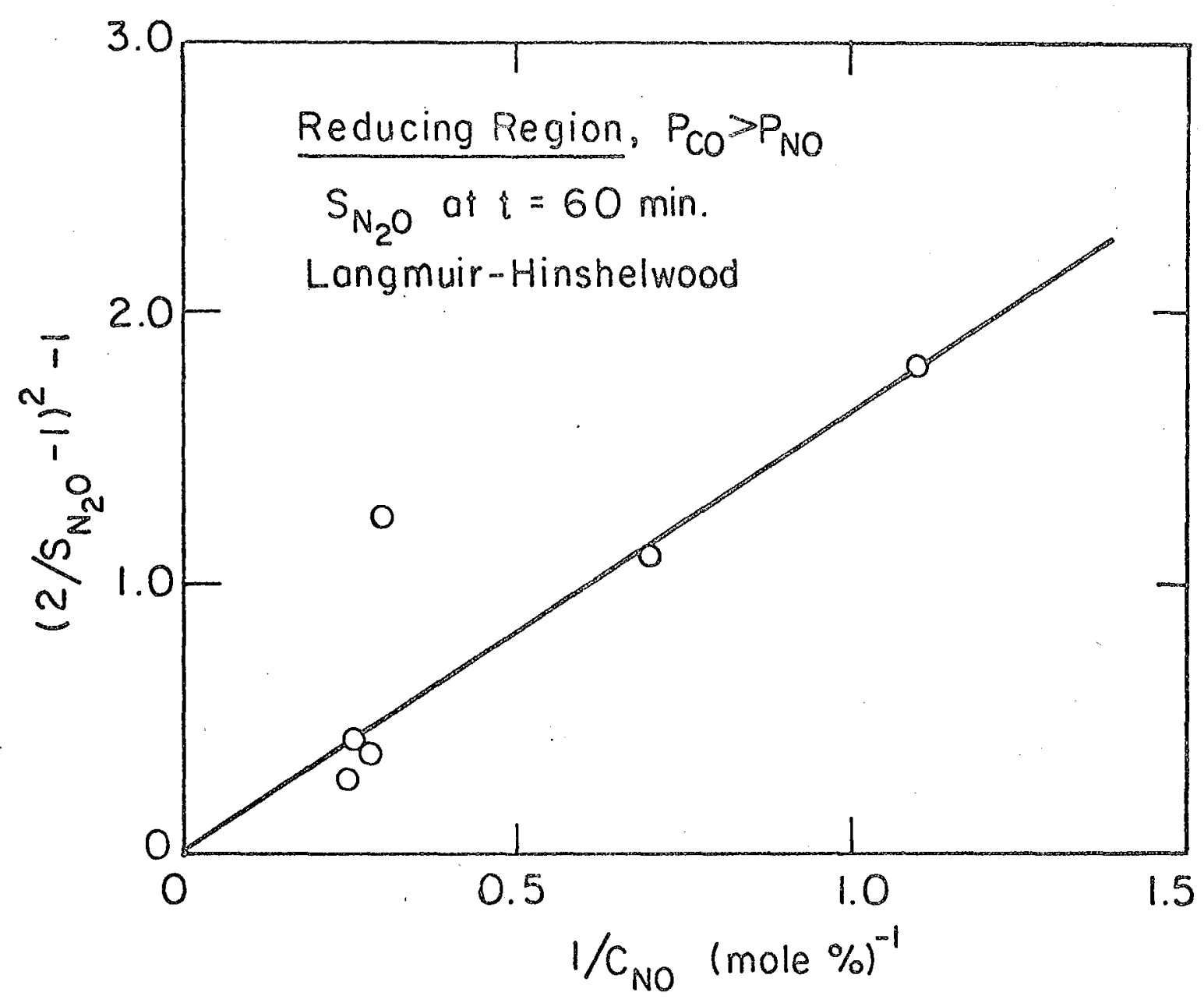

XBL 786-5120

Fig. 29 


\section{TABIF 7}

Oxtdizing Region, $P_{C O} P_{\text {NO }}$

Assumed (6) co oxidation rate limiting

Eley-Rideal $\mathrm{N}_{2}$ O nroduction stop:

$$
\begin{aligned}
& R_{N_{2}} / R_{N_{2} O}=\frac{1}{2}\left[\left(1+\frac{4 k_{4} k_{6} P_{C O}}{k_{5}^{2} P_{N O}^{2}}\right)^{\frac{1}{2}}-1\right] \\
& \left(2 / s_{N_{2} O}-1\right)^{2}-1=\frac{4 k_{4} k_{6} P_{C O}}{k_{5}^{2} P_{N O}^{2}}=\frac{4 k_{4} F_{C O}^{0}}{k_{5}^{2} P_{N O}^{2}}
\end{aligned}
$$

Lancmuir-Hinsholwood $\mathrm{N}_{2}$ O production step:

$$
\begin{aligned}
& R_{N_{2} / R_{N_{2} O}}=\frac{1}{2}\left[\left(1+\frac{k_{4} k_{3}}{k_{5}^{2} k_{2} P_{N O}}\right)^{2}-1\right] \\
& \left(2 / S_{N_{2} O}-1\right)^{2}-1=\frac{4 k_{4} k_{3}}{k_{5}^{2} k_{2}}\left(1 / P_{N O}\right)
\end{aligned}
$$


oxidizing conditions, the surface was still covered with roughly 50 to 758 of the Co equilibrium coverage. As a result, the co coverage was considered approximately constant, and the site balance was made over the remaining sites. This is equivalent to assuming that $1 / 2$ to $3 / 4$ of the surface, being covered with $\mathrm{CO}$, is inactive toward the NO reduction reactions. Mathematically similar results would have been obtained for constant $\theta_{\mathrm{CO}}$ (between 0.5 and 0.75 ) with the site balance made over the entire surface.

Two mechanisms for $\mathrm{N}_{2} \mathrm{O}$ formation were considered, as was done in the reducing region. The results are summarized in Table 7 and derived in Appendix 3. The expression for $\mathrm{R}_{\mathrm{N}_{2}} / \mathrm{R}_{\mathrm{N}_{2} \mathrm{O}}$ for the LangmuirHinshelwood mechanism was obtained without additional assumptions. The Eley-Rideal mechanism, however, required additional simplifying assumptions. For this mechanism the site balance was reduced to:

$$
1 \sim \theta_{0}+\theta_{v}
$$

where $\theta_{0}$ and $\theta_{v}$ are fractional coverages of adsorbed oxygen atoms and vacant sites, respectively. Under highly oxidizing conditions, for small $\mathrm{P}_{\mathrm{CO}}$ and large $\mathrm{P}_{\mathrm{NO}}$ ' $\theta_{\mathrm{O}}$ was assumed to be the dominant surface species. In this case $\theta_{\mathrm{V}}$ will be small compared to 1 , and $\theta_{0}$ will be on the order of 1 . The rate of co reaction can be simplified to:

$$
R_{C O}=k_{6} O^{p} C O \simeq k_{6}{ }^{P} C O \text { for } \theta_{0} \simeq 1
$$


In a CFSTR at 1008 CO conversion,

$$
\mathrm{F}_{\mathrm{CO}}{ }^{\mathrm{O}}=\mathrm{R}_{\mathrm{CO}}
$$

where $\mathrm{F}_{\mathrm{CO}}{ }^{\circ}$ is the input molar feed rate of $\mathrm{CO}$. This allows the replacement of the group $k_{6}{ }^{P} C_{C O}$ by $F_{C O}{ }^{\circ}$ (combining (16) and (17) above) in the expression for $\mathrm{R}_{\mathrm{N}_{2}} / \mathrm{R}_{\mathrm{N}_{2}} \mathrm{O}$ in Table 7, since under highly oxidizing conditions $\mathrm{P}_{C O}$ is not known accurately.

Algebraic rearrangement of the expressions obtained for the ratio $\mathrm{R}_{\mathrm{N}_{2}} / \mathrm{R}_{\mathrm{N}_{2} \mathrm{O}}$ yield equations which can be plotted to test the data. The quantity $\left(2 / \mathrm{S}_{\mathrm{N}_{2} \mathrm{O}}-1\right)^{2}-1$ is plotted versus $1 / \mathrm{P}_{\mathrm{NO}}$ in Figure 30 and versus $\mathrm{F}_{\mathrm{CO}}{ }^{\circ} / \mathrm{P}_{\mathrm{NO}}{ }^{2}$ in Figure 31, corresponding to the Langmuir-Hinshelwood and Eley-Rideal mechanisms, respectively. The large range of numerical values required use of a $\log -\log$ scale. As can be seen in Figures 30 and 31 , neither mechanism results in a correlation of the data along a straight line. In particular, at low $\mathrm{P}_{\text {No }}$ the experimental values of the quantity plotted on the ordinate are larger than anticipated by the model. Failure of the model in this regime may be associated with a breakdown in the assumption that $\mathrm{CO}$ oxidation represents the rate limiting step, since as $\mathrm{P}_{\mathrm{NO}}$ declines it eventually becomes comparable in magnitude with $P_{C O}$. When this becomes true, it is likely that the kinetics will undergo a transition to the rate limited no dissociation process. It should be noted further that at low $\mathrm{P}_{\text {NO }}$ the measurements of $\mathrm{S}_{\mathrm{N}_{2} \mathrm{O}}$ become inaccurate due to the very low rates of $\mathrm{N}_{2} \mathrm{O}$ formation that must be measured. In conclusion, then, since neither model appears 
$-110-$

Figure 30. Test of selectivity data for runs made under oxidizing conditions. Langruir-Hinshelwood mechanism. 


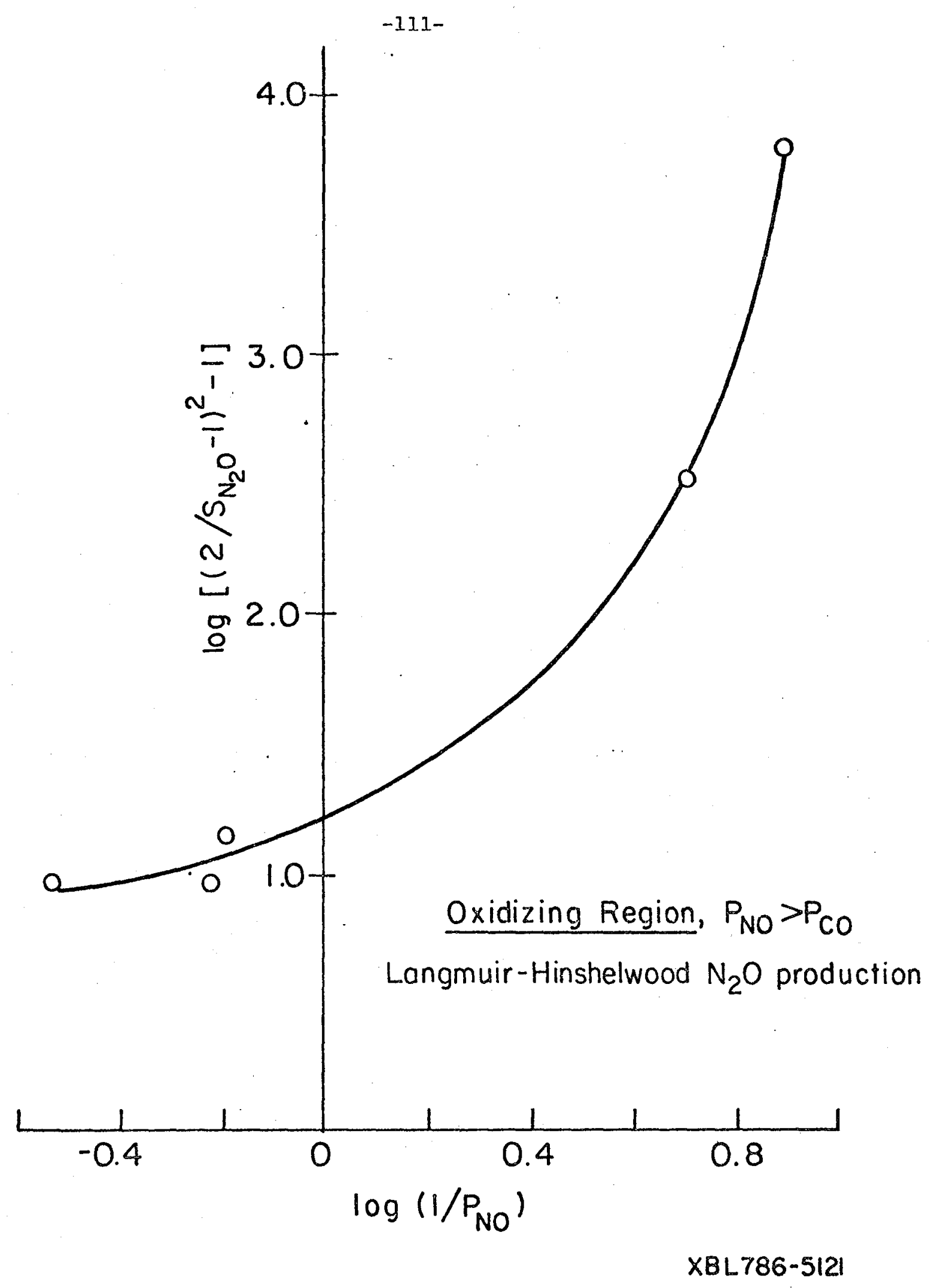

Fig. 30 
$-112-$

Figure 31. Test of selectivity data for runs made under oxidizing conditions. Eley-Rideal mechanisms. 


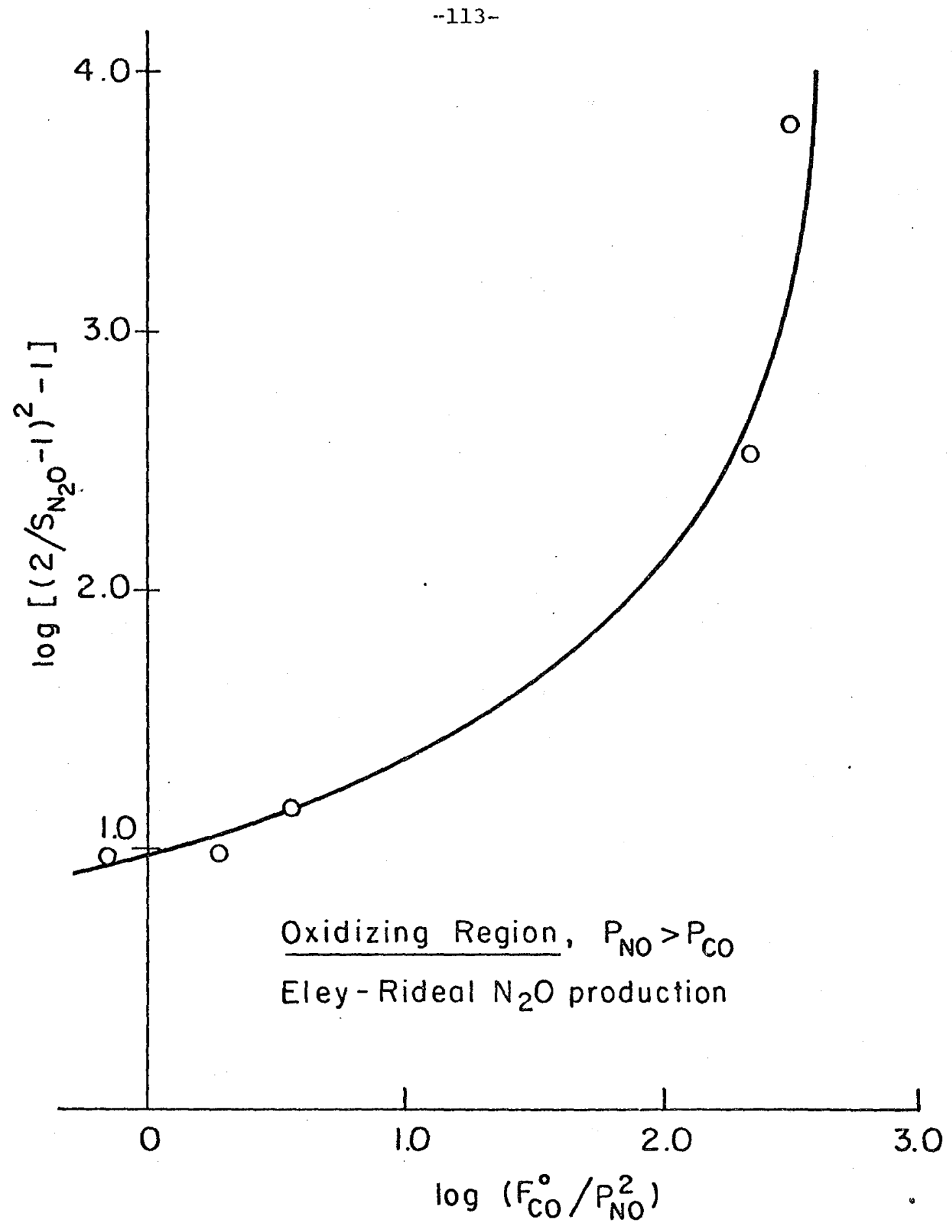

XBL 786-5122

Fig. 31 
to correlate the data, no distinction can be made regarding the importance of the two reaction paths.

\section{E. Investigation of the Deactivation Process}

One of the more interesting aspects of this study involved the investigation of the catalyst deactivation. Three chemical species were considered as possible contributors to the deactivation process. These were adsorbed oxygen atoms, adsorbed carbon atoms and the isocyanate species $(\mathrm{N} C \mathrm{C})$. The extent to which each of the three contributes to the deactivation is discussed in detail below.

\section{Oxygen}

Katzer (34) observed significant catalyst deactivation in a study of $\mathrm{NH}_{3}$ oxidation by $\mathrm{NO}$, which was attributed to the formation of a very stable $\mathrm{Pt}-\mathrm{O}$ species. In this study, it was found that the catalyst could be reactivated by reduction in $\mathrm{H}_{2}$, even though the deactivation process proceeded under highly reducing conditions.

The stability of the $\mathrm{Pt}-\mathrm{O}$ species and the behavior of oxygen on Pt surfaces has been the subject of many recent publications. Stable platinum oxide species have been observed by Monroe (35) and others $(36,37,38)$. Nitric oxide adsorption and decomposition studies reported by Pirug and Bonzel (6) and Amiranazmi and Boudart (39) conclude that adsorbed oxygen inhibits NO dissociation through the formation of a stable surface oxide. Since No dissociation appears to be the rate limiting step in the reducing region, the possibility of the Pt-o species being responsible for the deactivation is quite realistic in the light of the previously mentioned literature. 
To test the susceptibility of the catalyst to deactivation by a surface oxygen species, attempts were made to poison the catalyst surface by pretreatment with NO and $\mathrm{O}_{2}$ prior to the introduction of the reactants. In each case, a $5 \mathrm{hr}$ pretreatment with either No (at a concentration of 5 molez in He) or oxygen (20 molez in $\mathrm{He}$ ) at $300^{\circ} \mathrm{C}$ failed to deactivate the catalyst. Upon introduction of reactant mixture (108 $\mathrm{CO}, 58$ NO in $\mathrm{He}$ ) following the pretreatment, the catalyst exhibited a deactivation very similar to that observed for $r$ uns made with the standard oxidation/reduction pretreatment. This behavior is shown in Figure 32 .

The results of the oxidation pretreatment experiments strongly suggest tht the Pt-O species cannot be responsible for the catalyst deactivation. If this species were indeed the poison, the No pretreatment should have deactivated the catalyst via the same process (i.e. NO dissociation) that occurs under reaction conditions. In addition, further experiments (explained in detail below) indicate that catalyst reactivation can be accomplished without reduction, and that therefore it is highly unlikely that the deactivation is caused by an adsorbed oxygen or Pt-O species.

Furthermore, if NO dissociation were responsible for the formation of an oxide adspecies, then an excess of nitrogen containing products should have been observed (i.e., $R_{s}$ values greater than one). Thus it is difficult to explain the large excess $\mathrm{CO}_{2}$ production observed experimentally. It is conceivable, however, that excess $\mathrm{CO}_{2}$ is produced by a side reaction in which the activity declines in a manner 
$-116-$

Figure 32. Effect of nitric oxide pretreatment on catalyst deactivation. 


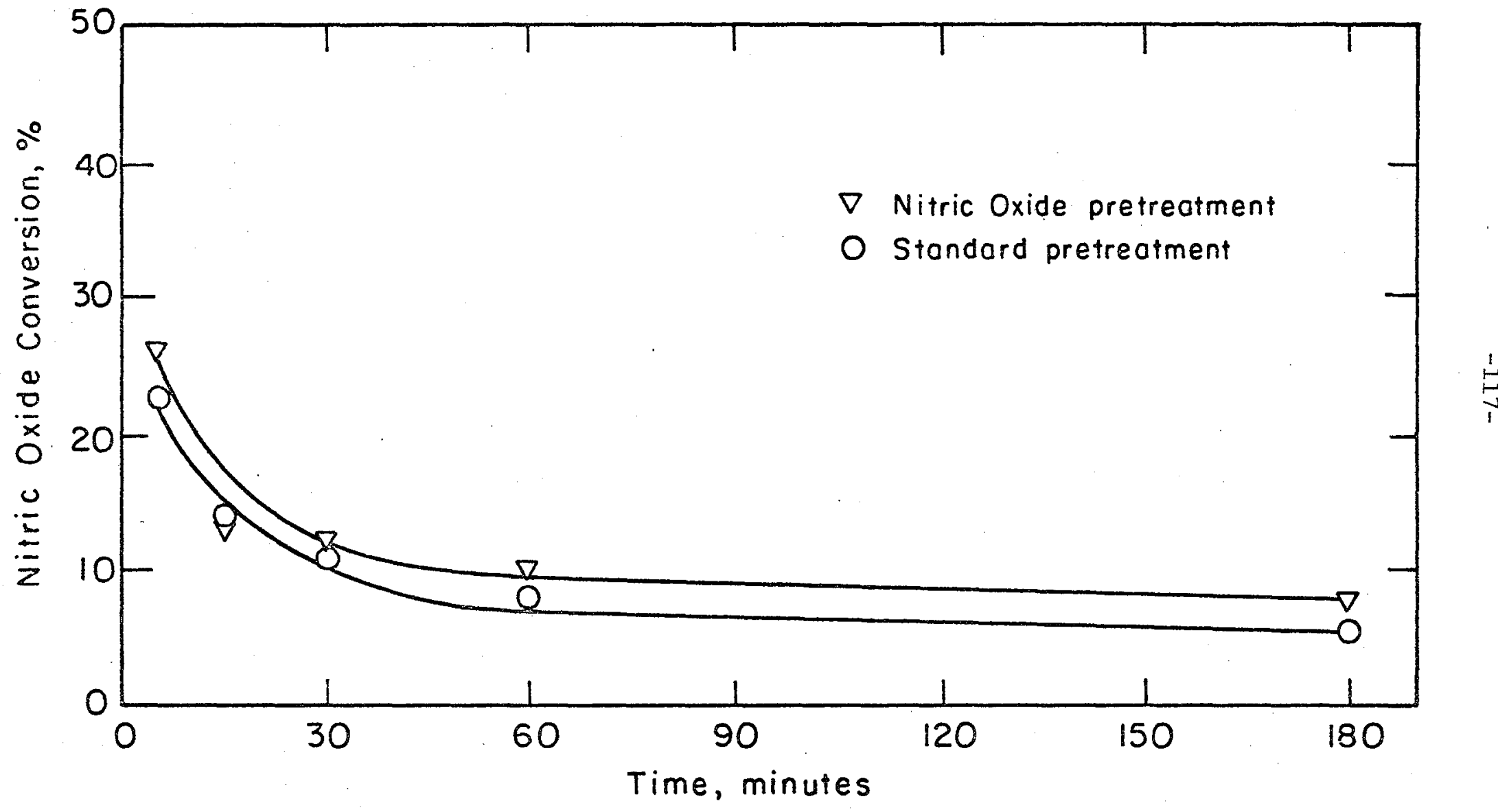

XBL 786-5199

Fig. 32 
similar to the main NO reactions. In this case the large amount of excess $\mathrm{CO}_{2}$ would tend to overwhelm any observable oxide formation. This is more likely to be true if the same sites are responsible for both the main (NO) and side (excess $\mathrm{CO}_{2}$ ) reactions, and if these sites are small in number compared to the total number of surface sites. Under these conditions the poisoning could occur by an oxidation process and not be detected via product distributions, but one would still expect to be able to poison these sites by prior No pretreatment.

\section{Carbon}

The second species considered with respect to its role in the deactivation process was carbon. Production of surface carbon via Co dissociation would result in excess $\mathrm{CO}_{2}$ formation according to equation (6). Somorjai et al (4) have reported co dissociation at coordinately unsaturated (step and kink) sites on a platinum surface.

In order to test the susceptibility of the catalyst to deactivation by co dissociation, an attempt was made to deactivate the catalyst by $C O$ pretreatment. Prior to the $C O$ pretreatment, two reference runs (KOR-35, 36) were made for comparison. After these runs, the catalyst was pretreated in the usual manner, followed by a two hour pretreatment of 10 moles $\mathrm{CO}$ in He at $300^{\circ} \mathrm{C}$. The $\mathrm{CO}$ pretreatment was followed by a 30 min He purge, prior to introduction of the reactants $(10 \% \mathrm{CO}$, 58 NO in $\mathrm{He}$ ).

The results of this experiment are shown in Figure 33 , in which No conversion is plotted as a function of time for the reference $r$ uns $(K O R-35 / 36)$ and the $C O$ pretreatment run $(K O R-37)$. The results shown in this figure indicate that the pretreatment had very little effect 
Figure 33. Effect of carbon monoxide pretreatment on catalyst deactivation. 


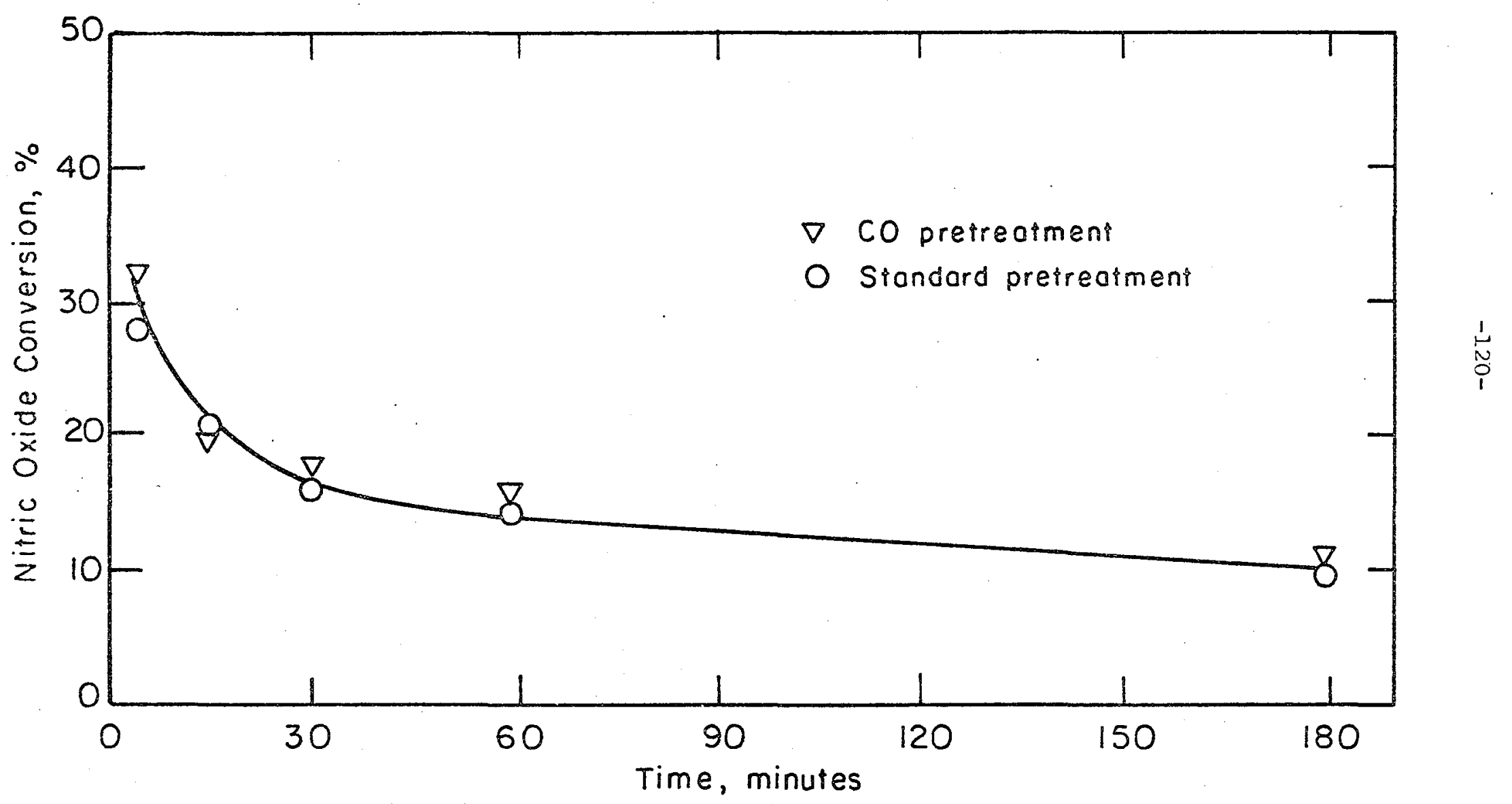

XBL $786-5200$

Fig. 33 
on the initial activity of the catalyst. This evidence suggests that the deactivation process is not due to the build up of a carbon species formed by co dissociation.

One of the main reasons for considering the possibility of carbon formation was the observed excess $\mathrm{CO}_{2}$ production. However, the data presented in Table 5 indicate that significant amounts (at least one monolayer) of surface carbon would have to be produced to account for the total integrated excess $\mathrm{CO}_{2}$ production. This is not likely since no change in the $C O$ infrared band intensity was observed, which indicates that a large percentage of the Pt surface was still covered with adsorbed $\mathrm{co}$. In order to reconcile both the infrared observations and the integrated excess $\mathrm{CO}_{2}$ quantities, it would be necessary to propose a carbon. structure that could grow to large (up to 5 monolayers) proportions and still occupy very little Pt surface. Additionally, this carbon structure would have to be reactive enough to be removed by the rather mild standard pretreatment conditions, in order to keep from eventually clogging up the catalyst. The existence of such a structure is highly unlikely, and as a result the evidence presented here does not support the production of excess $\mathrm{CO}_{2}$ via $\mathrm{CO}$ dissociation and surface carbon formation.

Further evidence suggesting that carbon deposition does not contribute to the cause of the deactivation was contributed by the following set of experiments. Following the $3 \mathrm{hr}$ run KOR-37 mentioned above, the flow of $C O$ was discontinued, while feeding a mixture of approximately 5 mole 8 No in He to the reactor $\left(\right.$ at $300^{\circ} \mathrm{C}$ ). This sondition was maintained for three hours, while montoring the infrared spectra to observe the 
effect of No on the isocyanate band. Following the No treatment period, the system was purged with He for 8 to 10 hours. Next, the reactant feed mixture (approximately $108 \mathrm{CO}, 5 \%$ No, in He) was introduced, omitting the standard pretreatment. The results of this $r$ un (labeled KOR-38A) are shown in Figure 34. The conditions in run KOR-38A were monitored for 60 minutes, at "which time the $c 0$ was turned off, allowing the 58 NO in He stream to continue for 20 minutes. At the end of this period, the reactor was purged with pure He for 20 minutes, then the same reactant feed mixture (used in KOR-38A) was reintroduced. This run (labeled KOR-38B) is also shown in Figure 34.

The main conclusion to be drawn from Figure 34 is that even though KOR-38A underwent a typical deactivation, the brief 20 minute $5 \%$ No purge was sufficient to reactivate the catalyst. The excess $\mathrm{CO}_{2}$ produced in the 60 minute period (KOR-38A) was over 260 micromoles. It is unlikely that this much carbon could have been removed in such short time and under relatively mild oxidation conditions.

\section{Isocyanate species}

The results of the previously described reactivation experiments along with infrared observations prompted a consideration of the isocyanate species as a possible contributor to the deactivation process. The proposition that the isocyanate species contribute to a loss in activity during No reduction by $C O$ had been noted by Nilyama et al (16) previously. These authors observed the transient deactivation of a $\mathrm{Pt} / \mathrm{Al}_{2} \mathrm{O}_{3}$ catalyst and the reactivation of the catalyst in a short $(<30 \mathrm{~min})$ period of time by $\mathrm{H}_{2} \mathrm{O}$ injection. The authors also recorded infrared spectra in which they observed the increasing intensity of a band near $2300 \mathrm{~cm}^{-1}$ 
$-123-$

Figure 34. Nitric oxide conversion as a function of time for runs KOR-38A and KOR-38B. 


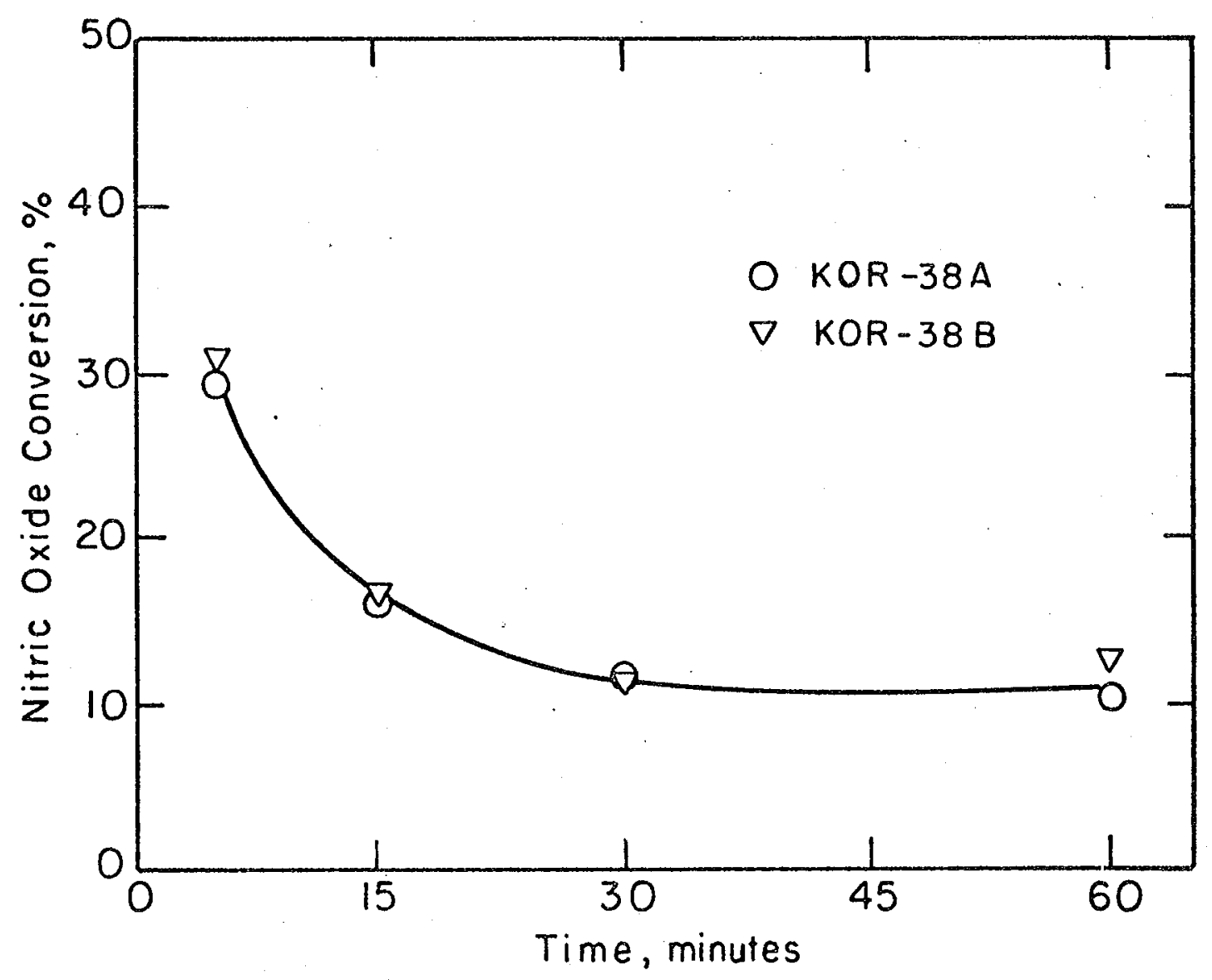

XBL786-5198

Fig. 34 
(identified as $\mathrm{Pt}-\mathrm{NCO}$ ) as the deactivation proceeded. As a result of these and other observations, Niiyama and coworkers concluded that the poisoning was due to the formation of a Pt-NCO species.

Formation of the isocyanate species on the Pt surface is believed to occur according to the reactions:

$$
\begin{aligned}
& \mathrm{s}+\mathrm{NO}_{(a)} \rightarrow \mathrm{N}_{(a)}+\mathrm{O}_{(a)} \\
& \mathrm{N}_{(a)}+\mathrm{CO}_{(\mathrm{g})} \longrightarrow \mathrm{NOO}_{(a)}
\end{aligned}
$$

If the removal of the adsorbed oxygen atoms is taken into account, then the overall stoichiometry for isocyanate formation is:

$$
\mathrm{Pt}+\mathrm{NO}+2 \mathrm{CO} \longrightarrow \mathrm{Pt}-\mathrm{NCO}+\mathrm{CO}_{2}
$$

The reaction sequence $(18 a, b)$ has been proposed by Unland (17) for isocyanate formation on $\mathrm{Pt}$ and is consistent with the mechanism presented earlier (Figure 28). An altnerative mechanism has been proposed by Harrison and Thornton (40) for isocyanate production over a tin oxide/ copper oxide catalyst:

$$
\begin{aligned}
& \mathrm{CO}_{(g)} \rightarrow \mathrm{C}_{(a)}+\mathrm{O}_{(\mathrm{a})} \\
& \mathrm{C}_{(\mathrm{a})}+\mathrm{NO}_{(\mathrm{g})} \rightarrow \mathrm{s}-\mathrm{CNO}(\mathrm{a}) \\
& \mathrm{s}-\mathrm{CNO}-\mathrm{s}^{+}-\mathrm{C}<\frac{0}{0}^{\mathrm{N}} \rightarrow \mathrm{s}-\mathrm{NCO}
\end{aligned}
$$


which proceeds via dissociation of co followed by the reaction of the adsorbed carbon fragment with No ( $\mathrm{Eq} .21)$ and a rapid isomerization of the resultant fulminate to the stable isocyanate structure, via a cyclic oxaziranyl intermediate (Eq. 22). This mechanism is not likely to be important for a Pt catalyst due to the necessity of CO dissociation.

An important consequence of the $\mathrm{Pt}-\mathrm{NCO}$ formation is the production of excess $\mathrm{CO}_{2}$ (Eq. 19). Since for every NCO molecule formed a molecule of $\mathrm{CO}_{2}$ is produced, one is faced with a dilemma similar to that considered. in the case of carbon formation. Judging by the excess $\mathrm{CO}_{2}$ production, the large amounts of NOO formed make it difficult to rationalize that this material remains on the Pt surface, since the growth of the infrared isocyanate band does not affect the $\mathrm{CO}$ band intensity or frequency. If signifcant quantities of the NCO species were present on the Pt surface, not only would one also expect to see a decrease in co band intensity, but one also expect to see a frequency shift due to the interaction of the NCO species on the adsorbed CO (41). The very large accumulated NCO infrared band intensities are consistent with the greater than monolayer excess $\mathrm{CO}_{2}$ formation, and cannot be due to a species adsorbed on the Pt surface, since the size of the $2300 \mathrm{~cm}^{-1}$ band is of ten larger than the corresponding co band (assuming comparable extinction coefficients).

The dilemma concerning the site of adsorption of the isocyanate species can be resolved if we consider that this structure is not on the Pt surface, but rather on the silica support. The support has many times the surface area of the catalyst, and could provide a large 
reservoir for any species with which it could bond. Direct evidence for the existence of a stable isocyanate species bonded to the silica support has been obtained in this study (section $\mathrm{C}-1$ ), and this observation is supported by work published by Eley et al (2I) and others $(42,43,22,20)$, described in detail below.

Eley, et al. (21) have published infrared spectra following the dissociative adsorption of ethyl isocyanate on silica. They observed very intense bands at $2308 \mathrm{~cm}^{-1}$ and $2210 \mathrm{~cm}^{-1}$ and attributed these bands to Si-NCO and surface cyanide (CN) groups, respectively. Isotopic substitution experiments and calculations performed by Morrow and Cody (42) confirm the frequency assignments made by Eley et al Eley and co-workers have also observed the removal of $2308 \mathrm{~cm}^{-1}$ and $2210 \mathrm{~cm}^{-1}$ bands by exposure to water vapor at $25^{\circ} \mathrm{C}$.

Guillet et al (22) have published a similar study involving the dissociative acisorption of n-butyl isocyanate on both silica and alumina surfaces. Also reported are infrared spectra of HNCO adsorption on silica and alumina. Intense infrared bands observed at $2300 \mathrm{~cm}^{-1}$ to $2310 \mathrm{~cm}^{-1}$ on silica and $2270 \mathrm{~cm}^{-1}$ on alumina were attributed to adsorbed NCO species. These findings (for alumina) are in good agreement with studies of $\mathrm{Pt} / \mathrm{Al}_{2} \mathrm{O}_{3}$ catalysts, reported by Dalla Betta and Shelef (20) and Solymosi et al (44), who have identified infrared bands at $2260 \mathrm{~cm}^{-1}$ and $2267 \mathrm{~cm}^{-1}$, respectively, as belonging to a support bonded isocyanate species. Dalla Betta and Shelef (20) have also reported an isocyanate band for $\mathrm{pt} / \mathrm{SiO}_{2}$ at $2304 \mathrm{~cm}^{-1}$, and attribute this band to an isocyanate species bonded to the silica support. 
Under some conditions, very large NCO bands appeared to split, resolving into bands at $2330 \mathrm{~cm}^{-1}$ and $2290 \mathrm{~cm}^{-1}$. Such a split (see Figure 25) is not evident in spectra published by Eley et al (21), however a shoulder at approximately $2350 \mathrm{~cm}^{-1}$ is present. After replacement of the reactants (NO and $\mathrm{CO}$ ) with He, the split peaks merged into a single peak at $2300 \mathrm{~cm}^{-1}$. No infrared data has been published for $\mathrm{Pt}-\mathrm{NCO}$ on an unsupported metal, although the frequency $\left(\nu_{a}(\mathrm{NCO})\right)$ for $\left[\left(\mathrm{C}_{6} \mathrm{H}_{5}\right)_{3}^{\mathrm{P}}\right] 2^{\mathrm{Pt}(\mathrm{NCO})} 2$ has been reported (45) to be $2234 \mathrm{~cm}^{-1}$. At this time the explanation of the splitting is not clear, and it is not known whether the splitting is associated with species solely on the support, or whether perhaps isocyanate species on the Pt surface are involved. It is not likely that small amounts of Pt-NCO would be observable against the large background intensity of the Si-NCo.

A model for the catalyst deactivation under reducing conditions can now be proposed. The deactivation is believed to involve the transient build-up of the isocyanate species on the Pt crystallites. Due to the high co gas phase partial pressures, a large percentage of the catalyst surface will be covered with $C O$, leaving only a small fraction of the surface sites remaining for No adsorption and dissociation. Since the rate of No dissociation (and therefore the overall rate) is proportional to the vacant site concentration $\left(\theta_{v}\right)$, the build-up of the relatively non-reactive NCO species will cause a drop in observed catalytic activity through the accupation of vacant sites. As a result of the small number of vacant sites present under reducing conations, very small NCO surface coverages can have a sjgnificant effect on the overall rate. 
The transient activity of the catalyst can be explained by considering the transient formation and diffusion of the isocyanate. The problem is much too complex to be treated analytically, without knowledge of NCO diffusion coefficients, reaction rates, or site concentrations. Only a qualitative description can be offered at this time. Initially, the rate of NCO production will be at a maximum, since the concentration of NCO on the support near the crystallites wll be close to zero. This is true, assuming that the diffusion on the silica is much slower than diffusion on the Pt. As the concentration of NCO builds up on the support near the crystallites, the NCO concentration will begin to rise on the crystallites (decreasing $\theta_{v}$ ), resulting in a drop in activity and a subsequent drop in NCO formation. This process will continue until the rate of formation equals the overall rate of diffuson away from the crystallite. At this time, the activity will reach a steady state value.

Experimental observation of the isocyanate production rate can be derived from the excess $\mathrm{CO}_{2}$ production rates, assuming that all the excess $\mathrm{CO}_{2}$ is due to $\mathrm{NCO}$ formation. In this case, the rate of excess $\mathrm{CO}_{2}$ production equals the rate of NCO production. Interpretation of Figure 17 in this manner indicates that the NCO production behavior is consistent with the proposed diffusion model. It is interesting to note that the maximum, $\mathrm{NCO}$ formation rate $(t=5 \mathrm{~min})$ is roughly $20 \%$ of the total tro conversion $(t=5 \mathrm{~min}$, based on the nitrogen products $\mathrm{N}_{2}$ and $\mathrm{N}_{2} \mathrm{O}$ ). This indicates that isocyanate production is not a major competitor fo: acisorbed nitrogen atoms, however it may have an effect on $\mathrm{N}_{2} \mathrm{O}$ selectivity, especially at times close to zero. 
The experimentally observed reactivaton of the catalyst also can be explained by the proposed deactivation mechanism. Once the reactants No and $\mathrm{CO}$ have been removed from contact with the catalyst, the NOO formation ceases, and the NOO species continue to diffuse until the concentration has equilibrated on the silica support. The higher chemical stability of the Si-NCO species provides the driving force for the diffusion off the Pt crystallites. This process may explain why the initial activity can be regained independent of whether oxidizing or reducing conditions are used during pretreatment.

It is also suspected that the $\mathrm{Pt}-\mathrm{NCO}$ species nay react with No (in absence of $\mathrm{CO}$ ) to give $\mathrm{N}_{2}$ and $\mathrm{CO}_{2}$ :

$$
\mathrm{Pt}-\mathrm{NCO}+\mathrm{NO} \rightarrow \mathrm{Pt}+\mathrm{CO}_{2}+\mathrm{N}_{2}
$$

even though the $\mathrm{Si}-\mathrm{NCO}$ species is non-reactive toward NO. This reaction was proposed by Unland (17) to explain the lack of NOO infrared bands when mixtures of excess No were dosed over $P t / A I_{2} O_{3}$. It is likely that reaction 23 above is much slower than NCO production (reaction $18 \mathrm{~b}$ ) in the presence of $\mathrm{CO}$. In the oxidizing region investigated in this study, where $C O$ partial pressures were very low and No partial pressures high, reaction 23 may be responsible for the much lower levels of NCO observed.

It is interesting to note that Niiyama et al (16) observed the deactivation in 38 NO, 18 Co reaction mixture. In this case, the Co partial pressure is probably still high enough to maintain the NCO production faster than the decomposition. The $\infty$ partial pressure 
under these conditions is sufficient to keep the majority of the Pt surface covered with adsorbed co. As a result, $\theta_{v}$ will be small and any Pt-NCO build-up will reduce activity, as was observed in this study for reducing conditions. It must be emphasized that the oxidizing conditions in this study were highly oxidizing, and the high catalyst activity was most likely a result of the decreased Co surface coverage as well as reduced Pt-NCO formation. Unland (17) dosed by filling a constant volume reactor with 100 torr of reaction mixture for a period of 30 minutes prior to observing the infrared spectra. Examination of the spectra published in (17) shows a very small co band for an initial dose of 108 NO, $58 \mathrm{CO}$ in $\mathrm{N}_{2}$, indicating that the $\mathrm{CO}$ partial pressure was very small at the time the spectrum was taken. As a result, unland's conditions were much closer to the oxidizing conditions in this study than those of Niiyama et al (16). The important point to be made here is that the isocyanate formation is dependent on the ratio and magnitude of $\mathrm{P}_{\mathrm{NO}}$ and $\mathrm{p}_{\mathrm{CO}}$ for oxidizing conditions over the catalyst, not the stoichiometry of the feed or the initial composition of a dosing mixture.

Thus far no explanation has been given to account for the gas phase transport of the NCO species. The observation of the Si-NCO band on the reference IR disk definitely indicates that some type of gas phase transport does occur. The most likely species to be found in the gas phase is isocyanic acid (HNCO), or its trimer forms: 


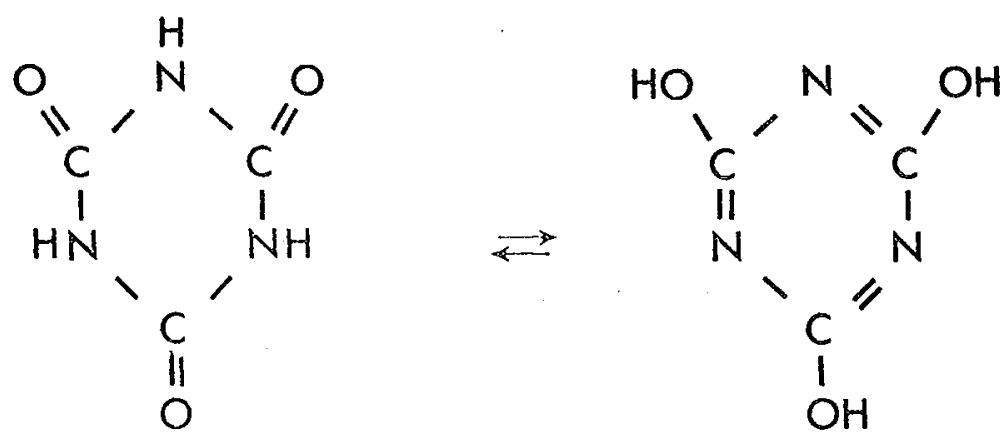

isocyanuric acid $\rightleftharpoons$ cyanuric acid

The trimer form converts to HNCO at approximately $330^{\circ} \mathrm{C}(46)$. For mation of HNCO might occur through reaction of Si-NCO with hydrogen supplied by a hyroxyl group on the silica surface, since the reverse process, adsorption of HNCO on silica, has been observed (18):

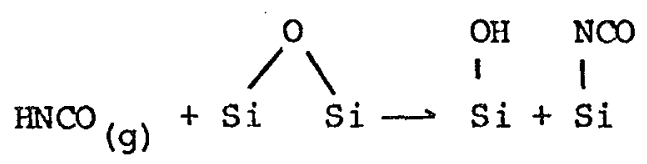

To what extent the formation of HNOO occurred in this study is not known, and it is likely that the amounts of HNCO produced were dependent on the concentration and reactivity on th or groups on the Si surface. However, the formation and decomposition of HNCO is not expected to represent a major NCO transport mechanism due to the stability of the observed infrared isocyanate bands. Long periods under constant He purge at $300^{\circ} \mathrm{C}$ appeared to have little effect on the intensity of the $2300 \mathrm{~cm}^{-1}$ bands. Eley et al (21) observed the desorption of the $2300 \mathrm{~cm}^{-1}$ and $2210 \mathrm{~cm}^{-1}$ bands at high temperatures and found very little decrease in the infrared band intensities at temperatures up to $500^{\circ} \mathrm{C}$ in vacuo. 
Many authors $(17-19,20,47,48)$ have recently pondered the role of isocyanate formation in the production of $\mathrm{NH}_{3}$ over noble metal catalysts. The results presented in this study in conjunction with work reported by Voorhoeve et al (48) may help to shed some additional light on this subject. Voorhoeve et al (48) have studied the reaction of $\mathrm{H}_{2}, \mathrm{CO}$, and No over supported and unsupported pt catalysts, and have obtained some very interesting results. These authors found that reaction of a mixture of $0.38 \mathrm{NO}, 0.5 \% \mathrm{H}_{2}$, and $58 \mathrm{CO}$ in He over an unsupported Pt catalyst resulted in $100 \%$ NO conversion to ammonium cyanate $\left(\mathrm{NH}_{4} \mathrm{OCN}\right)$. Exposure of the same reactant mixture to an alumina supported Pt catalyst produced no $\mathrm{NH}_{4} \mathrm{OCN}$, only $\mathrm{NH}_{3}$. The authors concluded that NCO groups formed on the Pt surface were converted to $\mathrm{NH}_{3}$ by hydrolysis after migration to the alumina support. Evidence and mechanisms concerning the migration of NCO groups described in the present work strongly support this hypothesis.

Hydrolysis of the silicon isocyanate species was observed in this study at $25^{\circ} \mathrm{C}$. The formation of ammonia is described in the following overall reaction:

$$
\mathrm{Si}-\mathrm{NCO}+2 \mathrm{H}_{2} \mathrm{O} \rightarrow \mathrm{NH}_{3}+\mathrm{CO}_{2}+\mathrm{Si}-\mathrm{OH}
$$

In addition to ammonia, HNCO can also be formed according to reaction 25 mentioned above:

$$
\mathrm{Si}-\mathrm{NCO}+\mathrm{Si}-\mathrm{OH} \longrightarrow \mathrm{HNCO}+\mathrm{Si-O-Si}
$$


The production of cyanide groups during hydrolysis, as observed by the growth of the $2200 \mathrm{~cm}^{-1}$ in Figure 27, indicates that the following reaction may be occurring:

$$
2 \mathrm{Si}+\mathrm{H}_{2} \mathrm{O}+\mathrm{Si}-\mathrm{NCO} \longrightarrow \mathrm{Si}-\mathrm{CN}+2 \mathrm{Si}-\mathrm{OH}
$$

The cyanide groups formed in reaction 27 can react further and produce ammonia according to:

$$
\mathrm{Si}-\mathrm{CN}+3 \mathrm{Si}-\mathrm{OH}-\mathrm{NH}_{3}+\mathrm{CO}_{2}+2 \mathrm{Si}+\mathrm{Si}-\mathrm{O}-\mathrm{Si}
$$

This reaction does not appear to proceed to a large extent at $25^{\circ} \mathrm{C}$, since the spectra (in Figure 27) do not reveal a decrease in the 2200 $\mathrm{cm}^{-1}$ band intensity during prolonged exposure to water. It is likely, however, that reaction 28 does proceed upon heating. This would account for the removal of the $2200 \mathrm{~cm}^{-1}$ band in the spectrum represented by curve e, Figure 27. The importance of reaction 25 in comparison to reaction 26 was not determined in this study, since neither of the products $\left(\mathrm{NH}_{3}\right.$ and $\mathrm{HNCO}$ ) could be detected with the chromatographic analys is system. 


\section{CONCLUSTONS}

The following conclusions can be stated with regard to the kinetics and product selectivities observed in this study. Under reducing conditions, the overall nitric oxide reaction rate was found to be first order in ${ }^{P_{N O}}$ and inverse second order in $\mathrm{P}_{\mathrm{CO}}$. A reaction mechanism based on the dissociation of nitric oxide as the rate limiting step was used to correlate nitric oxide reaction rates and product selectivities. As a part of the mechanism, the assumption of a Langmuir-Hinshelwood process for the formation of nitrous oxide was found to correlate the selectivity data. The Langmuir-Hinshelwood process involves the reaction of an adsorbed nitrogen atom with an adsorbed nitric oxide molecule. Under highly oxidizing conditions, the overall rate becomes positive order in $\mathrm{P}_{\mathrm{CO}}$. It was not possible to correlate either rate or selectivity expressions for the oxidizing regime.

The transient catalyst deactivation observed under reducing conditions can be qualitatively described utilizing a simple model. The essential part of the model is the formation of an isocyanate species on the Pt crystallites and the subsequent diffusion of these species to the silica support. The deactivation is the result of a transient isocyanate build-up on vacant Pt sites, thereby inhibiting the dissociation of nitric oxide. This process is aggravated by the high co coverages present under reducing conditions. The isocyanate deactivation mechanism points out the importance of the catalyst support in the reduction of NO by $\mathrm{CO}$ over $\mathrm{Pt}$. Since the hydrolysis of silicon isocyanate produces ammonia and is easily accomplished at $25^{\circ} \mathrm{C}$, the 
catalyst support may also have an important role during the formation of ammonia in the presence of water and hydrogen. 


\section{ACKNOWLEDGMENTS}

I would like to express my gratitude for the support and guidance given throughout the course of this project by Professor Alex Bell. I would also like to thank Professor Eugene Petersen for many enlightening and stimulating conversations. The help and encouragement of John Ekerdt and steve Kellner is thankfully acknowledged, along with the cooperation and services of the personell at the Lawrence Berkeley Laboratories and the college of Chemistry. I would like to thank the National Science Foundation, the Department of Chemical Engineering, and the University of California for their financial support of this project. Finally, I would like to express my sincere gratitude for the unceasing optimism and love bestowed upon me by my parents, without whose help the successful completion of this project would not have been possible. 


\section{APPENDICES}

\section{Appendix 1}

Flow System Calculations

Flow in a capillary can be described with the Hagen-Poiselle equation:

$$
Q=\frac{\pi R^{4}}{8 L_{\mu}} \Delta P
$$

where

$$
\begin{aligned}
& Q=\text { volumetric flow rate }, \mathrm{cm}^{3} / \mathrm{sec} \\
& R=\text { capillary radius, } \mathrm{cm} \\
& \mathbf{L}=\text { capillary length, } \mathrm{cm} \\
& \mathbf{P}=\text { pressure drop across capillary, dynes } / \mathrm{cm}^{2} \\
& \mu=\text { viscosity, poise }
\end{aligned}
$$

For constant $R, L$, and $\mu$, the volumetric flow rate is proportional to the pressure drop across the capillary,

$$
Q=K \Delta P
$$

where

$$
\begin{aligned}
K & =\text { flow factor } \\
& =\pi R^{4} / 8 \mathrm{~L} \mu
\end{aligned}
$$

If the capillary is at a pressure other than atmospheric, then the flow rate at atmospheric pressure, $Q_{O}$, is related to $\Delta \mathrm{P}$ by:

$$
Q_{0}=K \Delta P\left(1+P^{\prime} / P_{0}\right)
$$

where

$$
\begin{aligned}
& \mathrm{P}_{0}=\text { barimetric pressure } \\
& \mathrm{P}^{\prime}=\text { capillary pressure }
\end{aligned}
$$


Calibration of the capillary was performed by experimentally determining $K$ for a reference gas such as He, then the value of $K$ for other gases such as No and CO was calculated using:

$$
\begin{aligned}
\mu_{i} k_{i} & =\mu_{\mathrm{He}} \mathrm{K}_{\mathrm{He}} \\
\mathrm{k}_{i} & =\frac{\mu_{\mathrm{He}}}{\mu_{i}} \mathrm{~K}_{\mathrm{He}}
\end{aligned}
$$

Equation 1-4 can also be used to correct the flow factors for temperature, if values of $\mu_{i}(T)$ are available. 


\section{Appendix 2}

Derivation of $\mathrm{R}_{\mathrm{N}} / \mathrm{R}_{2} \mathrm{v}_{2} 0$ Selectivity Relationships, Reducing Region

A. Eley-Rideal $\mathrm{N}_{2} \mathrm{O}$ Production, $\mathrm{F}_{\mathrm{CO}}>\mathrm{P}_{\text {NO }}$

The reactions pertaining to the following development are reactions $1-4,5 a$, and 6 in Figure 28 .

The site balance including all surface species is:

$$
1=\theta_{v}+\theta_{0}+\theta_{\text {NO }}+\theta_{C O}+\theta_{N}
$$

where the fractional surface concentrations are denoted by:

$$
\begin{aligned}
& \theta_{\mathbf{v}}=\text { vacant site concentration } \\
& \theta_{\mathbf{O}}=\text { adsorbed oxygen atom concentration } \\
& { }^{\theta_{N O}}=\text { adsorbed No molecule concentration } \\
& { }^{\theta_{C O}}=\text { adsorbed co molecule concentration } \\
& \theta_{N}=\text { adsorbed nitrogen atom concentration }
\end{aligned}
$$

Assuming $\theta_{\mathrm{O}^{\prime}} \theta_{\mathrm{NO}}$, and $\theta_{\mathrm{N}}$ are small compared to $\theta_{\mathrm{CO}}$, equation (2-1) reduces to:

$$
1 \simeq \theta_{\mathbf{v}}+\theta_{\mathrm{CO}}
$$

From Figure 28, reactions 4 and $5 \mathrm{a}$, the ratio of $\mathrm{N}_{2}$ to $\mathrm{N}_{2} \mathrm{O}$ production rates is:

$$
\frac{\mathrm{R}_{\mathrm{N}_{2}}}{\mathrm{R}_{\mathrm{N}_{2}}}=\frac{\mathrm{k}_{4} \theta_{\mathrm{N}}}{\mathrm{k}_{5} \mathrm{P}_{\mathrm{NO}}}
$$

Assuming there is no build-up of adsorbed nitrogen atoms on the surface, the production rate must equal the reaction rate, therefore:

$$
k_{3} \theta_{N O} \theta_{v}=k_{4} \theta_{N}^{2}+k_{5} \theta_{N}{ }^{P} \text { NO }
$$


Assuming reactions 1 and 2 in Figure 28 are at equilibrium, the following expressions are obtained:

$$
\begin{aligned}
& \frac{{ }^{\theta}{ }_{\mathrm{NO}}}{\mathrm{P}_{\mathrm{NO}}{ }_{\mathrm{v}}}=\mathrm{K}_{2}, \quad \theta_{\mathrm{NO}}=\mathrm{K}_{2}{ }_{\mathrm{P}_{\mathrm{NO}} \theta_{\mathrm{v}}} \\
& \frac{{ }^{\theta} \mathrm{Co}}{\mathrm{P}_{\mathrm{Co}^{\theta} v}}=\mathrm{K}_{1}
\end{aligned}
$$

Combining equations $2-2$ and $2-6$;

$$
\theta_{v}=\frac{i}{1+k_{1} P_{C O}}
$$

Combining equations $2-5$ and 2-7 and substituting into 2-4 yields:

$$
k_{4} \theta_{N}^{2}+k_{5} P_{N O} \theta_{N}-\frac{k_{3} K_{2} P_{N O}}{\left(1+k_{1} P_{C O}\right)^{2}}=0
$$

Solving the quadratic equation above for $o_{N}$ yields:

$$
\theta_{\mathrm{N}}=\frac{\mathrm{k}_{5} \mathrm{P}_{\mathrm{NO}}}{2 \mathrm{k}_{4}}\left[\left(1+\frac{4 \mathrm{k}_{4} \mathrm{k}_{3} \mathrm{~K}_{2}}{\mathrm{k}_{5}^{2}\left(1+\mathrm{k}_{1} \mathrm{P}_{\mathrm{CO}}\right)^{2} \mathrm{P}_{\mathrm{NO}}}\right)^{1 / 2}-1\right]
$$

Substitution of $2-9$ into $2-3$ results in the final expression for $\mathrm{R}_{\mathrm{N}_{2}} / \mathrm{R}_{\mathrm{N}_{2} \mathrm{O}}$

$$
\frac{\mathrm{R}_{\mathrm{N}_{2}}}{\mathrm{R}_{\mathrm{N}_{2} \mathrm{O}}}=\frac{1}{2}\left[\left(1+\frac{4 k_{4} \mathrm{k}_{3} \mathrm{~K}_{2}}{\mathrm{k}_{5}{ }^{2}\left(1+\mathrm{K}_{1} \mathrm{P}_{\mathrm{CO}}\right)^{2} \mathrm{P}_{\mathrm{NO}}}\right)^{1 / 2}-1\right]
$$

The $\mathrm{N}_{2} \mathrm{O}$ selectivity can be expressed in terms of this $\mathrm{R}_{\mathrm{N}_{2}} / \mathrm{R}_{\mathrm{N}_{2}} \mathrm{O}$ ratio: 


$$
\begin{aligned}
& \mathrm{S}_{\mathrm{N}_{2} \mathrm{O}}=\frac{1}{\mathrm{R}_{\mathrm{N}_{2}} / \mathrm{R}_{\mathrm{N}_{2} \mathrm{O}}+\mathrm{I}}, \\
& \frac{\mathrm{R}_{\mathrm{N}_{2}}}{\mathrm{R}_{\mathrm{N}_{2} \mathrm{O}}}=\frac{1}{\mathrm{~S}_{\mathrm{N}_{2} \mathrm{O}}}-1
\end{aligned}
$$

The relationship presented in Table 6 is derived by the combination and rearrangement of equations $2-10$ and $2-11$ :

$$
\left\{\frac{1}{\mathrm{P}_{\mathrm{NO}}\left[\left(\frac{2}{\mathrm{~S}_{\mathrm{N}_{2} \mathrm{O}}}-1\right)^{2}-1\right]}\right\}^{1 / 2}=\frac{\mathrm{k}_{5}}{4 \mathrm{k}_{4} \mathrm{k}_{3} \mathrm{~K}_{2}}\left(1+\mathrm{k}_{1}{ }^{{ }}{ }_{\mathrm{CO}}\right)
$$

B. Langmuir-Hinshelwood $\mathrm{N}_{2} \mathrm{O}$ Production, $\mathrm{P}_{\mathrm{CO}}>{ }^{\mathrm{P}_{\mathrm{NO}}}$

The reactions pertaining to the following derivation are 1-4, $5 \mathrm{~b}$, and 6 in Figure 28. From this figure, by inspection of reactions 4 and $5 \mathrm{~b}$, the ratio of $\mathrm{N}_{2}$ to $\mathrm{N}_{2} \mathrm{O}$ production rates is:

$$
\frac{\mathrm{R}_{\mathrm{N}_{2}}}{\mathrm{R}_{\mathrm{N}_{2} \mathrm{O}}}=\frac{\mathrm{k}_{4}{ }^{\theta_{\mathrm{N}}^{2}}}{\mathrm{k}_{5}{ }^{{ } \mathrm{N}^{\theta}{ }_{\mathrm{NO}}}}=\frac{\mathrm{k}_{4}}{\mathrm{k}_{5}} \frac{\theta_{\mathrm{N}}}{\theta_{\mathrm{NO}}}
$$

Assuming that nitrogen atom surface concentration is at steady-state, the rate of production equals the rate of reaction, and:

$$
k_{3} \theta_{N O} \theta_{v}=k_{4} \theta_{N}^{2}+k_{5} \theta_{N} \theta_{N O}
$$

Dividing through by $\theta_{\text {NO }}^{2}$ and rearranging yields:

$$
k_{4}\left(\frac{\theta_{N}}{\theta_{N O}}\right)^{2}+k_{5}\left(\frac{\theta_{N}}{\theta_{N O}}\right)-k_{3} \frac{\theta_{V}}{\theta_{N O}}=0
$$


Solving equation 2-5 for $\theta_{\mathrm{v}} / \theta_{\text {NO }}$ and substituting into 2-15 above yields:

$$
k_{4}\left(\frac{\theta_{N}}{\theta_{N O}}\right)^{2}+k_{5} \frac{\theta_{N}}{\theta_{N O}}-\frac{k_{3}}{k_{2} P_{N O}}=0
$$

Using the quadratic equation to solve for $\theta_{N} / \theta_{N O}$, one obtains:

$$
\frac{\theta_{N}}{\theta_{N O}}=\frac{k_{5}}{2 k_{4}}\left[\left(1+\frac{4 k_{4} k_{3}}{k_{5}^{2} k_{2} P_{N O}}\right)^{1 / 2}-1\right]
$$

Substituting $2-17$ into $2-13$ yields:

$$
\frac{\mathrm{R}_{\mathrm{N}_{2}}}{\mathrm{R}_{\mathrm{N}_{2} \mathrm{O}}}=\frac{1}{2}\left[\left(1+\frac{4 \mathrm{k}_{4} \mathrm{k}_{3}}{\mathrm{k}_{5} \mathrm{~K}_{2} \mathrm{P}_{\mathrm{NO}}}\right)^{1 / 2}-1\right]
$$

Substituting 2-18 into $2-11$ and re-arranging produces the expression:

$$
\left(\frac{2}{\mathrm{~S}_{\mathrm{N}_{2} \mathrm{O}}}-1\right)^{2}-1=\frac{4 \mathrm{k}_{4} \mathrm{k}_{3}}{\mathrm{k}_{5}^{2} \mathrm{~K}_{2}}\left(\frac{1}{\mathrm{P}_{\mathrm{NO}}}\right)
$$

presented in Table 6 . 
Appendix 3

Derivation of $\mathrm{R}_{\mathrm{N}_{2}} / \mathrm{R}_{\mathrm{N}_{2}} \mathrm{O}$ Selectivity Relationships, Oxidizing Region

A. Eley-Rideal $\mathrm{N}_{2} \mathrm{O}$ production, $\mathrm{P}_{\mathrm{NO}}>\mathrm{P}_{\mathrm{CO}}$

The site balance for the entire Pt surface is:

$$
s_{T}=s_{N O}+s_{C O}+s_{N}+s_{O}+s_{v}
$$

where:

$$
\begin{aligned}
S_{T} & =\text { total number of surface sites } \\
S_{N O} & =\text { number of sites occupied by NO } \\
S_{C O} & =\text { number of sites occupied by } \mathrm{CO} \\
S_{N} & =\text { number of sites occupied by nitrogen atoms } \\
S_{O} & =\text { number of sites occupied by oxygen atoms } \\
S_{V} & =\text { number of vacant sites }
\end{aligned}
$$

Assuming that $\mathrm{s}_{\mathrm{CO}}$ is approximately constant, then $\mathrm{S}_{\mathrm{T}}-\mathrm{S}_{\mathrm{CO}}$ is constant,

$$
S_{T}-S_{C O}=S_{N}+S_{O}+S_{N O}+S_{V}
$$

Dividing by $\mathrm{s}_{\mathrm{r}}-\mathrm{s}_{\mathrm{CO}}$ :

$$
1=\theta_{N}+\theta_{0}+\theta_{N O}+\theta_{v}
$$

where the $\theta$ 's are fractional coverages based on $\mathrm{S}_{\mathrm{T}}{ }^{-S_{\mathrm{CO}}}$ number of sites. Under highly oxidizing conditions, reaction 6 in Figure 28 is assumed rate limiting and the site balance $3-3$ is reduced to:

$$
1 \approx \theta_{0}+\theta_{v}
$$


The expression for the ratio $\mathrm{R}_{\mathrm{N}_{2}} / \mathrm{R}_{\mathrm{N}} \mathrm{O}$ is the same as equation $2-3$ presented earlier in Appendix 2:

$$
\frac{\mathrm{R}_{\mathrm{N}_{2}}}{\mathrm{R}_{\mathrm{N}_{2} \mathrm{O}}}=\frac{\mathrm{k}_{4}}{\mathrm{k}_{5}} \frac{{ }^{\theta} \mathrm{N}}{\mathrm{P}_{\mathrm{NO}}}
$$

Assuming no build-up of adsorbed nitrogen atoms, we obtain:

$$
k_{3} \theta_{v} \theta_{N O}=k_{4} \theta_{N}^{2}+k_{5}{ }^{\theta}{ }_{N} p_{N O}
$$

Assuming no buildup of adsorbed oxygen atoms,

$$
\mathrm{k}_{3}{ }^{\theta_{\mathrm{NO}}} \theta_{\mathrm{v}}=\mathrm{k}_{6}{ }^{\mathrm{P}} \mathrm{CO}{ }^{\theta_{\mathrm{v}}}
$$

Assuming reaction 2 in Figure 28 is at equilibrium,

$$
\theta_{\mathrm{NO}}=\mathrm{K}_{2} \theta_{\mathrm{v}} \mathrm{P}_{\mathrm{NO}}
$$

Solving equation 3-4 for $\theta_{O}$ and substituting into 3-7 yields:

$$
k_{3} \theta_{\text {NO }} \theta_{v}=k_{6}{ }^{P} \mathrm{CO}\left(1-\theta_{v}\right)
$$

Substituting $3-8$ into $3-9$ :

$$
\begin{aligned}
& \mathrm{k}_{3} \mathrm{k}_{2} \theta_{\mathrm{v}}^{2} \mathrm{p}_{\mathrm{NO}}=\mathrm{k}_{6} \mathrm{p}_{\mathrm{CO}}\left(1-\theta_{\mathrm{v}}\right) \\
& \theta_{\mathrm{v}}^{2}=\frac{\mathrm{k}_{6} \mathrm{p}_{\mathrm{CO}}}{\mathrm{k}_{3} \mathrm{k}_{2} \mathrm{p}_{\mathrm{NO}}}
\end{aligned}
$$

If $\theta_{\mathrm{v}}$ is assumed smali. compared to 1 ,

$$
\theta_{v}^{2}=\frac{k_{6} P_{c o}}{k_{3} K_{2}{ }^{P} \text { NO }}
$$


If equation $3-10$ is solved for $\theta_{v^{\prime}}$

$$
\theta_{v}=\frac{k_{6}{ }^{P_{C O}}}{2 k_{3}{ }^{k_{2}{ }{ }_{N O}}}\left[\left(1+\frac{4 k_{3} K_{2} P_{N O}}{k_{6}{ }^{P_{C O}}}\right)^{1 / 2}-1\right]
$$

Subsituting 3-8 and $3-10$ into $3-6$, one obtains:

$$
k_{4} \theta_{N}^{2}+k_{5} \theta_{N} P_{N O}=k_{6}{ }^{P} \text { CO }\left(1-\theta_{v}\right)
$$

Solving 3-13 for $\theta_{N}$ via the quadratic formula leads to:

$$
\theta_{N}=\frac{k_{6}{ }^{P}{ }_{N O}}{2 k_{4}}\left[\left(1+\frac{4 k_{4}{ }^{k}{ }_{6}{ }_{C O}(1-\theta)}{k_{5}^{2} P_{N O}^{2}}\right)^{1 / 2}-1\right]
$$

Substituting $3-14$ into $3-5$, the ratio $\mathrm{R}_{\mathrm{N}_{2}} / \mathrm{R}_{\mathrm{N}_{2}} \mathrm{O}$ is obtained:

$$
\frac{\mathrm{R}_{\mathrm{N}_{2}}}{\mathrm{R}_{\mathrm{N}_{2} \mathrm{O}}}=\frac{1}{2}\left[\left(1+\frac{4 \mathrm{k}_{4} \mathrm{k}_{6} \mathrm{P}_{\mathrm{C}}\left(1-\theta_{\mathrm{v}}\right)}{\mathrm{k}_{5}^{2} \mathrm{P}_{\mathrm{NO}}{ }^{2}}\right)^{1 / 2}-1\right]
$$

Under highly oxidizing conditions where $\theta_{0}$ is large compared to $\theta_{\mathrm{v}}, \theta_{\mathrm{v}}$ will be much less than one, and equation $3-15$ reduces to:

$$
\frac{\mathrm{R}_{\mathrm{N}_{2}}}{\mathrm{R}_{\mathrm{N}_{2} \mathrm{O}}}=\frac{1}{2}\left[\left(1+\frac{4 \mathrm{k}_{4} \mathrm{k}_{6} \mathrm{P}_{\mathrm{CO}}}{\mathrm{k}_{5}{ }^{2}{ }_{\mathrm{NO}}{ }^{2}}\right)^{1 / 2}-1\right]
$$

Assuming reaction 6 in Figure 28 is rate limiting,

$$
\mathrm{R}_{\mathrm{CO}_{2}}=\mathrm{k}_{6}{ }^{\theta} \mathrm{O}^{\mathrm{P}} \mathrm{CO}
$$

Under highly oxidizing conditions, $\theta_{0}=1$ and therefore:

$$
\mathrm{R}_{\mathrm{CO}_{2}} \approx \mathrm{k}_{6}{ }^{\mathrm{P}} \mathrm{CO}
$$


In a CFSTR operating at $100 \% \mathrm{Co}$ conversion, $\mathrm{R}_{\mathrm{CO}_{2}}=\mathrm{F}_{\mathrm{CO}}^{\circ}$, where $\mathrm{F}_{\mathrm{CO}}^{\circ}$ is the input molar feed rate of $C O$. Under these conditions, 3-18 becomes:

$$
\mathrm{F}_{\mathrm{CO}}^{\mathrm{O}}=\mathrm{k}_{6} \mathrm{P}_{\mathrm{CO}}
$$

Substitution into 3-16 yields:

$$
\frac{\mathrm{R}_{\mathrm{N}_{2}}}{\mathrm{R}_{\mathrm{N}_{2} \mathrm{O}}}=\frac{1}{2}\left[\left(1+\frac{4 \mathrm{k}_{4} \mathrm{~F}_{\mathrm{CO}}^{\mathrm{O}}}{\mathrm{k}_{5}^{2} \mathrm{P}_{\mathrm{NO}}^{2}}\right)^{1 / 2}-1\right]
$$

Substitution of 3-20 into equation 2-11 in Appendix 2 yields, with rear rangement:

$$
\left(2 / \mathrm{S}_{\mathrm{N}_{2} \mathrm{O}}-1\right)^{2}-I=\left(\frac{4 \mathrm{k}_{4}}{\mathrm{k}_{5}^{2}}\right) \frac{\mathrm{F}_{\mathrm{CO}}^{\mathrm{O}}}{\mathrm{P}_{\mathrm{NO}}^{2}}
$$

Equation $3-21$ is presented in Table 7.

B. Langmuir-Hinshelwood $\mathrm{N}_{2} \mathrm{O}$ Production, $\mathrm{P}_{\mathrm{NO}}>\mathrm{P}_{\mathrm{CO}}$

The equation for $\mathrm{R}_{\mathrm{N}_{2}} / \mathrm{R}_{\mathrm{N}_{2}} \mathrm{O}$ is identical to that obtained under reducing conditions, since equations 2-13 through 2-17 are applicable in the oxidizing region as well. 
REFERENCES

1. N. W. Cant, P. C. Hicks, and B. S. Lenon, "The Reduction of Nitric Oxide by Carbon Monoxide Over Silica Supported Noble Metals," to be published.

2. W. L. Winterbottom, Surface Science, 37, 195, (1973).

3. R. M. Lambert and C. M. Comrie, Surface Science, 46, 61, (1974).

4. Y. Iwasawa, R. Mason, M. Textor and G. A. Somorjai, Chemical Physica] Letters, 44,468 (1976).

5. L. H. Little, "Infrared Spectra of Adsorbed Species," Academic Press, New York, 1966.

6. G. Pirug and H. P. Bonzel, Journal of Catalysis, 50, 64, (1977).

7. H. P. Bonzel and G. Pirug, Surface Science, 62, 45, (1977).

8. F. Solymosi, J. Sarkany and A. Schauer, Journal of Catalysis, 46, 297, (1977).

9. C. N. Ludvik, "An Infrared and Kinetic Study of No Reduction by Co Over a Pt Catalyst," M.S. thesis, Department of Chemical Enginering, University of California, Berkeley.

10. H. Dunken and H. Hobert, Z. Chem., 3, 398, (1963).

11. M. F. Brown and R. D. Gonzalez, Journal of Catalysis, 44, 477 (1976).

12. G. L. Bauerle, G. Service and K. Nobe, Ind. Eng. Chem. Prod. Res. Dev., 11, 54, (1972).

13. M. Shelef and J. T. Kummer, Chem. Eng. Prog. Symp. Ser., 67, 74, (1972).

14. M. Shelef and H. Gandhi, Ind. Eng. Prod. Res. Dev.. 11, 393, (1972). 
15. Shelef, K. Otto and H. Gandhi, Journal of Catalysis, 12, 361, (1968).

16. H. Nilyama, M. Tanaka, H. Iida and E. Echigoya, Bullet in of the Chemical Society of Japan, 49, 2047, (1976).

17. M. L. Unland, Journal of Physical Chemistry, 77, 1952 (1973).

18. M. L. Unland, Journal of Catalysis, 31, 459 (1973).

19. M. L. Unland, Science, ${ }^{179}, 567$ (1973).

20. R. A. Dalla Betta and M. Shelef, Journal of Molecular Catalysis, $1,431,(1975 / 76)$.

21. D. D. Eley, G. M. Kiwanuka and C. H. Rochester, J.C.S. Faraday Trans. I., 71, 1021, (1975).

22. A. Guillet, M. Coudurier and J. B. Donnet, Bulletin de la Soceite Chimique de France, 7-8, 1563, (1975).

23. E. E. Petersen, J. Landau and E. Saucedo, "Catalytic Chemistry of Nitrogen Oxides," ed. R. L. Klimisch and J. G. Larson, Plenum Press, New York, 1975.

24. A. F. Beck, M. A. Heine, E. J. Caule and M. J. Pryor, Corrosion Science, 2, 1-22, (1967).

25. D. H. Lorimer and A. T. Be11, I\&E.C. Fundamentals, 15, 71, (1976).

26. V. S. Boronin, V. S. Nikulina and I. M. Poltorak, Russ. J. Phys. Chem., 37, 626, (1963).

27. H. A. Benesi, R. M. Curtis and H. P. Studer, Journal of Catalysis, $10,328,(1968)$.

28. W. H. Weinberg and R. P. Merrill, Journal of Catalysis, 40, 268, (1975) .

29. P. B. Weisz and C. D. Prater, Advan. Catal., 6, 167, (1954).

30. M. Wilf and P. T. Dawson, Surface Science, 60, 561, (1976). 
31. K. Schawaha and E. Bechtold, Surface Science, 66, 383, (1977).

32. W. H. Weinberg and R. P. Merrill, Surface Science, 39, 206, (1973).

33. H. P. Bonzel and R. Ku, Journal of Vacuum Science and Technology, 9, (2), 663, (1972).

34. J. Katzer, "Catalytic Chemistry of Nitrogen Oxides," ed. R. L. Klimisch and J. G. Larson, Plenum Press, New York, 1975.

35. D. Monroe, Ph.D. thesis, Department of Chemical Engineering, University of California, Berkeley.

36. B. Lang, R. W. Joyner and G. A. Somorjai, Surface Science, 30, 454, (1972) .

37. J. I. Gland and V. N. Vorchak, GM Research Labs Report \#PC-66, June $28,1977$.

38. H. Hopster, H. Ibach and G. Comsa, Journal of Catalysis, 46, 37, (1977) .

39. A. Amiranazmi and M. Boudart, Journal of Catalysis, 39, 383 (1975).

40. P. G. Harrison and E. W. Thornton, J.C.S. Chem. Cornm., 398, (1977).

41. M. Primet, J. M. Basset, M. V. Mathieu and M. Prettre, J. Catal., $29,213(1973)$.

42. B. A. Morrow and I. A. Cody, J.C.S. Faraday Trans., I, 71, 1021, (1975) .

43. F. A. Miller and G. L. Carlson, Spectrochim. Acta, 17, 977, (1961).

44. F. Solymosi, J. Kiss and J. Sarkany, Proc. 7th Intern. Vac. Congr. and 3rd Intern. Conf. Solid Surfaces, Vienna, 1977.

45. W. Beck and W. P. Fehlhammer, Angew. Chem., 79, 146, (1967).

46. Kirk-Othmer Encyclopedia of Chemical Technology, 2nd ed., 20, 662, Interscience Publishers, New York, 1963. 
47. F. Solymosi and J. Rasko, Journal of Catalysis, 49, 240, (1977).

48. R. J. H. Voorhoeve, L. E. Trimble and D. J. Freed, "Synthesis of Ammonium Cyanate and Urea by Reduction of NO on Pt, Rh, and Ru Catalysts," to be published. 
.

1 
This report was done with support from the Department of Energy. Any conclusions or opinions expressed in this report represent solely those of the author(s) and not necessarily those of The Regents of the University of California, the Lawrence Berkeley Laboratory or the Department of Energy. 


$$
\therefore \quad=
$$

TECHNICAL INFORMATION DEPARTMENT LAWRENCE BERKELEY LABORATORY

UNIVERSITY OF CALIFORNIA BERKELEY, CALIFORNIA 94720 